\title{
Improving SensAct's Usability and Potential to Support Augmentative and Alternative Communication (AAC) Using Human-Centred Design Methods
}

\author{
by \\ Ebic Tristary \\ A thesis submitted to the Faculty of Graduate and \\ Postdoctoral Affairs in partial fulfillment of the requirements \\ for the degree of
}

\section{Master of Design}

in

the School of Industrial Design

Carleton University

Ottawa, Ontario

(C) 2019, Ebic Tristary 


\begin{abstract}
Individuals living with speech impairments may require an augmentative and alternative communication (AAC) device to be able to speak or interact with other people. The implementation of an AAC device is fundamental to facilitate effective communication, expand social interaction, and to be part of the community. A team of developers at Bruyère - Saint-Vincent Hospital has been developing an AAC device called SensAct to fulfill those needs. Despite extensive advancements, stakeholders at the hospital feel the technology has usability issues preventing it from being implemented and used by a wider target audience.
\end{abstract}

This study aims to investigate factors influencing SensAct's usability, specifically, focusing on SensAct's user interface (UI) and usability issues that arise when configuring the system for healthcare clients. Using qualitative methods from human-centred design, this study identified systemic factors that influence AAC/SensAct implementation, and three key usability issues that may undermine SensAct's ability to reach a broader audience: time constraints, the use of complex technical terms, and complex UI with minimal support. These findings informed the development of design recommendations to develop SensAct's UI. At a broader level, this study provides a basic framework to support further studies on SensAct to accomplish the goals of healthcare workers to better meet the needs of their clients.

Keywords: Augmentative and Alternative Communication (AAC), Design, User Interface, Usability, Human-Centred Design 


\section{ACKNOWLEDGEMENTS}

To Papa and Mama, who instill the values and virtues of life in me. I will forever be grateful that you brought me up to be the person I am today.

A warm thank you to my co-supervisors, Chantal Trudel and Dr. Adrian Chan, for your guidance throughout my study at Carleton University, for your dedication and doing the extra-mile in reviewing my thesis. I also want to thank you for giving me the opportunity to take part in the READi program, as it has broadened my perspectives in many ways on accessibility.

Special thanks to the staff at Bruyère - Saint-Vincent Hospital for sacrificing their lunch hours to participate in this study. I really appreciate your contribution and sacrifice for the improvement of SensAct.

Many thanks to my MDes professors WonJoon Chung, Lois Frankel, and Çağla Doğan; and HCI professors Robert Biddle, and Victor Cheung; for sharing their knowledge and expertise through interdisciplinary coursework. My sincere thanks to Valerie Daley, who supported and guided me through the administration process during my study.

To my fellow classmates, thank you for your support and encouragement during my study at Carleton University. I hope our friendships will continue long after our studies have completed.

And finally, to Lisa Ament, for listening to me and keeping me sane over the years, and for always being there when I needed you most. Thank you. 


\section{TABLE OF CONTENTS}

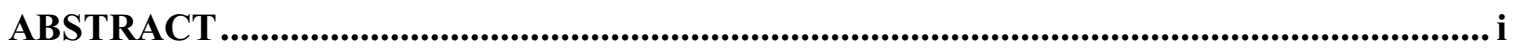

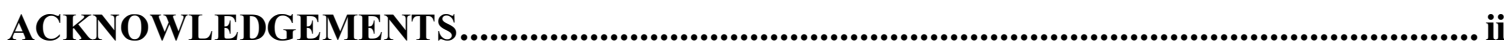

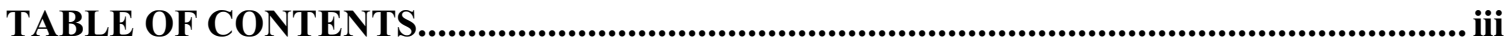

LIST OF FIGURES .............................................................................................................. vi

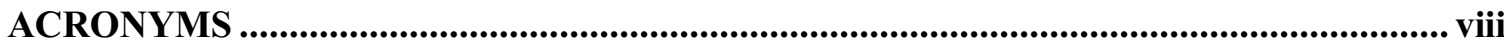

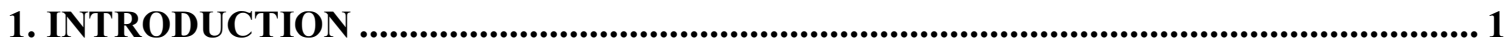

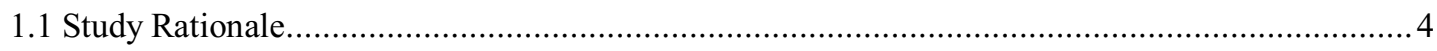

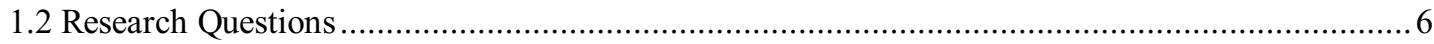

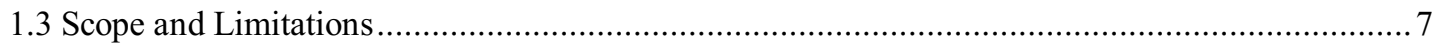

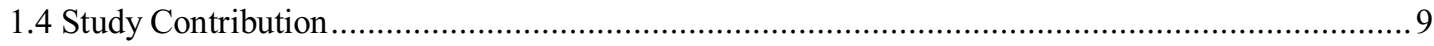

2. LITERATURE REVIEW ................................................................................................... 10

2.1 Background: What is Augmentative and Alternative Communication (AAC)? …....................... 10

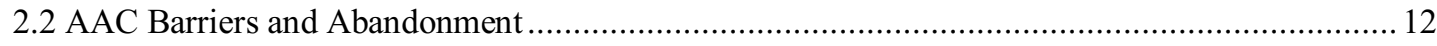

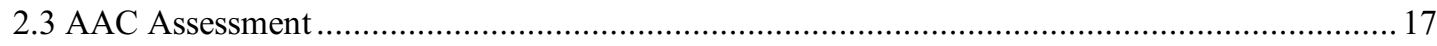

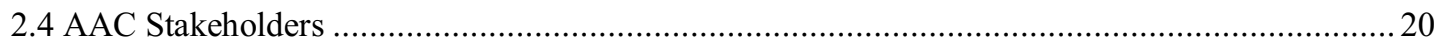

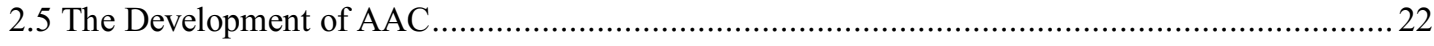

3. SENSACT OVERVIEW \& HISTORY OF DEVELOPMENT ..................................... 25

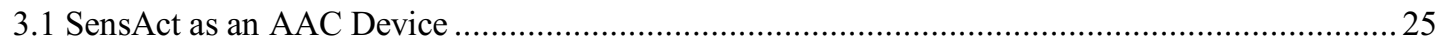

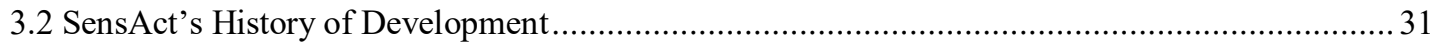

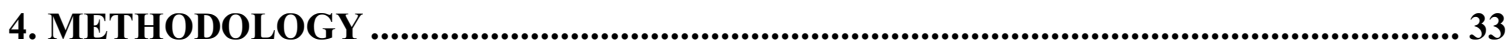

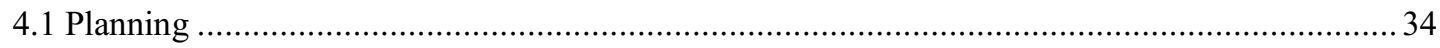

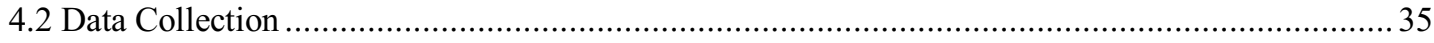

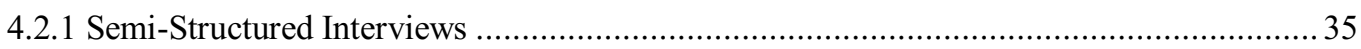

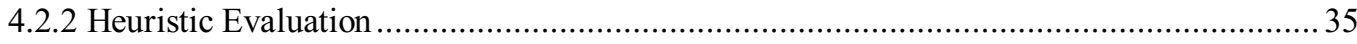

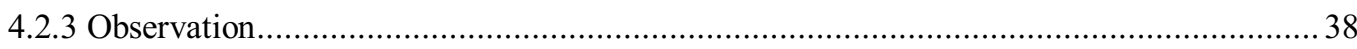

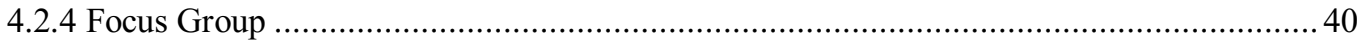


4.2.5 Prototyping

4.3 Analysis/Synthesis of Data \& Presentation of Findings .............................................. 41

4.4 Design Recommendations Based on Overall Findings.............................................. 43

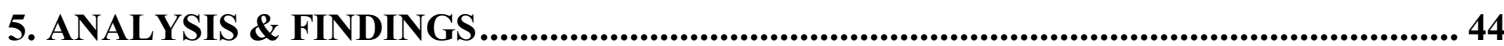

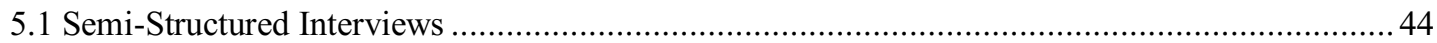

5.1.1 External Factors Have an Impact on the Success of AAC Implementation .....................46

5.1.2 Human Resources Are a Critical Factor in Supporting AAC Sustainability...................49

5.1.3 People’s Abilities, Limitations, Beliefs, Preferences, Motivation \& Attitudes Can Impact

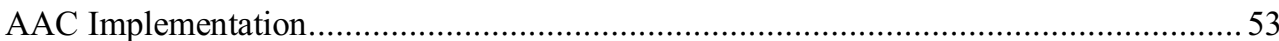

5.1.4 Core Theme: Systemic Factors Influencing AAC/SensAct Implementation ...................55

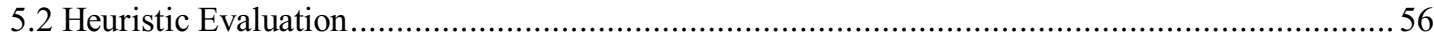

5.2.1 The use of complex and technical terms in the UI prevents the novice or non-technical users from comprehending the functionality of the software itself.

5.2.2 The SensAct software UI requires effective and efficient self-guiding system to direct user to achieve their objectives .58

5.2.3 Error management is critical for the user to prevent, mitigate, or recover from an error....61

5.3 Observation 62

5.3.1 Issues with Setting up and Using the SensAct Hardware 62

5.3.2 Issues with Using the SensAct UI ................................................................ 63

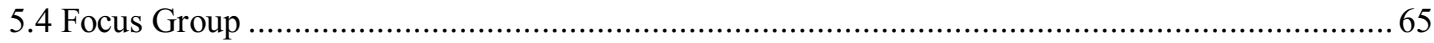

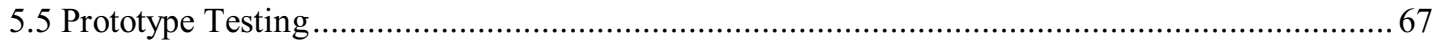

5.5.1 Scenario \#1 - Less Complex Client Requirement Using 'Wizard Setup'........................ 71

5.5.2 Scenario \#2 - 'Advanced Setup’ for More Complex and Detailed Configuration............. 77

5.5.3 Participants Interaction and Feedback on the Prototype .......................................... 82

6. DISCUSSION............................................................................................................................. 85

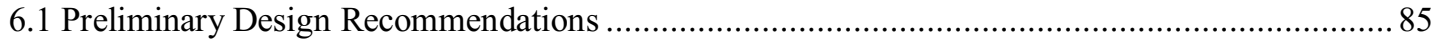

6.1.1 Improving AAC System Efficiency to Compensate For Time Constraints .................... 86

6.1.2 Replacing System-Oriented Terms with Users' Language and Conventional Terms........ 86

6.1.3 Designing a Simplified UI with a Self-Guidance System to Direct Users Configuring the SensAct System 
6.2 Stakeholders Involvement in SensAct's Development May Improve Usability 89

6.3 Improving Usability May Increase Consistency of AAC Usage .......................................91

6.4 Dedicated Resources Required to Support the Implementation of AAC ................................99

6.5 Applying an HCD Approach in SensAct's Development May Bridge the Communication Gap

Between Developers and Healthcare Specialists ........................................................ 94

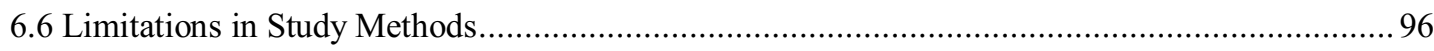

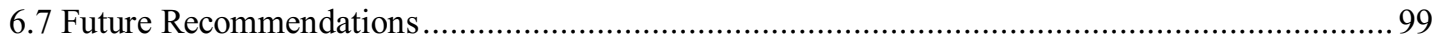

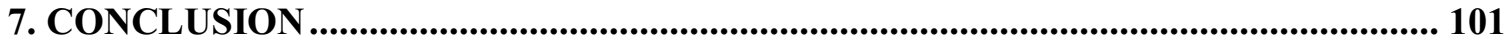

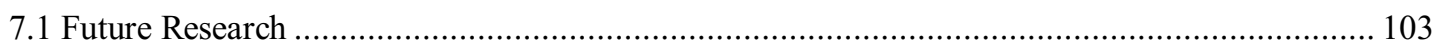

REFERENCES .......................................................................................................... 105

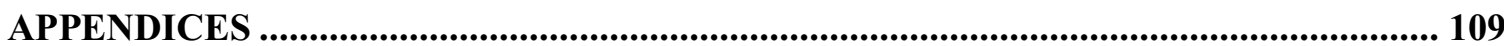

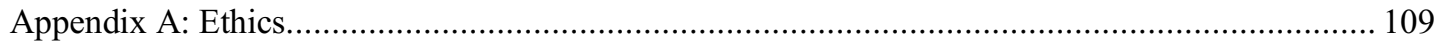

A.1 Ethics Clearance from Bruyère - Saint-Vincent Hospital ......................................... 109

A.2 Ethics Clearance from Carleton University .............................................. 111

A.3 Consent Form for Interview ........................................................................ 112

A.4 Consent Form for Observation.................................................................... 115

A.5 Consent Form for Co-Design Workshop .................................................... 118

A.6 Tri-Council Policy Statement (TCPS 2) Certification on Ethical Conduct for Research

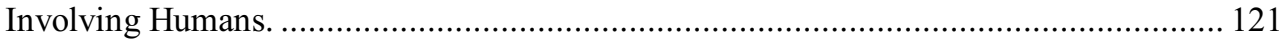

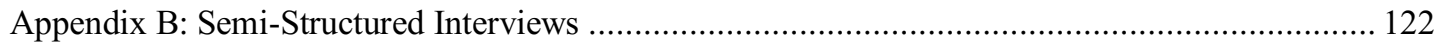

B.1 Interview Questions for SensAct Developer .............................................. 122

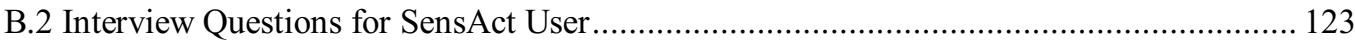

B.3 The First and Second Cycle Coding of the Interviews Sorted by Occurrences ................ 124

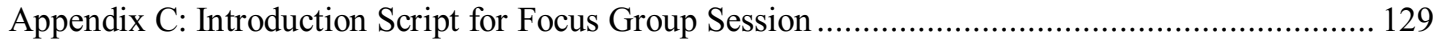




\section{LIST OF FIGURES}

Figure 1. Canadian population aged 15 years and over with a disability, by age group and sex, 2017 (Statistics Canada, 2018).

Figure 2. Canadian population aged 15 years and over, living below Canada's Official Poverty Line, by age group, disability status and severity, 2015 (Statistics Canada, 2018) ..................... 5

Figure 3. Canadian population aged 15 years and over with a disability and unmet needs due to cost, by age group and severity, 2017 (Statistics Canada, 2018) ........................................ 6

Figure 4. The study overview of this research is defined in 'Scope of Study A' .......................... 8

Figure 5. Low-tech Communication Board Options [Online image]. Retrieved August 28, 2019 from

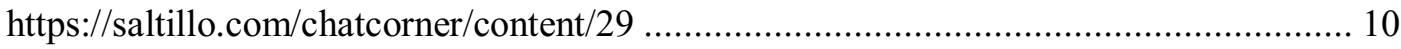

Figure 6. Tobii Dynavox I-Series+ [Online image]. Retrieved August 28, 2019 from https://linkassistive.com/product/eye-gaze-device/iseriesp/ .................................... 11

Figure 7. The relation between DSS role and AAC abandonment ........................................... 15

Figure 8. AAC assessment process adapted from Binger et al. (2012) ........................................ 19

Figure 9. Stakeholder categories based on their roles ...................................................... 21

Figure 10. AssistiveTouch - Turn a pinch into a tap. [Online image]. Retrieved September 9, 2019 from https://www.apple.com/ca/accessibility/ipad/mobility/ .................................... 24

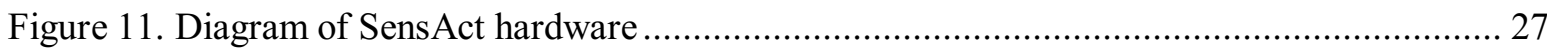

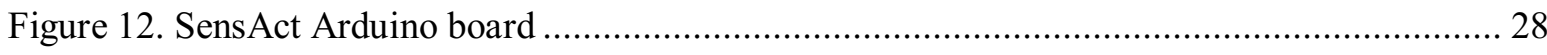

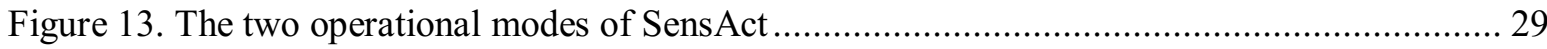

Figure 14. Example of SensAct setup as a TV remote control ................................................... 30

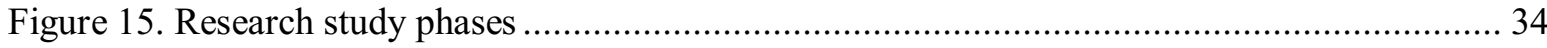

Figure 16. Nielsen's 10 heuristic evaluation guidelines and severity ratings of usability problems

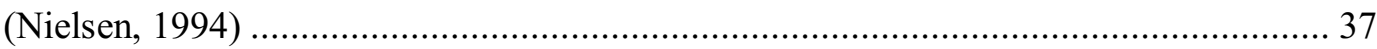

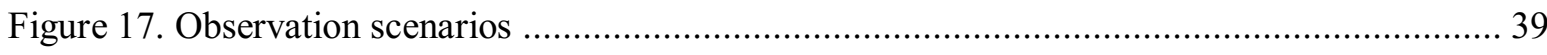

Figure 18. Streamlined diagram from raw data to overall theme adapted from Saldaña (2015)...... 42

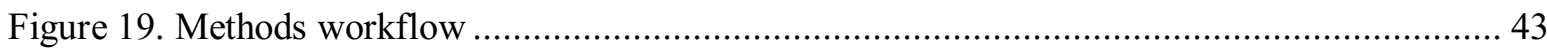

Figure 20. Core theme and subthemes generated from the second cycle coding .......................... 45

Figure 21. Relationship between market and cost of hardware ............................................... 47

Figure 22. AAC assessment procedure based on job roles ................................................ 50 
Figure 23. Examples of terminology in the Sens Act UI that may not be understandable to novice,

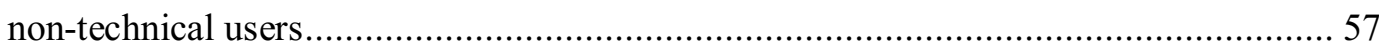

Figure 24. Lack of visibility of system status on Sens Act UI ................................................ 58

Figure 25. Example of a high memory load demand placed on the users ................................... 59

Figure 26. Example of SensAct UI configured to simulate mouse control and complexity involved to

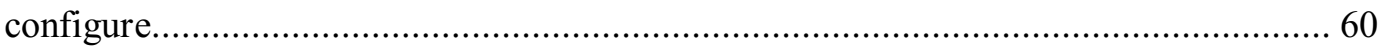

Figure 27. Example of an error that can be prevented by using a warning dialog box ................... 61

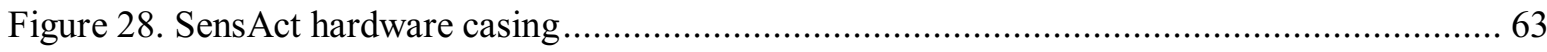

Figure 29. Participants interaction during observation session .............................................. 64

Figure 30. Key usability issues with SensAct's UI that recurred throughout the previous four research methods 69

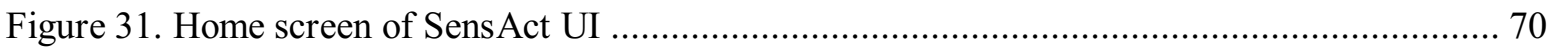

Figure 32. Initial screen of the 'Wizard Setup' illustrating how to set up hardware connections .....72

Figure 33. First software configuration step using the 'Wizard Setup' ...................................... 72

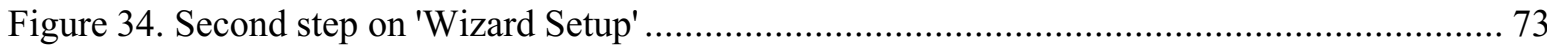

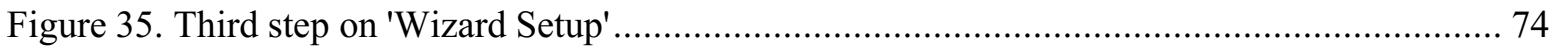

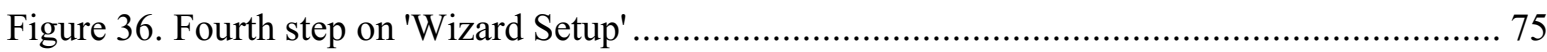

Figure 37. Final step on 'Wizard Setup' showing the UI for 'Customized Settings' ......................76

Figure 38. Confirmation screen on 'Wizard Setup' showing selected options.............................. 76

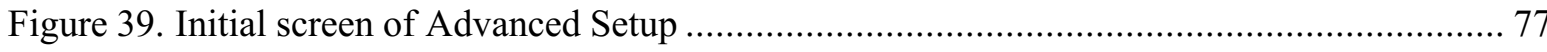

Figure 40. Input method configuration on 'Advanced Setup' ................................................... 78

Figure 41. An example of instruction that guides the user to proceed to the next step in 'Advanced Setup'

Figure 42. Comparison between prototype UI and current Sens Act UI on adding new configuration

Figure 43. List of saved configurations on 'Advanced Setup' ................................................. 81

Figure 44. Dialog box to confirm deletion of selected configuration ......................................... 82

Figure 45. Preliminary design recommendations for SensAct UI framed in reference to relevant

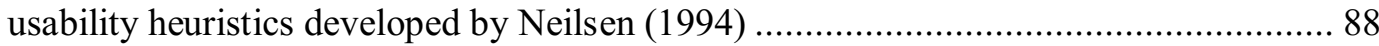




\section{ACRONYMS}

$\begin{array}{ll}\text { AAC } & \text { Augmentative and Alternative Communication } \\ \text { AT } & \text { Assistive Technologist } \\ \text { BSVH } & \text { Bruyère - Saint-Vincent Hospital } \\ \text { CHEO } & \text { Children's Hospital of Eastern Ontario } \\ \text { DSS } & \text { Direct Support Staff } \\ \text { HCD } & \text { Human-Centred Design } \\ \text { HCI } & \text { Human-Computer Interaction } \\ \text { OT } & \text { Occupational Therapist } \\ \text { SLP } & \text { Speech Language Pathologist } \\ \text { UI } & \text { User Interface } \\ \text { USB } & \text { Universal Serial Bus }\end{array}$




\section{INTRODUCTION}

"Having the power to speak one's heart and mind changes the disability equation dramatically. In fact, it is the only thing I know that can take a sledgehammer to the ageold walls of myths and stereotypes and begin to shatter the silence that looms so large in many people's lives" (Williams, 2000, p. 249).

Humans are social beings. Communication is like the oil in a complex machine to make sure it runs smoothly. Losing the ability to communicate may cause friction within that complex machinery, which eventually could cause the system to fail. When someone loses their ability to communicate, but then regains that ability, it may feel like being born again. Some clients at Bruyère - Saint-Vincent Hospital (BSVH; Ottawa, Ontario), a complex continuing care hospital, have reported this experience. BSVH has an accredited augmentative and alternative communication (AAC) clinic that consists of an interdisciplinary team of speech-language pathologists (SLP), occupational therapists (OT), and an assistive technologist (AT). This team works collaboratively to prescribe AAC devices to clients who are unable to speak verbally or write using their hands. An AAC device is an assistive technology device that is used to improve the communication ability of individuals with complex communication needs (Volkmar, 2013).

Although the present funding scheme for AAC devices through the Ontario Ministry of Health and Long-Term Care's Assistive Device Program has been addressing many of the communication needs of BSVH's clients, there are still unmet needs and 
restrictions in accessing technology that are undermining their quality of life. These areas of need include communication, recreation, education, and environmental control. With ageing, many of us will come to a stage in our lives when we could benefit from some kind of assistive technology (Segalman, 2011). It is, therefore, imperative to be proactive in designing more inclusive technologies in terms of access, usability, and cost.

Stakeholders at the hospital have expressed concerns about clients having limited ability and/or the financial means to access devices offering both entertainment and education while stimulating whatever functionality they still possess. The AAC team at the BSVH clinic works with specialized volunteers (e.g., expertise in computer programming and electronics), who help maximize their resources cost-effectively by developing solutions that go beyond the standard technologies available through the Assistive Device Program. These volunteers design novel systems to support the unmet needs of BSVH clients using off-the-shelf smart devices like sensors, smartphones, and tablets. Further, healthcare workers and volunteers have developed apps that require only a browser to explore the possibilities offered by relatively inexpensive tablets both with and without internet access.

Stakeholders at the hospital have reported that this model of care, which includes healthcare professional staff and specialized volunteers, as well as students, educational institutions, and non-profit partner organizations interested in assistive technology, allows them to conduct research in this area and develop more cost-effective assistive devices. They see this as a strategic initiative and a development model for the assistive technology community at large. 
For the past several years, the AAC team at BSVH in collaboration with their volunteers have been developing a generic interface device called SensAct to provide clients with a technology that can assist them in social interaction and/or environment control. SensAct has been developed with open-source and low-cost materials to alleviate some of the access limitations due to cost. Despite this preliminary success, BSVH stakeholders feel that SensAct faces some usability issues as a result of limited funding and human resources available to develop and test the device extensively. Usability issues may prevent SensAct from reaching its full potential to be used by a broader audience (e.g., healthcare workers, clients, and informal caregivers), without the need for a highly trained individual to provide technical expertise. The hospital's concern for usability issues has also ignited this study which aims to identify the issues, investigate factors influencing such issues, and develop a design recommendation to help the hospital move forward with its objectives to better serve their clients.

The following thesis is organized into seven chapters. Chapter 1 provides the basic overview of the thesis including the rationale, research questions, and the scope of this study. An introduction to AAC, the stakeholders, and the process of implementing an AAC device are examined through a literature review in Chapter 2. An overview of the SensAct system and its history of development are discussed in Chapter 3. Chapter 4 explains the various methods used in this study based on a human-centred design (HCD) approach to identify usability issues with SensAct. The analysis and results of data collected from these research methods are reported in Chapter 5. These findings are discussed in reference to the literature review and research questions in Chapter 6. This 
study concludes with Chapter 7, which provides a summary of the usability issues that were identified and reflection on these issues for future study.

\subsection{Study Rationale}

In 2017, one in five Canadians aged 15 and over reported to have one or more disabilities (Statistics Canada, 2018), which represents a large portion of the population (Figure 1). Understanding this population segment and the challenges they face in everyday life can better inform government policy, education support services, employment initiatives, and community outreach programs.

Canadian population aged 15 years and over with a disability, by age group and sex, 2017 percent

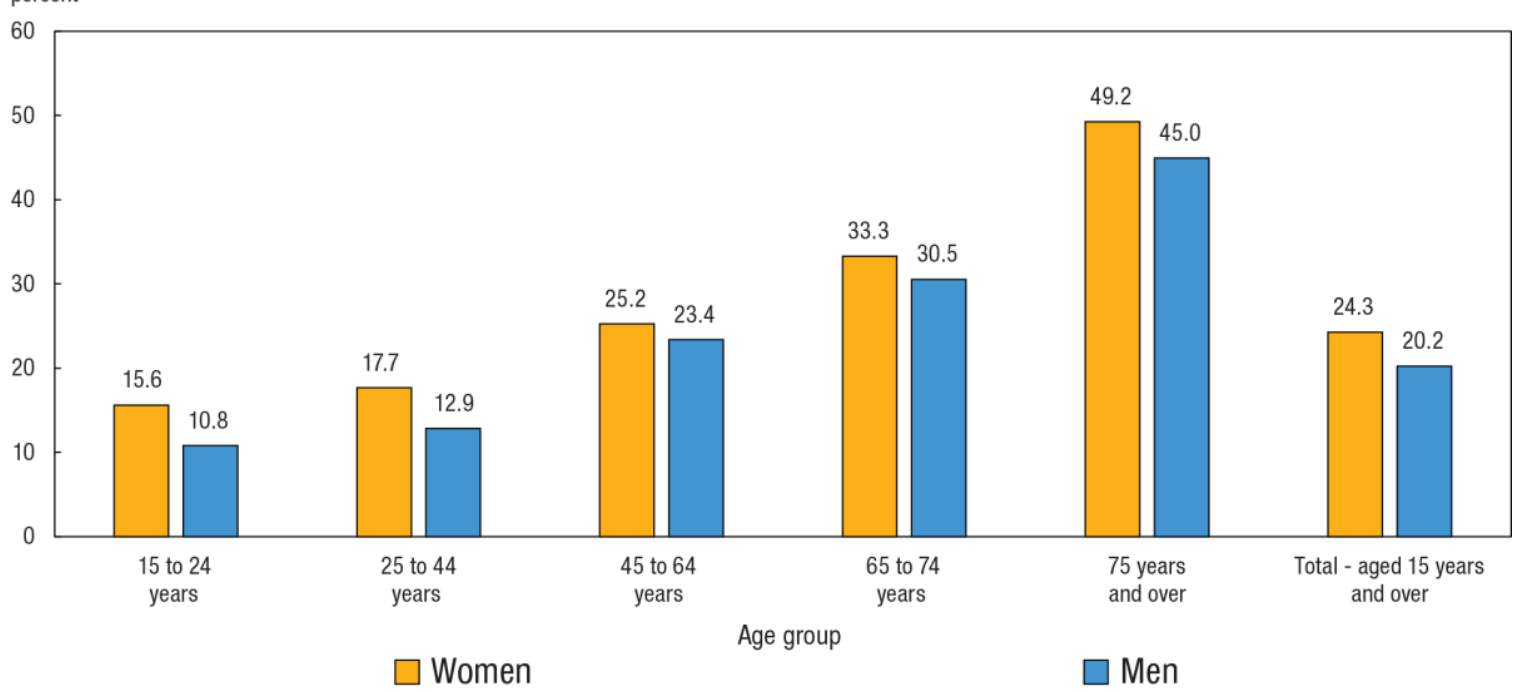

Figure 1. Canadian population aged 15 years and over with a disability, by age group and sex, 2017 (Statistics Canada, 2018)

The risk of living in poverty is higher in the working-age population than in the senior population as the severity of the disability increases (Figure 2). More than a 
quarter of youth population (aged 15 to 24 years) and working adults (aged 25 to 64

years) living with a severe disability fall below the poverty line (Statistics Canada, 2018).

As such, the risk of falling below the poverty line for working-age adults living with more severe disabilities is nearly triple compared to persons without a disability. This unfortunate socio-economic picture becomes worse when coupled with statistics on access to aid and assistive devices for persons with disabilities.

\section{Canadian population, aged 15 years and over, living below Canada's Official Poverty Line, by age group, disability status and severity, 2015}

\begin{tabular}{lrrr}
\hline & & & \multicolumn{2}{c}{$\begin{array}{c}\text { Persons with } \\
\text { disabilities }\end{array}$} \\
\cline { 2 - 5 } Age group & $\begin{array}{c}\text { Persons without } \\
\text { disabilities }\end{array}$ & Milder & More severe \\
\cline { 2 - 5 } 15 to 24 years & \multicolumn{3}{c}{ percent } \\
25 to 64 years & 16.7 & 22.5 & 27.6 \\
65 years and over & 10.0 & 14.2 & 28.3 \\
\hline
\end{tabular}

Figure 2. Canadian population aged 15 years and over, living below Canada's Official Poverty Line, by age group, disability status and severity, 2015 (Statistics Canada, 2018)

The 2017 Canadian Survey on Disability showed that among individuals with disabilities aged 15 years and over, 1.5 million had unmet needs for aides or assistive devices (Figure 3). Of these, 49.2\% indicated that cost was the reason for their unmet needs (Statistics Canada, 2018). Designing an aid device that is cost-effective could alleviate some of the cost burdens for people living below the poverty line. 


\section{Canadian population aged 15 years and over with a disability and unmet needs due to cost, by age group and severity, 2017}

\begin{tabular}{lrr}
\hline & \multicolumn{2}{c}{ Unmet needs due to cost } \\
\cline { 2 - 3 } Age group & number & percent \\
\hline 15 to 64 years & $1,221,370$ & 28.6 \\
65 years and over & 405,640 & 20.6 \\
Severity of disability & & \\
Milder & 625,790 & 17.5 \\
More severe & $1,001,230$ & 37.4 \\
\hline
\end{tabular}

Figure 3. Canadian population aged 15 years and over with a disability and unmet needs due to cost, by age group and severity, 2017 (Statistics Canada, 2018)

SensAct, a cost-effective assistive device developed by the AAC team from BSVH, may fulfill some of the unmet needs of persons with disabilities. The system can be built with inexpensive materials and customized to meet specific client's needs, unlike most commercial AAC devices on the market today. However, stakeholders from BSVH have shared their concerns with the usability of the current system, which if remediated, could potentially reach more clients. This is why it is important to identify the current challenges with SensAct and support the development of this system.

\subsection{Research Questions}

Through qualitative methods, this research study aims to answer the question: How to improve SensAct's usability and potential to support AAC implementation for individuals with complex communication needs?

In support of this question, the research seeks to answer the following: 
- What issues are developers and healthcare specialists experiencing when they use SensAct's current user interface (UI) to configure the system for a client?

- What factors may be undermining SensAct's ability to progress and reach a wider audience?

\subsection{Scope and Limitations}

There are many stakeholders involved in the development of SensAct, as shown in Figure 4 below. These stakeholders can be grouped into three main categories based on their roles, objectives, and requirements:

\section{1) Developers \& Healthcare Specialists}

Developers: Assistive technologist, students, and volunteers.

Healthcare Specialists: Speech-language pathologists and occupational therapists.

\section{2) Clients}

\section{3) Caregivers}

Family members, and direct support staff (e.g., nurses, home caregivers).

Each stakeholder group may have different goals and specific requirements, which involves assessing particular risks and benefits. Therefore, a variety of human factors must be taken into account when conducting any research involving humans (Kirk, McClelland \& Suri, 2015). Although the study on the clients and caregivers are both equally important, BSVH did not want the initial study to involve the clients and caregivers because they did not want to place unnecessary demands on them. The hospital decided that they would first, examine the usability from the developers and 
healthcare workers' perspectives, remediate these issues and then conduct studies on the clients after these issues had been studied. For that reason, this research study is only focused on the developer and healthcare specialist stakeholders, and specifically on identifying their usability issues with setting up the current SensAct device.

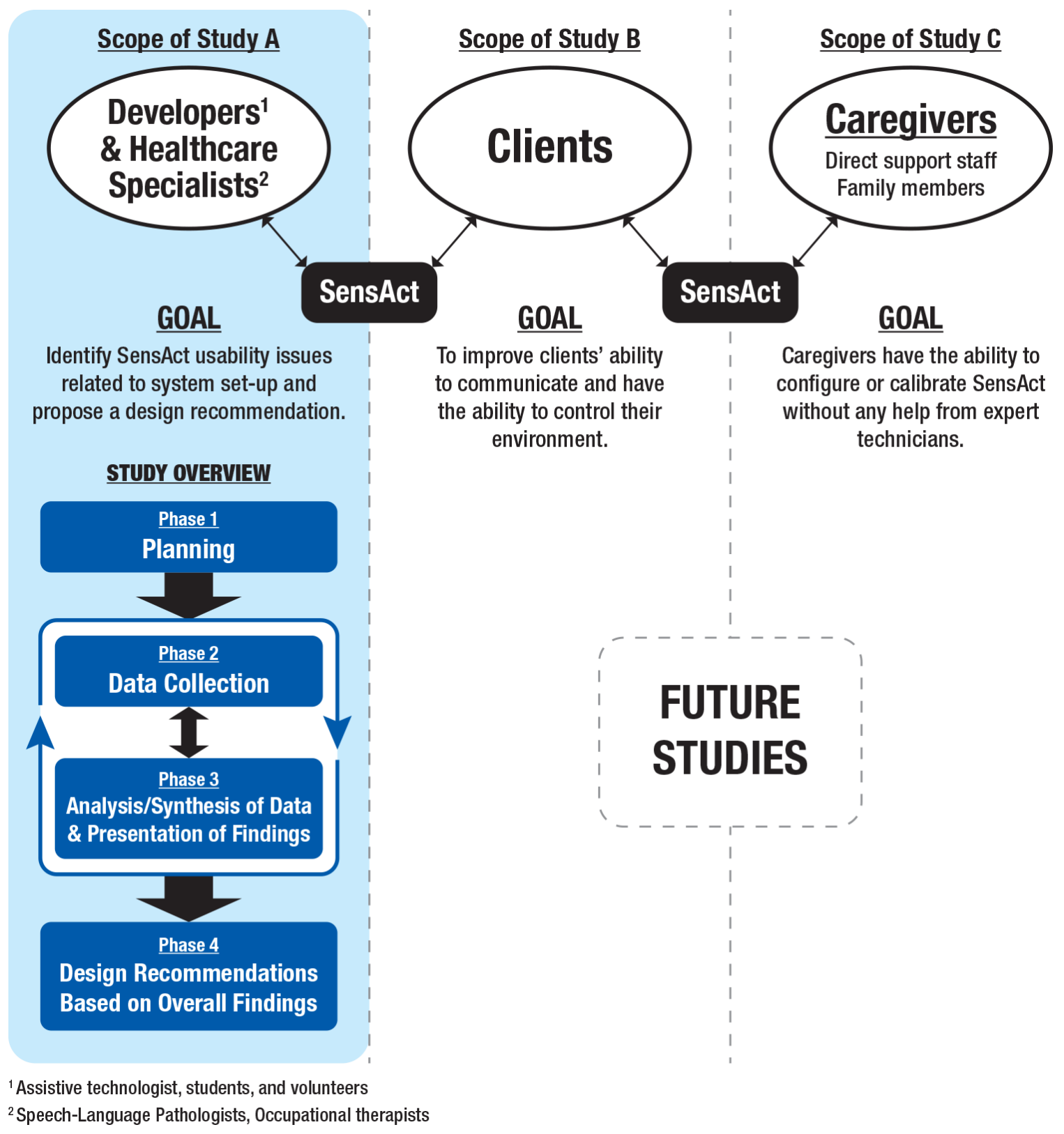

Figure 4. The study overview of this research is defined in 'Scope of Study A' 


\subsection{Study Contribution}

The primary contribution of this study is identifying SensAct usability issues through an HCD approach. This approach focuses on prioritizing the needs of the intended audience (Vechakul, Shrimali \& Sandhu, 2015) which in this study specifically includes addressing the needs of developers and healthcare specialists to better assist their clients. As shown in Figure 4, there are other areas in the development of Sens Act that still require further research and exploration. Although this study is only a small part of a bigger picture, the results and findings of SensAct's usability issues can introduce research opportunities in related fields, such as human-computer interaction (HCI) and engineering disciplines working in healthcare.

On a broader level, this study may foster a discussion on factors that may be undermining the future success of SensAct, and how to improve the AAC assessment process, healthcare workers' time management, and the design process in general. This study facilitates those improvements by:

- capturing the voice or 'first-person perspective' from stakeholders;

- describing the hospital's current AAC assessment and implementation procedure;

- exploring the use of a multi-method HCD approach to promote the inclusion of all stakeholders in the design and development process;

- developing design recommendations for possible areas of improvements and providing a basic framework for further SensAct research. 


\section{LITERATURE REVIEW}

\subsection{Background: What is Augmentative and Alternative Communication (AAC)?}

Augmentative and alternative communication (AAC) is a way for an individual with a speech impairment to convey a message through a range of different modes, such as facial expressions, non-speech vocalizations, personal communication books, and speech-generating devices (Subrahmaniyan, Higginbotham \& Bisantz, 2017; Teachman \& Gibson, 2018). AAC can vary from low-tech to high-tech methods. People may have difficulties with face-to-face communication for many different reasons. Severe physical disabilities and motor coordination problems can make the production of speech difficult or nearly impossible. Inclusive Technology from the United Kingdom describes AAC as various methods that can be utilized to support individuals with complex communication needs to be able to communicate and interact with others.

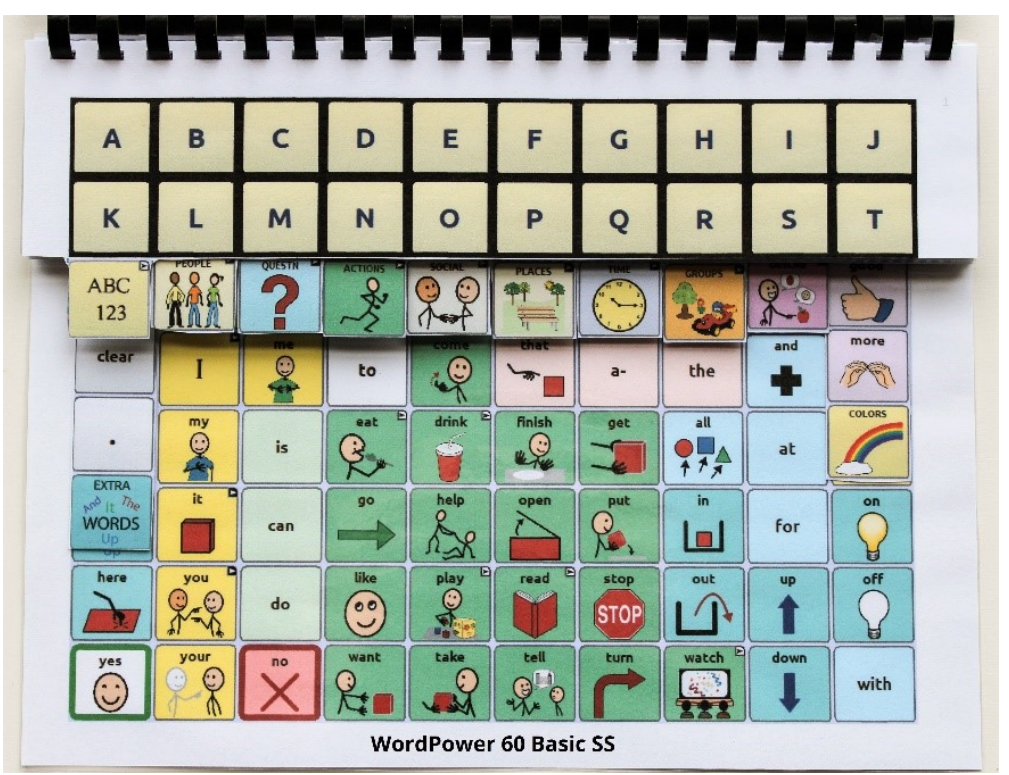

Figure 5. Low-tech Communication Board Options [Online image]. Retrieved August 28, 2019 from https://saltillo.com/chatcorner/content/29 
Low-tech communication methods are a simple and non-computerized way to communicate. While low-tech methods do not produce speech, they still provide a powerful and flexible way to communicate. For literate people who are unable to speak or have difficulty being understood, a communication board (Figure 5) is an example of a low-tech solution to facilitate communication. A communication board consists of commonly used words and letters on the alphabet to create words. High-tech communication methods normally use advanced computer technology and can produce speech from various input methods based on a person's ability (Figure 6). Early AAC devices were initially meant to help individuals with a speech impairment to interact with other individuals (Light, 1989). However, with the rapid development of electronic technologies over the last two decades, AAC devices are no longer being utilized only as a communication tool to communicate with other people, but also being used to communicate with other electronic devices, such as televisions, computers, smartphones, tablets, etc. (Light \& McNaughton, 2012; Williams, Krezman \& McNaughton, 2008) and for different purposes (e.g., to play video games, music or video, etc.).

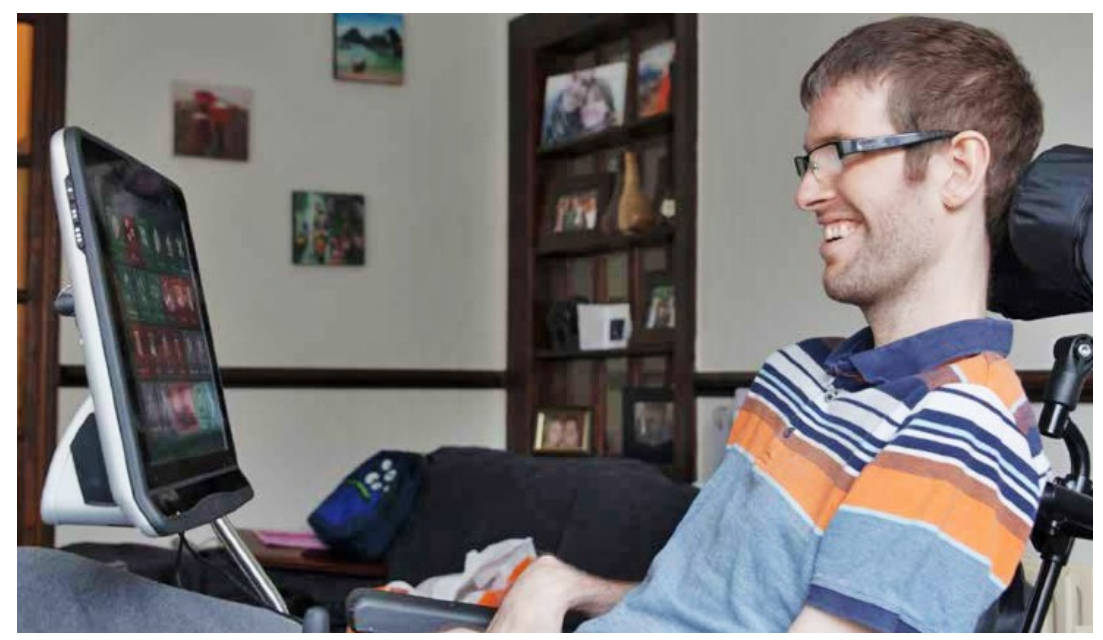

Figure 6. Tobii Dynavox I-Series + [Online image]. Retrieved August 28, 2019 from https://linkassistive.com/product/eye-gaze-device/iseriesp/ 
These devices are sometimes referred to as tools or machines. Perhaps in doing so, we have failed to realize the significant role of these machines to individuals with speech impairment. These AAC devices are more than a tool or a machine; they are the voices and the hands of the people with high-level of disabilities to be able to communicate or interact with other people, without which, would leave them excluded from society (Allen, 2005).

\subsection{AAC Barriers and Abandonment}

AAC devices have gone through many trials and errors since their early development. It is nearly impossible to develop the perfect AAC solution for each client because of the wide variety and complexity of disability they experience (Mumford, Lam, Wright \& Chau, 2013) and the time required to customize a solution. When developing an AAC design, developers may not be trained to design for/with users. Another reason, researchers have given for the lack of HCD in AAC device development stems from clients' limited ability to communicate effectively to be able to fully participate in design and development (Subrahmaniyan et al., 2017).

According to the National Core Indicators data from 2012, in the United States less than $10 \%$ of individuals with intellectual disabilities and complex communication needs had access to any form of AAC device. The 2013-14 data shows that 76\% of individuals with a disability have little to no input in making a decision in everyday life choices, such as housing, roommates, daily routines, jobs, support staff or providers, what to spend money on, and social activities (National Core Indicators, 2014). Such data 
demonstrates that individuals living with a disability may not be fully involved in the decision process related to their needs and preferences.

Due to this lack of involvement in the decision-making process, individuals with complex communication needs are more likely to be forced to adapt to the demands of assistive technology, rather than the developers design a technology that meets the needs, preferences, and skills of the users (Light \& McNaughton, 2013).

Currently, there is a lack of standardization in designing assistive devices across the field (Mumford et al., 2013). Once a set of designs are made and widely accepted by the majority of the population, it is less likely to be replaced with a better or more effective solution later on, (e.g., better keyboard layout, more accessible screen grid layout systems, etc.) (Light \& McNaughton, 2013). This mindset can create a barrier, limiting the possibilities of improving assistive device technology in the future.

Rombouts, Maes \& Zink (2016) have categorized the cause of AAC barriers into three main themes: 1) consistency of AAC usage, 2) time constraints, and 3) friction in the relationship between healthcare workers. Typically, healthcare workers only use AAC when there is a critical need for communication support, and there are no other options available to solve this problem (Light \& McNaughton, 2012).

Healthcare workers realize the long-term benefits of applying AAC systems consistently. However, due to time constraints, their evaluation of a successful AAC implementation is typically determined by short-term outcomes rather than long-term progress (Torrison, Jung, Baker, Beliveau \& Cook, 2007). 
To be able to perform their activities of daily living, individuals with a disability may require assistance from a healthcare professional; and those healthcare professionals are usually referred to as Direct Support Staff(DSS). In hospital settings or long-term care facilities, DSS may be referred to as Licensed Practical Nurses (LPN) or Registered Practical Nurses (RPN). While in the client's home setting, DSS are also commonly referred to as 'homecare aides' or 'caregivers'.

DSS normally interact with clients based on an interpersonal relationship; whereas, speech-language pathologists rely on their logical thinking and expert knowledge, in order to prescribe an AAC device to clients to improve their communication ability (Rombouts et al., 2016). These different approaches may cause some friction when the 'experts' are trying to prescribe a particular AAC method based on their expertise; while on the other hand, the DSS may not fully understand the practical reason behind it (Bradshaw, 2001). If this misconception continues, the DSS may use the device less frequently or even abandon it entirely.

Other researchers have discussed how AAC abandonment may be rooted to DSS interactions with clients in day-to-day activities (Baxter, Enderby, Evans \& Judge, 2011). For example, once the AAC system has been prescribed by a speech-language pathologist, DSS must possess the knowledge of how to apply the specific AAC device with the client in order to fulfill their daily activities (Hodge, 2007). Therefore, it is essential for the DSS to continually update their knowledge of AAC devices as any knowledge gap or inability to troubleshoot an error increases the risk of abandoning the AAC strategy. 
Figure 7 below illustrates factors which may be contributing to AAC

abandonment as it relates to the DSS role in implementing the AAC prescription.

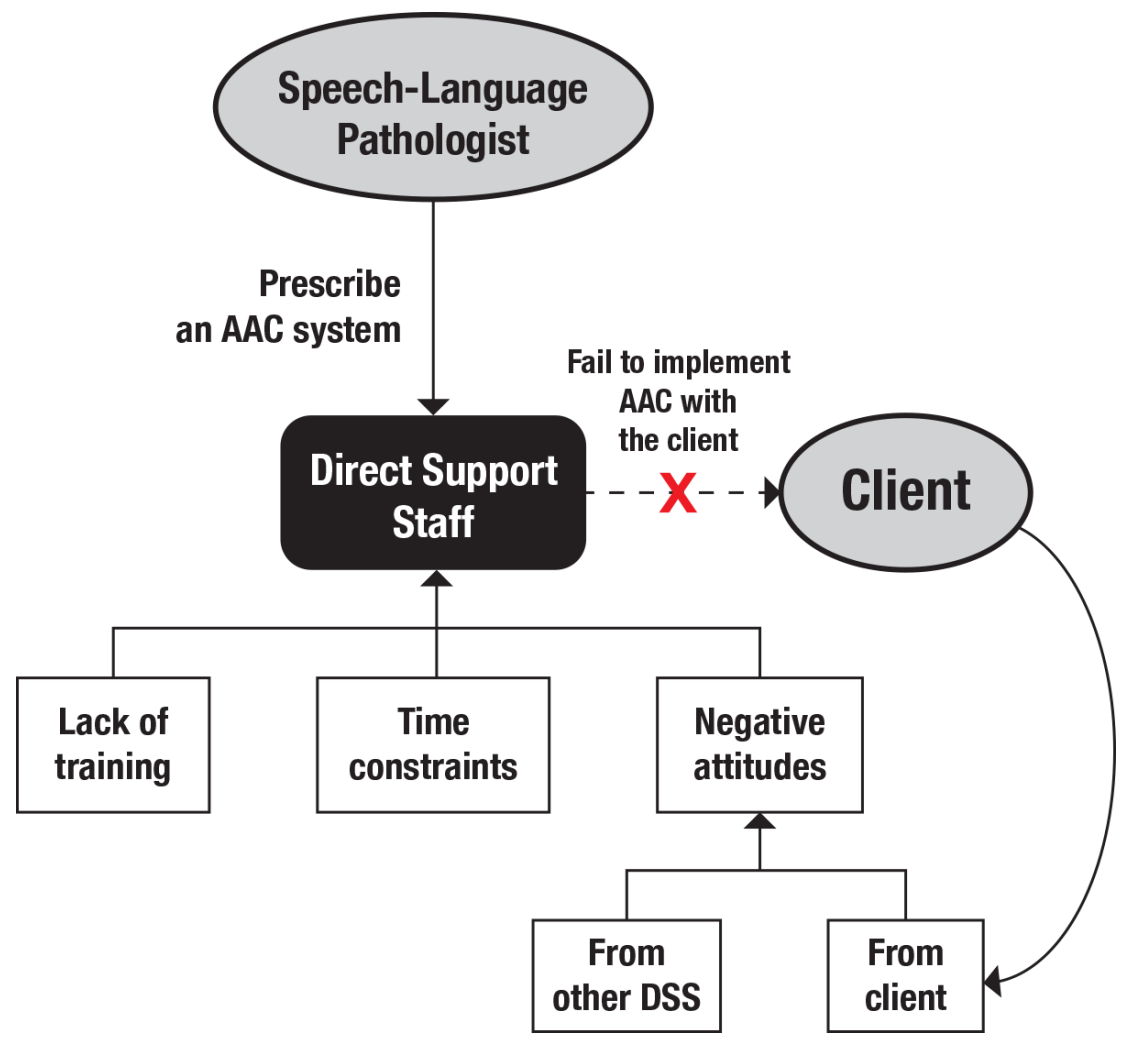

Figure 7. The relation between DSS role and AAC abandonment

It would be natural to assume that almost any line of work requires some sort of training program to train workers to do their tasks effectively and this concept applies to DSS work as well. The frustration caused by an ineffective AAC strategy implementation is one of the leading causes of AAC system abandonment (Cockerill et al., 2013). DSS often state that they gain their job skills through a series of trials and errors, which indicates that they may not have all the necessary skills and knowledge to perform their duties (Windley \& Chapman, 2010). Insufficient training has also been reported to be one 
of the leading causes of inadequate knowledge in implementing AAC strategies, which may lead to AAC abandonment (Torrison et al., 2007).

Time constraints also play a significant role in AAC abandonment. Ellen Rombouts and her colleagues (2016) acknowledge that DSS have to prioritize their tasks carefully due to their high workload. DSS often see AAC implementation as a disruptive part of their daily routines because they have to constantly choose between implementing the AAC system or carrying out their daily tasks (Hemsley, Balandin \& Worrall, 2012). It is widely known that hospitals and long-term care programs are often plagued with a shortage of healthcare workers. DSS have a limited amount of time they can spend with each client to assist them in doing their daily activities (e.g., eating, changing clothes, taking a bath, etc.). If the prescribed AAC system takes more time to implement than using natural sign language, for example, the DSS may abandon using the AAC system altogether to save time.

DSS may develop negative attitudes about AAC which can impact the implementation of an AAC strategy and cause friction between healthcare workers or clients. DSS may develop negative attitudes derived from fellow DSS and/or their clients. Implementing an AAC strategy can be ineffective if the staff themselves are not willing to comply with the AAC strategy, or do not support their co-workers (Johnson, Inglebret, Jones \& Ray, 2006). The staff's apathy or lack of confidence in the client's ability to operate an AAC device may also deter the progress of an AAC implementation (Calculator, 1999). On the contrary, if DSS feel that their fellow workers value the importance of AAC strategies, they would be more inclined to apply them effectively and consistently (Fishbein \& Ajzen, 2010); for example, making AAC system 
recommendations as a team may promote professional development through peer support, because complex clinical decisions are made based on expertise, experience, and knowledge of many professional clinicians (Batorowicz \& Shepherd, 2011). Supportive colleagues who value teamwork and collaboration are key to successful AAC implementation.

Negative attitudes towards AAC may come from the client themselves. DSS are more likely to abandon an AAC implementation if the client does not want to use it frequently. However, when DSS do not actively implement the AAC strategy with the client, they may be compromising the effectiveness of the AAC strategy (Rombouts et al., 2016). This cycle of negative attitudes and behaviours may cause a downward spiral that leads to AAC abandonment.

\subsection{AAC Assessment}

The end goal of AAC implementation is to facilitate effective communication between individuals with complex communication needs and their communication partners, to develop social interaction, and to take part in the community daily activities just like everyone else (Light \& McNaughton, 2014). But AAC assessment is a complex process, involving different stakeholders with varying levels of expertise, playing a vital role in AAC implementation. Failure to define the roles of stakeholders and potential barriers (e.g., the device is too difficult to use, lack of motivation, etc.) in the assessment process can lead to an ineffective AAC strategy and abandonment (Binger et al, 2012). AAC experts recognize that there are many factors that can affect their performance: time spent on AAC training; personal opinions on AAC methods; opportunities to 
communicate with clients using AAC; collaboration with fellow co-workers; and personal attitude towards AAC (Murphy, Markova, Collins \& Moodie, 1996; McCall, Markova, Murphy, Moodie \& Collins, 1997).

The implementation of AAC strategies relies heavily on the expertise of clinicians. Typically, clinicians prefer to select AAC technologies that they are familiar with which may exclude the viability and implementation of new technologies (Light \& McNaughton, 2013). The burden of learning and adapting to new technologies may be contributing to this problem.

Presently, there is no formal or standardized process for conducting an AAC assessment (Dietz, Quach, Lund \& Mckelvey, 2012) and researchers have tried to formulate some basic guidelines (Binger et al., 2012; Mumford et al., 2013). Generally, the AAC assessment involves different stakeholders at different stages of the process. The stakeholders may be: a) an AAC finder or someone who identifies individuals who may be eligible for assessment; b) a healthcare specialist who conducts the evaluation, identifies, and recommends AAC options; c) an AAC manufacturer or vendor who develops and produces the AAC device; d) an AAC funding agency who determines whether an individual is qualified for funding and releases funding for the client; e) a communication partner who interacts with the client on a daily basis; and f) the client.

Considering the complexity and unpredictable variables in AAC assessment, experts in the field of AAC feel the steps shown in the diagram below are relatively consistent and necessary to support the successful implementation of an AAC strategy: 


\section{Step 1: Referral}

Clinicians (e.g., SLP, OT, DSS, etc.) identify an individual who might benefit from AAC implementation.

\section{Step 2: History and data collection}

Clinicians gather relevant information from the individual's medical history, (e.g., any communication methods that have been applied previously, current communication needs and status, etc.).

\section{Step 3: Evaluation}

From the data gathered, the clinicians explore all possible AAC solutions for the client.

\section{Step 4: Recommendation}

Identify the best possible AAC strategy (short-term or long-term solution) and propose a recommendation to the funding agencies to secure funding for devices or equipment required.

\section{Step 5: Funding}

Determine the financial process to acquire the AAC device, either by loan or purchase.

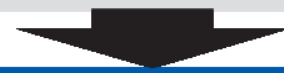

\section{Step 6: Follow up}

Within a certain timeframe, if there are any changes in the client's abilities, needs, or preferences; the previous steps may be repeated to find a better solution for the client.

Figure 8. AAC assessment process adapted from Binger et al. (2012)

Technology advancements have broadened the possibility to solve a wide range of communication challenges for individuals with speech impairment. However, without the support of experts from various backgrounds, the potential of these technologies cannot be fully exploited (Baxter et al., 2011). The end-user or client may also be classified as an 'expert', based on their experience in using similar products but this view of 'clients as experts' is generally not acknowledged. For example, some clients may be denied access to an AAC system simply because the decision-makers conclude that they do not have the 
necessary prerequisite skills (Light \& McNaughton, 2013). Further, young children and individuals with severe cognitive or linguistic impairments stand a higher risk to be deemed as not having the prerequisite skills or abilities because they cannot explicitly define their own needs and preferences (Stancliffe et al., 2010).

Many AAC experts have agreed that the key to minimizing AAC abandonment lies in the assessment of the AAC strategy itself (Mumford et al., 2013). The assessment process will determine the choice of AAC technology that best fit the needs of the client. This points to the need for AAC developers to understand this assessment process more deeply when developing a product.

In many cases, the development of new AAC technologies is not driven by the needs or abilities of individuals with complex communication needs; but rather by concerns over funding or limiting choice to available technologies (Light \& McNaughton, 2013). This misaligned focus on funding and technology, rather than the needs of the clients, may result in an ineffective AAC solution.

\subsection{AAC Stakeholders}

Communication is a dynamic interaction process between two or more people which includes: a) their cognitive and physical abilities; b) intentions or messages they would like to convey; c) a condition underlying how such intentions or messages are being relayed (e.g., at home or school, through the internet or face-to-face, etc.); d) their social relationships; and e) the goals of each interaction (Blackstone, Williams \& Wilkins, 2007). 
$\mathrm{AAC}$ is a unique interaction because it may involve different types of communication methods or mediums (e.g., speech, hand gestures, facial expressions, electronic devices, etc.) to convey a message. Stakeholders involved in AAC implementation must comprehend the elements of the various methods and mediums to achieve meaningful conversation, which requires a variety of expertise. The stakeholders can be categorized into three main group roles depending on the environment where the communication takes place: 1) the client; 2) the mediator; 3) the communication partner.

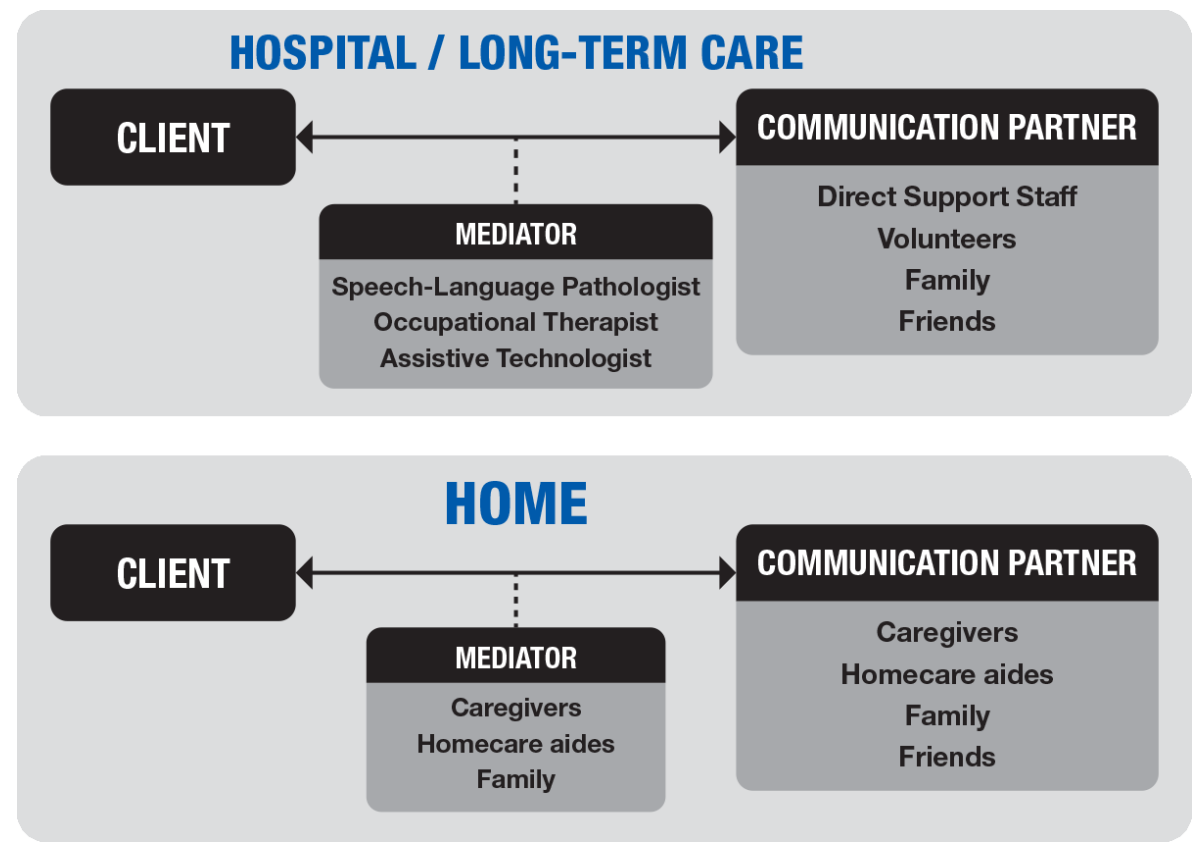

Figure 9. Stakeholder categories based on their roles

A communication partner is someone whom the client communicates to, via specific modes of communication (e.g., hand gestures, communication board, AAC device, etc.). At a hospital or long-term care setting, the client's communication partners mainly consist of the hospital staff, such as DSS, nurses, volunteers, and other healthcare staff; they interact with the client on a daily basis to assist them in daily activities. The role of the mediator is to provide support or troubleshoot issues with the AAC device if 
the communication between the client and their communication partner has broken down. In the hospital or long-term care setting, this mediator role is assigned to the speechlanguage pathologist (SLP), occupational therapist (OT), or assistive technologist (AT). Ideally, the communication partner (e.g., DSS, volunteers, and other healthcare staff) should be able to adjust, fix an error, and troubleshoot the AAC device themselves, considering the high-workload demand of most SLPs, OTs, or ATs (Rombouts et al., 2016). This would minimize inefficiencies waiting for an AAC expert to fix the issue.

In home settings, the role of the communication partner mainly consists of the caregivers or homecare aides, family, and friends. In terms of troubleshooting, since there is no real AAC expert readily available, either the caregivers or family members must be able to take charge of this mediator role and adjust the AAC device to accommodate changes in the client's ability or user preferences. This points to the wider need to have a user-friendly AAC device.

\subsection{The Development of AAC}

When voice assistant devices (e.g., Google Home, Alexa, etc.) were introduced to the market, they were designed mainly for the mainstream market. However, over time people with mobility issues found these voice assistant devices very useful in simple everyday tasks, such as listening to music, turning lights on or off, making phone calls, and many other activities. Although persons with disabilities may find this technology beneficial, they were not the primary target audience when this technology was first being developed. This market inclusion shows that a technology that was initially developed for the mainstream market can also benefit the disability sector (Clarkson \& 
Coleman, 2015). Many current mobile technology apps have included accessibility features built within their programs, which is perhaps a sign of social acceptance that accessibility has become a part of our daily lives (McNaughton \& Light, 2013).

Imagine one day in the future, where individuals can buy an AAC device off-theshelf at any big box store, as easily as we can buy a tablet or a smartphone today. We are already seeing this in other areas of adaptive technology, such as the Microsoft Xbox Adaptive Controller. Even with today's technology, family members of individuals with complex communication needs may no longer have to wait for a recommendation from clinicians on which AAC device to purchase. They can make their own purchasing decisions about which AAC device they would prefer because there is a wide range of mobile technologies and applications that have accessibility features already built-in (Light \& McNaughton, 2012). Apple products, such as the iPad and iPhone, are just some examples of mainstream market products that support the inclusivity of individuals with complex communication needs. The AssistiveTouch feature on the Apple iPad allows the user to adapt the multi-touch screen to their physical needs (Figure 10). The iPad user can create their own gestures or customize the menu layout of the AssistiveTouch screen. These types of accessibility features have encouraged other mainstream products to follow suit to promote their competitive edge in market inclusion. 


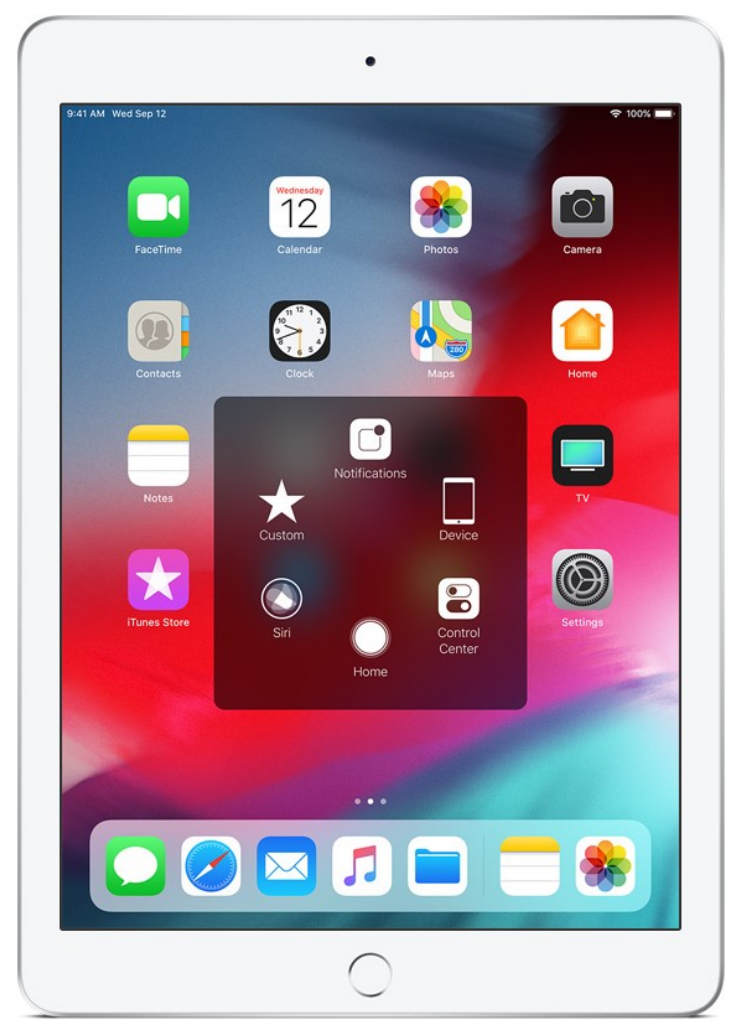

Figure 10. AssistiveTouch - Turn a pinch into a tap. [Online image]. Retrieved September 9, 2019 from https://www.apple.com/ca/accessibility/ipad/mobility/

Human needs have evolved from decades ago where individuals with complex communication needs could make only simple requests (e.g., what activity they would like to do, which food they would like to eat, etc.). Technologies can help people establish new friendships, learn new things in an educational environment, manage their own healthcare and social needs, and to be included in society (Light \& McNaughton, 2014). We can continue the evolution of this process by building more social awareness that not everyone is the same; some people may require special needs to communicate, but it does not lessen the need to communicate itself. Individuals with complex communication needs may like to talk to someone else as much as we do in our daily lives. It is our responsibility as a society to embrace, accept, respect, and adapt to their needs. 


\section{SENSACT OVERVIEW \& HISTORY OF DEVELOPMENT}

\subsection{SensAct as an AAC Device}

In Ontario, Canada, individuals with a disability can get access to assistive devices through the Assistive Device Program. This program is operated by the Ministry of Health and Long-Term Care to provide support and financial-aid to Ontario residents who have long-term physical disabilities. The Centralized Equipment Pool provides eligible Ontario residents with the distribution and support for AAC devices. According to the Government of Ontario website (Communication aids, n.d.), the Assistive Device Program only covers $75 \%$ of the cost of communication aids. However, the cost of an AAC device can range from hundreds of dollars for the less sophisticated ones to tens of thousands of dollars for complex speech generating devices. The high cost of an assistive device can be a massive burden for individuals who fall below the poverty line.

As defined by the Cambridge Dictionary (n.d.), an 'interface' is a connection between two pieces of electronic equipment, or between a person and a computer. An assistive technologist and a group of volunteers at BSVH have been developing a generic interface device that provides the client at the hospital a method to access an electronic device. This interface device is named "SensAct", which means a sensor or an input mechanism to activate another device. Designed to be cost-effective, it is also versatile in that it can be customized to fit a client's complex needs.

SensAct was initially built because the type of AAC devices that were available on the market could not meet the needs of the clients at BSVH. Due to the complex 
nature of the various clients' disabilities, the hospital and clients needed an assistive technology that could be adjusted easily when abilities and conditions change and/or new needs arise (e.g., changes in physical or cognitive abilities, changes in user preferences, changes in environment from hospital to home settings). When changes do occur, not only is there a long turnaround time to reset or upgrade the AAC device, but also the cost to maintain such devices to continue to meet the client's needs can be very high. These issues sparked the initiative at BSVH to develop an AAC device that is economical and highly adaptable to complex client needs.

SensAct was designed to accommodate numerous possible input methods (user controls) that can be customized to meet clients' needs and abilities. This versatility means that SensAct can be used as a communication device but can also be customized to interact or control other electronic devices (e.g., control a nurse call-bell/button system, control television commands, browse the internet, operate room lighting or room temperature, play music or videos on a media player, etc.).

In terms of hardware, SensAct utilizes Arduino, which is an open-source electronic platform to create interactive connectivity between an input sensor and other electronic devices (e.g., television, computer, tablet, etc.). The type of input method used can be selected based on the client's ability. There are currently several different input sensors that can be implemented with SensAct to match a person's abilities (e.g., switches, buttons, a light sensor, a touch sensor, a gyroscope sensor, and a joystick). Similar to other AAC devices available on the market, SensAct's input sensors can be configured and calibrated to suit a client's specific ability through a software that is installed on a computer desktop or a laptop. 


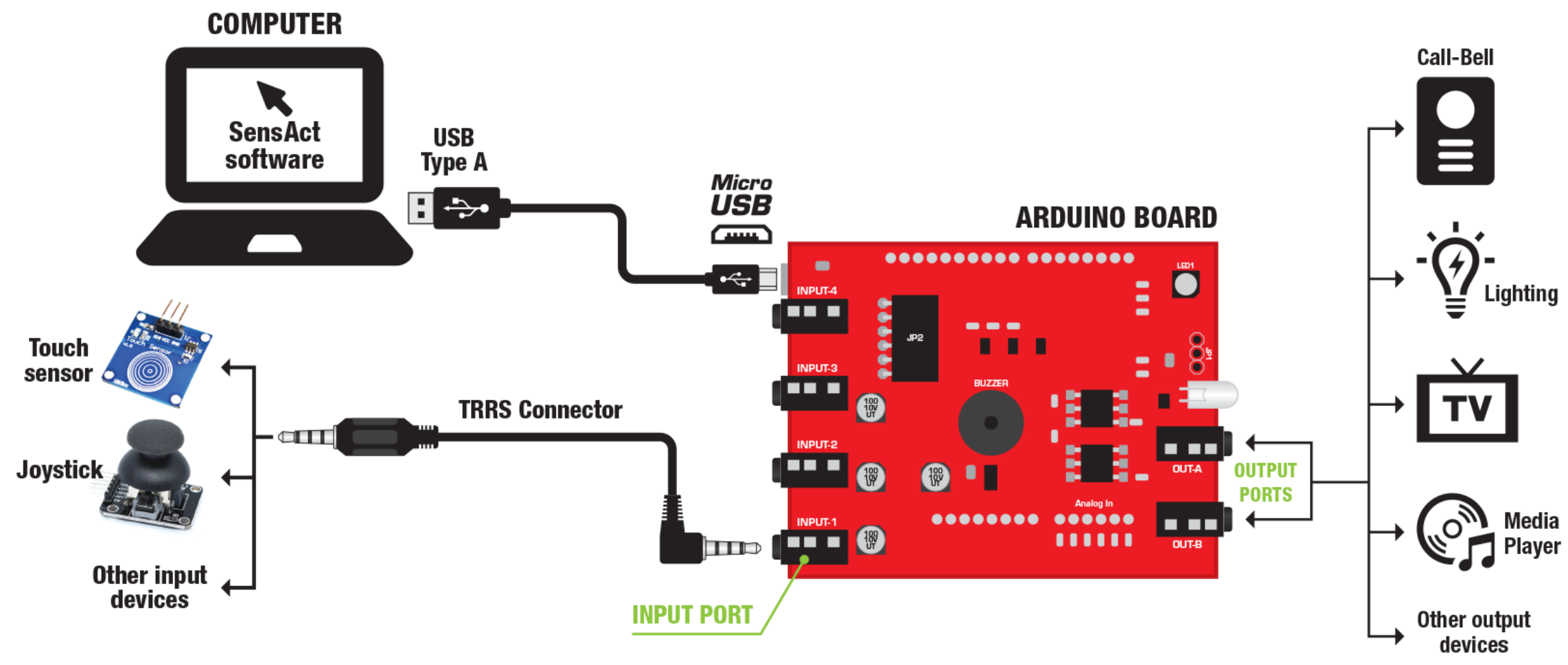

Figure 11. Diagram of SensAct hardware 
To configure SensAct, the Arduino board first has to be connected to a computer via a Universal Serial Bus (USB) cable. Selected input methods (e.g., touch sensor, joystick, gyroscope sensor, etc.) are plugged into one of the four SensAct input ports. Once all these devices are plugged into the Arduino board, the user can run the SensAct software installed on the computer to complete the setup configuration.

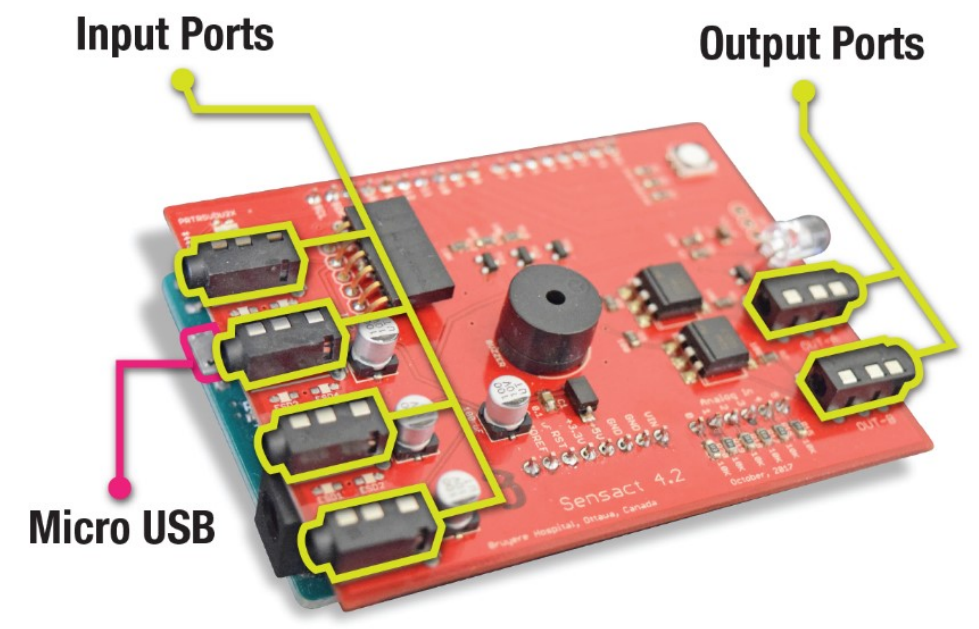

Figure 12. SensAct Arduino board

SensAct has the functionality to be a translator between a human and an electronic device. For example, if a client would like to control a television, they would normally use a television remote control. However, if the person has a high level of disability where they can only use a certain part of their body, the design of the television remote control may not support what they are still capable of doing. SensAct, on the other hand, can offer a solution by providing a variety of input methods to choose from to match a person's abilities (e.g., using a one button touch sensor to support limited finger mobility, a light sensor for limited range of motion or issues with applying force, a joystick to support upper limb abilities, a gyroscope sensor which can use head movement as a form of control, etc.). 
There are two operational modes involved in using SensAct: a) a configuration mode, and b) an application mode. The configuration mode is the first step in setting up the system where the developer or healthcare specialist assigns an input method (e.g., touch sensor, light sensor, gyroscope, etc.) to perform a certain task. The application mode is used to perform the actions that the client wants to do. Setting up these operational modes is also referred to as the mapping process. For example, using the television control example, one press on a touch sensor may activate the change channel up function on the television and two presses may activate the change channel down function. Other functions (e.g., change volume up/down) can also be set up using the same process. If there is a change in the client's needs or preferences, the developer or healthcare specialist will still be able to reconfigure or readjust it later on. Once all the mapping configurations have been set, the client can start using SensAct as a translator device to perform any task that the device is assigned to do.

\section{Configuration Mode}

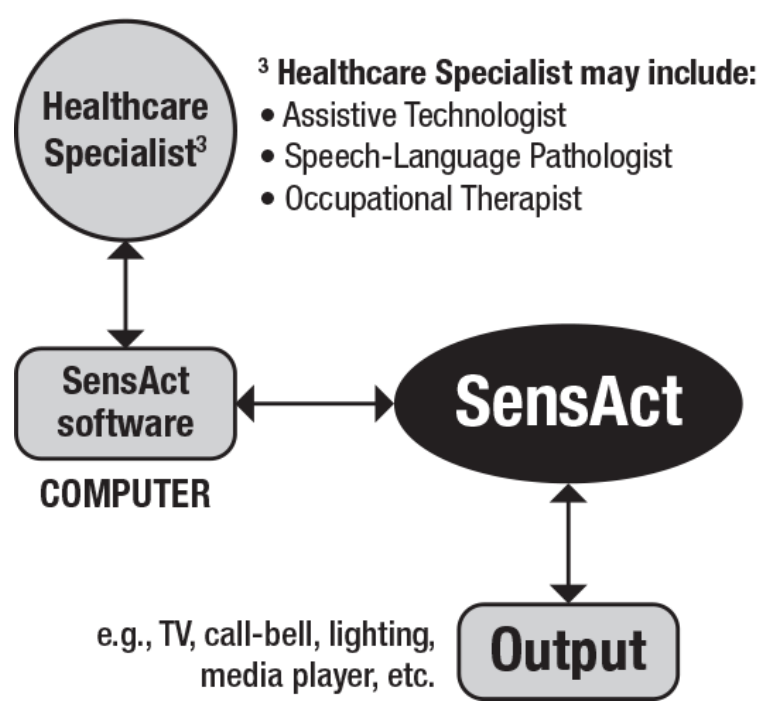

\section{Application Mode}

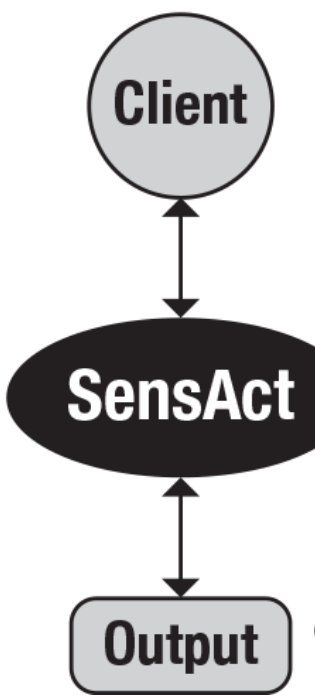

Power source e.g. power bank, wall power outlet e.g., TV, call-bell, lighting, media player, etc.

Figure 13. The two operational modes of SensAct 
The micro USB port on the SensAct Arduino board is used to connect the SensAct unit to the computer to perform the mapping process where each input action is being assigned to activate a certain output method in configuration mode. In the application mode, the micro USB port is used as a power source when connected to a power outlet or a power bank via USB cable, and can also act as an interface for a Human Interface Device (e.g., SensAct can mimic the functionality to control a mouse or a keyboard). The Arduino board is protected with a plastic casing to prevent it from being damaged. The diagram below (Figure 14) is an example of a SensAct setup designed to mimic the functionality of a television remote control.

SensAct developers have prepared a manual demonstrating how to setup and configure the SensAct unit in a digital word processing file format. This file is packaged together with the SensAct software program files and can be downloaded from a shared GitHub link.

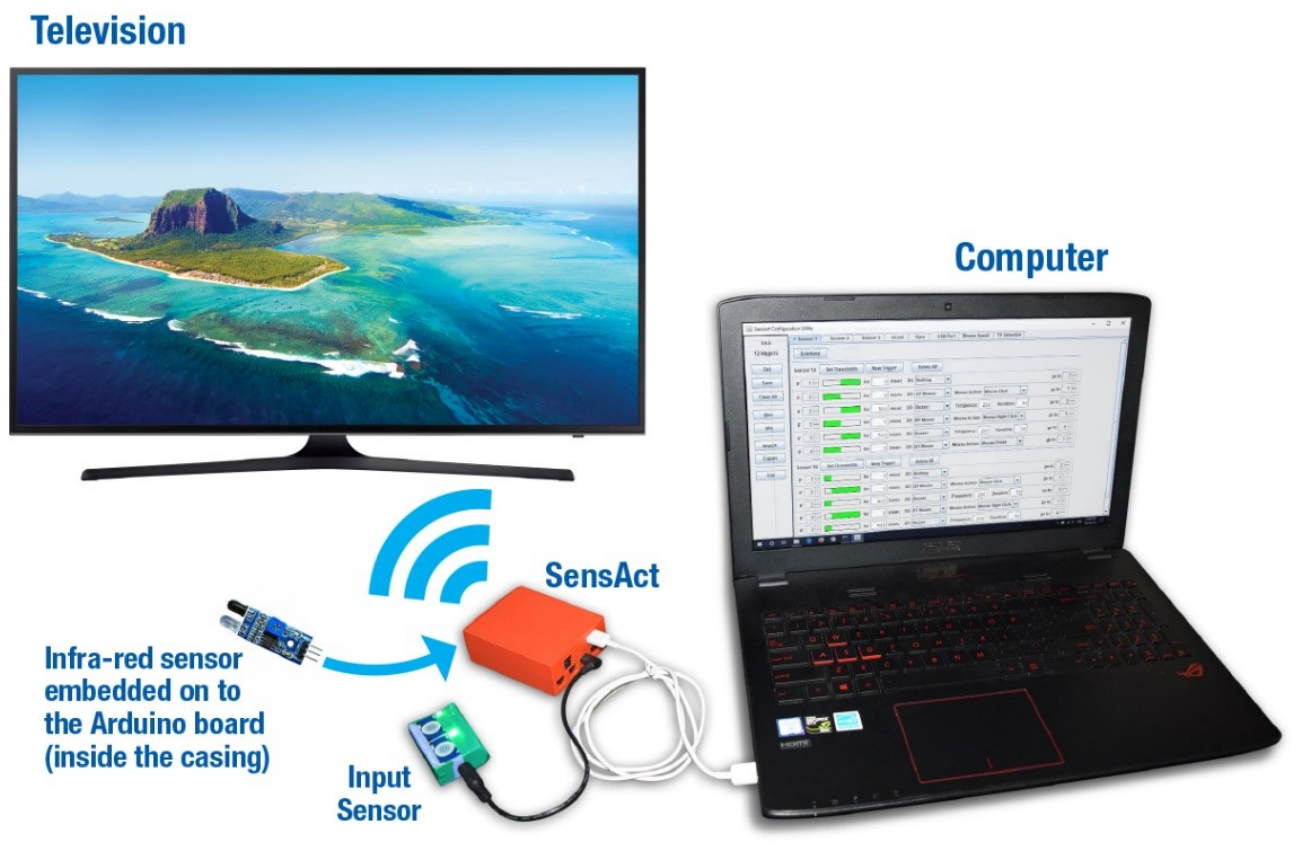

Figure 14. Example of SensAct setup as a TV remote control 
Since SensAct utilizes open-source hardware, it allows customization with different types of input sensors readily available in the open market. The developer team is also able to minimize the cost to build one SensAct unit for under $\$ 55^{4}$. Compare this to the cost of other AAC devices, such as the Tobii I-15 from Tobii Dynavox (a wellknown manufacturer of AAC devices) with an estimated price tag of $\$ 17,000^{5}$; the monetary value of getting SensAct to more individuals, especially non-funded clients, is clear.

\subsection{SensAct's History of Development}

SensAct is currently being used in clinical practice and has been tried and tested with several clients at BSVH. There have been two main groups of people involved in the development of SensAct: a) the developers, and b) the healthcare specialists. The developers build and create the backbone of the system and include: an assistive technologist, volunteers with computer programming and electronic engineering backgrounds, and university students conducting research at BSVH. Due to limited funding, the developer team relies heavily on volunteers and students to design, develop, and build SensAct. Since its inception, this team has built a working prototype of SensAct and successfully solved several clients' accessibility and communication needs.

The healthcare specialists in this study (Scope of Study A, shown in Figure 4) include speech-language pathologists and occupational therapists who make an assessment of their client's needs and prescribe an assistive device. In order to efficiently

\footnotetext{
${ }^{4}$ The cost was revealed through the interview process. The cost was calculated based on the hardware materials cost. Labour costs were not calculated because all the work-hours came from volunteering.

${ }^{5}$ The interview was conducted in February 2019. Price estimate may change over time.
} 
prescribe SensAct, they need to understand the system in order to configure the device themselves without being dependent on the developers.

Although volunteers have brought a wealth of knowledge to the developer's team, stakeholders at BSVH have acknowledged that there are still some challenges in translating the developers' technical knowledge in configuring SensAct to healthcare specialists. Healthcare specialists may not have the necessary computer programming or electronic engineering background to configure the systems like SensAct and to date, they have had limited involvement in developing a more appropriate user interface due to their workload. Stakeholders recognize the importance of being able to configure SensAct easily as they conduct the AAC assessments and work with their clients on a daily basis, not the developers. In this scenario, the 'real consumer' of the AAC device is not necessarily just the client who uses the device, but rather the clinicians who prescribe and implement the AAC device (Subrahmaniyan et al., 2017). Also, from an ethical perspective, clinicians need to fully comprehend the device's capability before they can make sound recommendations to their client.

Stakeholders from BSVH feel that the current usability issues with SensAct have limited its potential to be used with a broader audience. By identifying these usability issues, this research study can contribute to unlocking the potential of SensAct as a universal accessibility tool. The ultimate goal for SensAct is to be an assistive device which can fulfill clients' communication and accessibility needs. In order to reach that goal, this device should be able to be accessed, configured, and implemented by its intended users, from anywhere, and at anytime; so that the client can utilize SensAct effectively and efficiently. 


\section{METHODOLOGY}

This study was conducted in 4 different phases (Figure 15), as described below:

- Phase 1 - Planning

This phase involved building a core understanding of the overall issues through interdisciplinary coursework, a literature review, as well as training in accessible design and ethical considerations.

- Phase 2 - Data Collection

Phase 2 consisted of semi-structured interviews with developers and healthcare specialists, a heuristic evaluation of SensAct, observations of participants setting up SensAct, a focus group concentrated on the UI design, and developing a prototype based on previous findings and evaluating it with participants for usability.

- Phase 3 - Analysis/Synthesis of Data \& Presentation of Findings

Phase 3 occurred concurrently alongside each method and focused on identifying issues and opportunities through memoing, coding and theming methods throughout the analysis process.

- Phase 4 - Design Recommendations Based on Overall Findings

Phase 4 involved developing design recommendations based on the cumulative findings from the methods to support future development. 


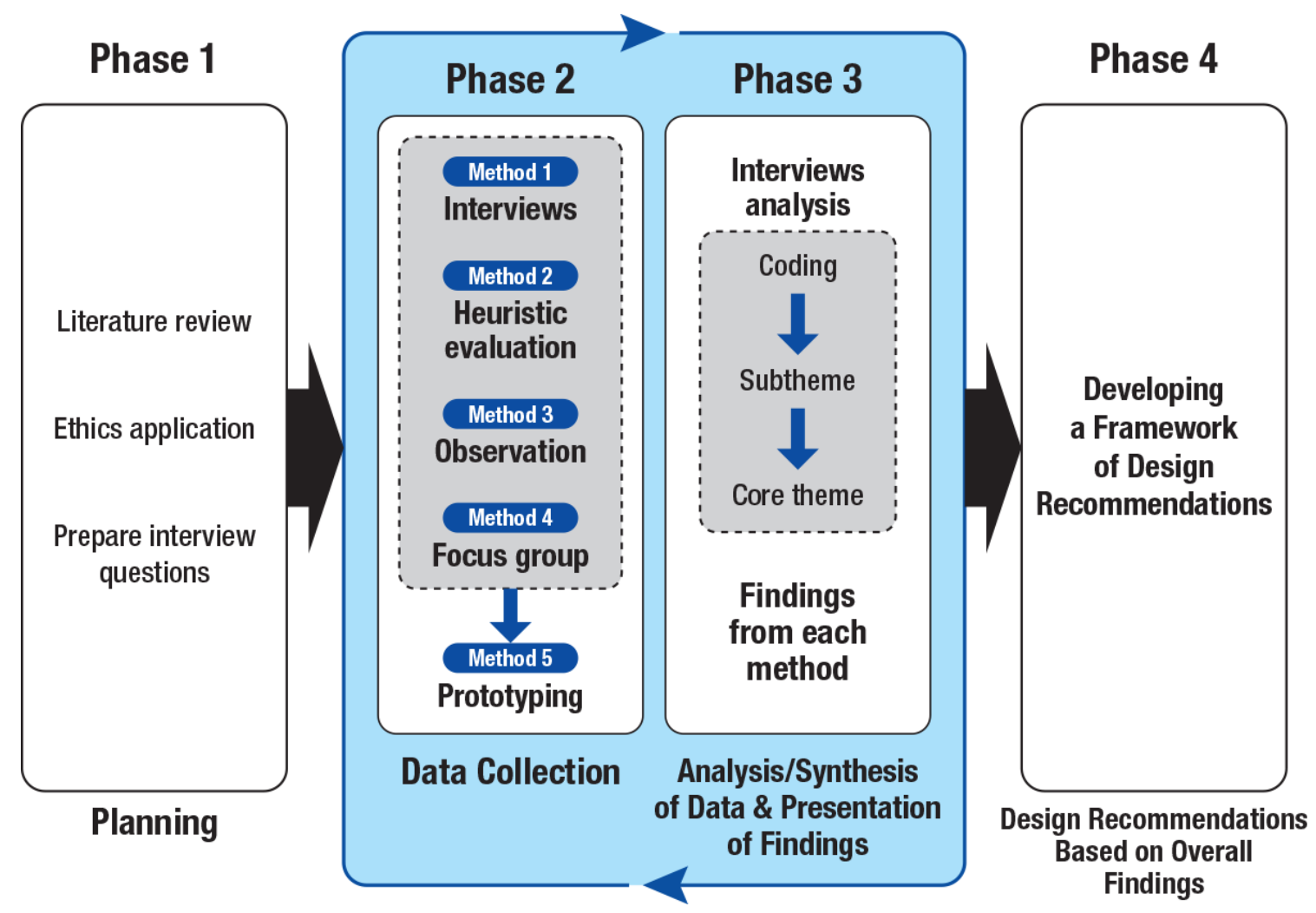

Figure 15. Research study phases

\subsection{Planning}

The planning phase in this study included:

- A literature review on AAC, design analysis and research methods.

- Completing training from the Tri-Council Policy Statement (TCPS 2) on Ethical Conduct for Research Involving Humans (Appendix A.6) and developing an ethics application for site work with human participants at BSVH.

- Attaining ethics clearance from the BSVH and Carleton University to conduct research with BSVH staff at their facility.

- Preparing field work techniques in consultation with the program co-supervisors. 


\subsection{Data Collection}

This research study has been approved by the Bruyère Research Ethics Board (Appendix A.1) and Carleton University's Research Ethics Office (Appendix A.2) to conduct research activities at BSVH as part of their program evaluation, quality improvement, or quality assessment activity.

\subsubsection{Semi-Structured Interviews}

The purpose of conducting interviews was to gain insight about possible issues with SensAct and future goals from the perspectives of the developers and healthcare specialists. Due to the limited number of individuals that have used SensAct, combined with the availability of participants, only 5 in-person, semi-structured interviews were conducted at the hospital. The healthcare specialists included 2 Speech-Language Pathologists (SLP), 2 Occupational Therapists (OT), and for the developer category, 1 Assistive Technologist (AT). Interviews took 30 minutes except for one interview with the AT which was 90 minutes. All interviews were audio recorded for further analysis. The researcher took notes to capture comments emphasized during the interviews. The audio files were transcribed, with all potentially identifying data such as name, gender, and any specific notes removed or coded to conceal the identity of the participants. The transcribed data was then analyzed.

\subsubsection{Heuristic Evaluation}

According to the International Organization for Standardization (ISO), usability is the "extent to which a system, product or service can be used by specified users to 
achieve specified goals with effectiveness, efficiency and satisfaction in a specified context of use" (ISO 9241-11, 2018). This raises the question of how we can evaluate whether the product meets the specific goals of effectiveness, efficiency, and satisfaction of the users.

There is a wide range of methods to perform an evaluation to assess a system's usability. Heuristic evaluation is a popular and widely used method in the field of HCI. First introduced by Jakob Nielsen and Rolf Molich in 1990, heuristic evaluation uses a set of usability principles or guidelines to aid designers in conducting usability evaluation. Nielsen has since refined the "10 Usability Heuristics for User Interface Design" (1994) from its original inception in 1990, which are highlighted on Figure 16. The purpose of conducting the heuristic evaluation in this study was to better understand and gain insight about the SensAct UI design from the researcher's perspective. 


\section{Nielsen's 10 Usability Heuristics for User Interface Design}

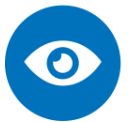

\section{Visibility of system status}

The users should always be informed of the status of the system through proper feedback and within a reasonable time.

\section{Match between system and} the real world

The system should use familiar language that is easy to understand by the users. Following real-world conventions instead of using system-oriented terms.

\section{User control and freedom}

Provide users with the ability to control their mistakes with obvious undo and redo functions.

\section{Consistency and standards}

Maintain consistency of words, situations, or actions throughout the system to avoid confusion.

\section{Error prevention}

Mitigate errors by eliminating error-prone conditions or provide users with a confirmation option before proceeding to perform an action.

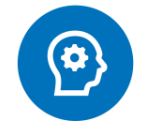

Recognition rather than recall

Minimize the use of memory load by designing objects, actions, and options to be more obvious.

\section{Flexibility and efficiency of use}

Provide shortcuts for advanced users, and appropriate system walkthrough for novice users.

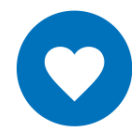

Aesthetic and minimalist design

Avoid displaying unnecessary information so that the users can focus more on important contents.

Help users recognize, diagnose, and recover from errors

Error message should be clear and understandable by the users, followed by a suggestion on how to solve the problem.

\section{Help and documentation}

Provide necessary help and documentation to the users. This information must easy to find, concise, and in a simple step-by-step instruction.

\section{Severity Ratings for Usability Problems}

\section{[0] This is not a usability problem.}

[1] Cosmetic problem only: unnecessary to fix unless extra time available.

[2] Minor usability problem: low priority to fix this problem.

[3] Major usability problem: high priority to fix this problem.

[4] Usability catastrophe: imperative to fix before the product can be released.

Figure 16. Nielsen's 10 heuristic evaluation guidelines and severity ratings of usability problems (Nielsen, 1994) 
The UI of SensAct's software was analyzed using these guidelines to find potential usability problems. Nielsen also formulated the severity of problems into five levels, as shown in Figure 16, based on three factors ("Severity Ratings for Usability Problems", n.d.):

- Frequency: does the problem commonly occur?

- Impact: will it be easy or difficult to solve this problem?

- Persistence: will there be a reoccurrence of this problem once it is fixed?

The heuristic evaluation was performed by the researcher under the following conditions:

- The evaluation was conducted from the perspective of a novice SensAct user (the researcher) without reference to any documentation provided by the developer.

- Only the two-button touch sensor as the input method was available to conduct this evaluation.

- The researcher was aware that there may have been some bugs during the evaluation of SensAct software version 4.6 on an Arduino board version 4.2.

- The evaluation was conducted on the Microsoft Windows operating system.

\subsubsection{Observation}

An observation of the SensAct system being configured by a novice user (an OT, who had seen the implementation of SensAct but had not personally configured it) and an expert user (an AT, who is one of the developers of SensAct) together was conducted at 
the BSVH therapy and rehabilitation office and video recorded for further analysis. Two typical use-case scenarios were observed, with the expert user assisting the novice user in setting up and configuring the SensAct unit. Each scenario took approximately 20 minutes with a 5 -minute break in between.

\begin{tabular}{|c|c|c|}
\hline \multicolumn{3}{|c|}{ SGENARIO \#1 } \\
\hline Client & Attributes \& Requirements & SensAct Solutions \\
\hline Client A & $\begin{array}{l}\text { - Male } \\
\text { - Severly disabled } \\
\text { - He has a reliable thumb movement } \\
\text { on one hand } \\
\text { - No cognitive issues } \\
\text { - Computer literate } \\
\text { - The client would like to do a basic } \\
\text { internet search and email }\end{array}$ & $\begin{array}{l}\text { - One button touch sensor } \\
\text { - The sensor is mounted to his } \\
\text { thumb } \\
\text { - Programmed to simulate } \\
\text { mouse movement on a laptop } \\
\text { - The clinician (novice user) may } \\
\text { use pre-programmed settings }\end{array}$ \\
\hline
\end{tabular}

\begin{tabular}{|c|c|c|}
\hline \multicolumn{3}{|c|}{ SGENARIO \#2 } \\
\hline Client & Attributes \& Requirements & SensAct Solutions \\
\hline Client B & $\begin{array}{l}\text { - Male } \\
\text { - Severly disabled } \\
\text { - He is only able to move his head } \\
\text { - Unable to use regular call-bell when } \\
\text { in bed because there is no tool to } \\
\text { hold the call-bell in place } \\
\text { - Client needs to use a customized } \\
\text { call-bell }\end{array}$ & $\begin{array}{l}\text { - One button touch sensor } \\
\text { - The sensor is mounted to his } \\
\text { cheek } \\
\text { - Programmed to simulate a } \\
\text { call-bell } \\
\text { - The clinician (novice user) has to } \\
\text { configure the settings manually }\end{array}$ \\
\hline
\end{tabular}

Figure 17. Observation scenarios

Field notes were used to capture concerns conveyed by the novice user or when the novice user questioned the expert on sections that were unclear. Any suggestions that could help improve the usability of the SensAct were also noted. The video recordings were reviewed to gain more insight into incidents. 


\subsubsection{Focus Group}

In the medical field, participants are typically involved in the later stages of development as subjects in usability testing (North, 2015). The purpose of conducting a focus group was to involve the developer and healthcare professionals in the design process, not as subjects, but as active participants who could provide critique, input, and feedback on the development of the product.

A 45-minute focus group was held at the BSVH therapy and rehabilitation office and included four participants (an SLP, an OT, an AT, and a university student on a fieldwork to study AAC) with the researcher acting as the facilitator. The session was video recorded for later analysis and involved the use of traditional pen and paper tools for participants who might prefer to express their thoughts through notes, drawings or sketches with several printed screenshots of the current SensAct UI design which were used as a point of reference. The facilitator started the focus group with a script (Appendix C) to initiate conversation between the participants and later probed questions throughout the session to provoke ideas, arguments, comments, and feedback among the participants on how to improve the usability of SensAct's UI design.

\subsubsection{Prototyping}

Based on information collected, reviewed, and analysed from the previous methods, a pilot prototype was developed to improve usability of SensAct's software interface. The prototype was made using HTML which could be tested using a web browser. Due to the researcher's limited knowledge of HTML, some design features, 
functions, and layout were not fully achieved; however, it did not affect the overall objectives of this prototype to present design recommendations.

Once developed, this prototype was tested by a panel consisting of an assistive technologist, a speech-language pathologist, and an occupational therapist at BSVH. The findings from prototype testing were then reviewed and analyzed to formulate design recommendations to improve the usability of SensAct's UI.

\subsection{Analysis/Synthesis of Data \& Presentation of Findings}

Analysis was conducted using the qualitative method of thematic analysis. The objective of a thematic analysis method is to identify, analyze, and interpret patterns of meaning or themes across the various data collected from the research subjects (Clarke \& Braun, 2016). Data collected from each method created building blocks to generate larger patterns of meaning guided by the research questions. The coding process is a crucial link between the raw data collected and their substantive meaning (Charmaz, 2001).

Data collected from the interviews was examined through coding and thematic analysis. The audio files from the interviews were transcribed into text and then coded based on common occurrences to conduct a first cycle of coding. Those first cycle codes were then further analyzed through a second cycle of coding to develop subthemes and underlying messages. The subthemes reflected the core issues discovered during the interview process (Saldaña, 2015). The interviews were analyzed using a process coding method to extract interaction or reaction in response to situations or problems. Process coding normally uses gerunds ("-ing" words) to describe the action from raw data (Saldaña, 2015). 
REAL

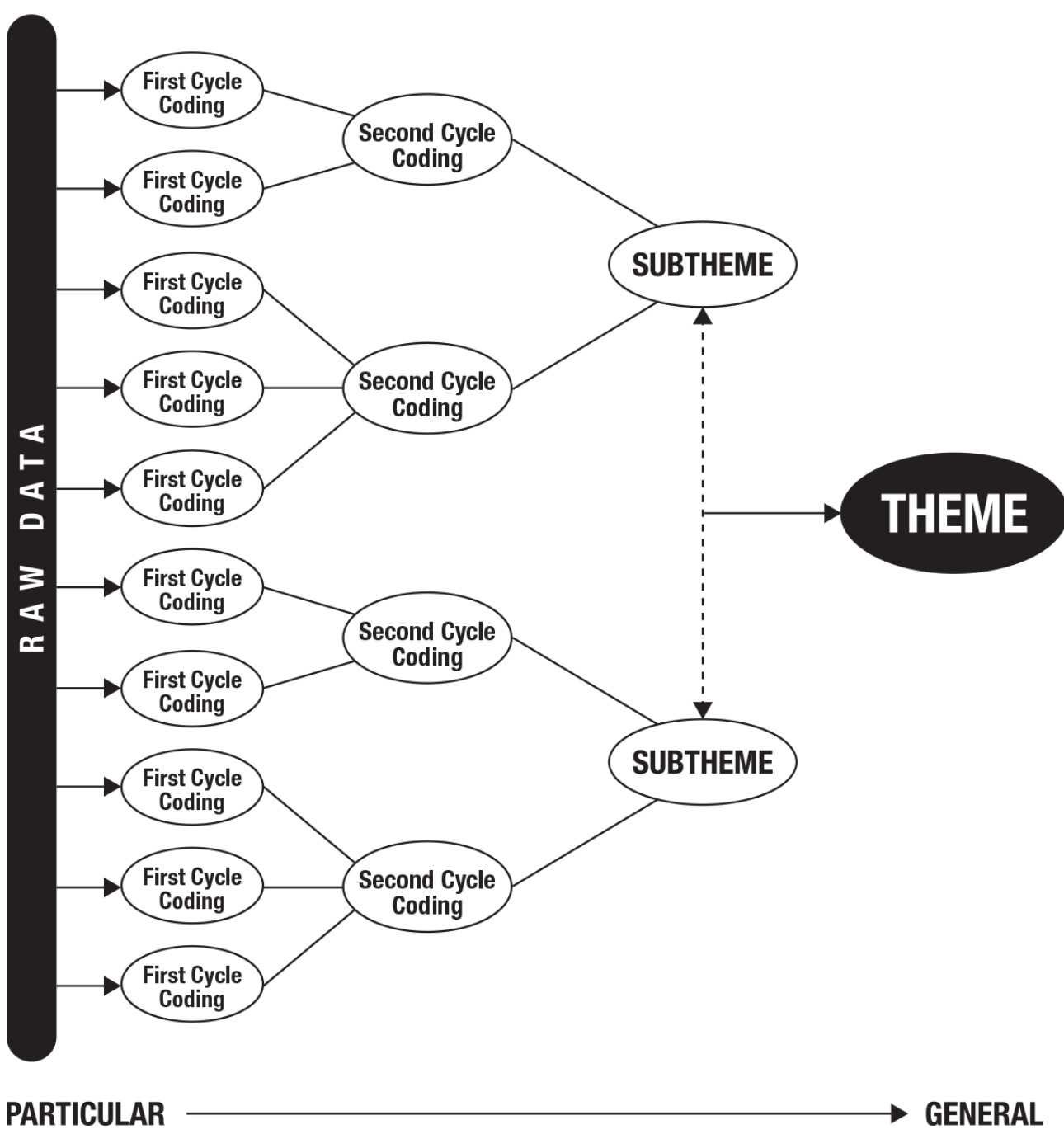

Figure 18. Streamlined diagram from raw data to overall theme adapted from Saldaña (2015)

The next stage analysis took place during the heuristic evaluation. The objective of using heuristic evaluation was to identify potential usability issues with SensAct's UI using Nielsen's guidelines. The field notes from the observation method were examined to gain insights about the implementation of SensAct in a clinical setting. The recordings and sketches derived from the focus group session were reviewed to capture the input and feedback from the healthcare specialists and the developer of SensAct. The findings from 
each of the 4 methods were then analyzed to formulate preliminary design requirements to develop a prototype of SensAct UI which was evaluated with the developer and healthcare specialists from BSVH.

METHODS

\section{OBJECTIVES}

(1) Semi-Structured Interviews $\longrightarrow$ To collect data about the source of SensAct usability issues (2) Heuristic Evaluation $\longrightarrow$ To explore SensAct user interface experiences (3) Observation $\longrightarrow$ To collect data about SensAct implementation process

(4) Focus Group $\longrightarrow$ To capture feedback and input from SensAct users
5 Prototype Design
\& Evaluation
A prototype design was developed based on analysis of the findings from the previous 4 methods above and tested it with the users

Figure 19. Methods workflow

\subsection{Design Recommendations Based on Overall Findings}

The root cause of design problems may not necessarily always come from lack of design experience or from misunderstanding a design brief, but it can also arise from various underlying factors. A final synthesis was done on the overall findings to develop design recommendations for the future improvement of SensAct's UI. Developing this framework also involved identifying barriers that may undermine SensAct's implementation to a broader audience and suggestions to mitigate these issues. 


\section{ANALYSIS \& FINDINGS}

This chapter outlines the analysis and findings from the 5 data collection methods described in phase 2 (Figure 15). Each method involved a different analysis approach to yield findings. The synthesis of these findings were then used to develop design recommendations.

\subsection{Semi-Structured Interviews}

The interviews revealed a number of key findings that can be used as a base for developing design recommendations and future research. The five participants discussed:

a) how they communicate and interact with clients;

b) their knowledge of AAC/SensAct and how they acquired this knowledge;

c) the assessment process for prescribing AAC/SensAct to a client;

d) their approach to implementing AAC/SensAct with a client;

e) issues, difficulties using AAC/SensAct based on personal experience; and

f) feedback or suggestions to improve the current state of AAC/SensAct.

Two of the five participants had several years of experience implementing AAC with clients but had not implemented SensAct with a client, which is why some of the questions on the interviews alternated between AAC and SensAct to suit the interviewee's experience.

A total of 217 process codes were generated for the first cycle coding, which were then reduced to 16 codes during second cycle coding (Appendix B.3). The 16 codes that 
were generated in the second cycle coding were then grouped into 3 subthemes that share some connections or underlying meaning. The essence and connections between these subthemes were then summarized into one core theme.

\section{CORE THEME \\ Systemic factors influencing AAC/SensAct implementation}

\section{External factors have}

an impact on the success

of AAC implementation

Lack of funding is a major issue in healthcare sector

Currently available AAC devices lack usability despite high-cost to obtain them

Commercial AAC devices do not have standardization or universal design compatibility

Clinicians are getting limited support to improve AAC implementation

Awareness of accessibility and usability in product design needs to be improved

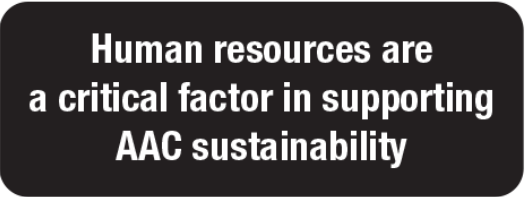

Due to limited resources, getting support from community is vital

Hospital or long-term care require standardization or definitive guidelines to assess and implement AAC

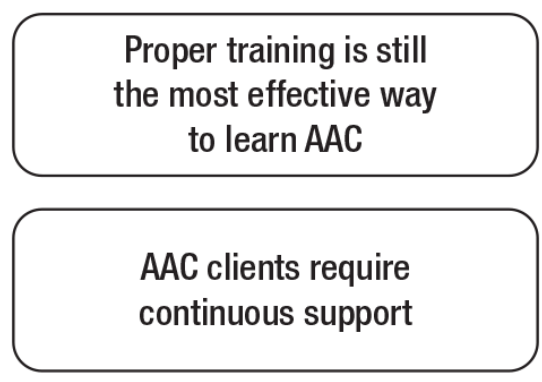

Ease of customization of an AAC device is key to meet clients' varied needs

Developing SensAct requires interdisciplinary team and human-centered design approach

Clinicians resourcefulness to adapt to circumstances is critical to the success of AAC implementation
People's abilities, limitations, beliefs, preferences, motivation \& attitudes can impact AAC implementation

Clinicians' point of view can affect the daily operation in hospital or long-term care settings

AAC users tend to choose familiar devices

Clients' attitudes and preferences are preventing them to access AAC

Current SensAct has met some clients' needs and encouraged further development

Figure 20. Core theme and subthemes generated from the second cycle coding 


\subsubsection{External Factors Have an Impact on the Success of AAC Implementation}

Three participants expressed during their interview that external factors have a more significant impact on implementing AAC than the AAC implementation process itself. For example, lack of funding has become a major issue in the healthcare sector. Participants highlighted several times that funding to build or maintain the hospital's infrastructure and healthcare in general had been cut over the years. One participant even mentioned that if a client can set up their home properly, it can be a better environment than the hospital. The lack of funding can be a significant barrier for clients to gain access to assistive technology in order to meet their basic needs.

"So there [was] limited funding for people who are in our institution to be able to get the type of technology they needed to be able to control [a] computer or smartphone, tablet, or TV, or even do a nurse call."

--

"And if the client is not qualified, or doesn't have insurance or money, or if the family think[s] it's not worth the investment, so it becomes a barrier for a client to not being able to control or have access to technology.”

$--$

"Like there's things out there in the world that if you had a fancy custom home, you could have deeper access to independence than we can provide here."

Interview Excerpt 1: Quotes from participants highlighting the lack of funding

There is also a long turnaround time required to upgrade or update an AAC device which can be a significant problem when a client needs the device urgently. One of the participants noted during the interview that the latest portable speech generating device 
Tobii Dynavox does not have a dedicated physical customer service office that provides repairs. The customer would have to contact the customer service using an online form on their website and then send the device by mail for repair.

Participants highlighted that currently available AAC devices on the market still have limited customization options to meet clients' needs. The participants also criticized that there is no standardization between commercial AAC devices on the market. The devices are not designed or built as universal products (e.g., do not have the same wire plugins, do not have the same software, etc.). One of the consequences of this they reported, is that more time is required to learn a new device.

One participant underlined that AAC devices are a small market, which explains their high price. They went on to say that if the technology can be developed for the mainstream market, then the cost of hardware can be reduced. The participant also gave an example of the size of the gaming industry and how the cost of hardware for gaming can be quite low (e.g., joystick controller, infra-red sensor, eye gaze sensor, etc.). They added that the cost of building a SensAct unit can be reduced if they can utilize some of the hardware and technology from the gaming industry.
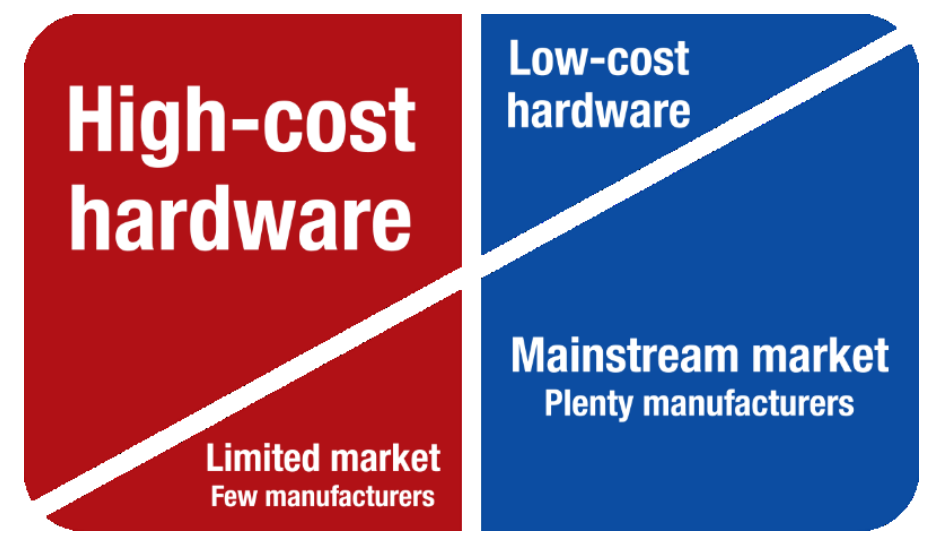

Figure 21. Relationship between market and cost of hardware 
SensAct also faces certain limitations which are influenced by external factors, factors which may be difficult for the development team to control. One of the difficulties mentioned by the developer participant is compatibility between input and output hardware. Since SensAct is built from open-source hardware, there are many hardware options available on the market, but some may not be cost-effective. For example, the Bluetooth transceiver, BlueSMiRF from SparkFun, is required to give SensAct wireless HID capability and in this case, act as remote control for a specific brand of television; but the transceiver costs $\$ 35$, which is more than the cost of the Arduino board itself (the latter is estimated between $\$ 25$ to $\$ 30)$.

Unfortunately, many things in this world were designed and developed without accessibility in mind, and this deficiency is another external factor influencing the implementation of AAC strategies. One of the examples that was brought up during an interview is the design of the UI in email programs. Various features are embedded in an email system, such as font editing (bold, italic, underline, font colour, etc.), emoticons, file attachments, adding an event to an online calendar, reminders, and many others. Two participants mentioned that sometimes, they themselves, have difficulties figuring out these new features on a regular email system and that features are continually being updated, further complicating the usability of the system. This participant found it difficult to imagine having to maneuver through such features on an email UI using a one button function, for example, on SensAct. One of the participants suggested that all email systems should have a "downgrade" version, which consists of a simple HTML layout with only Read Email, Reply, Compose, Send, and a simple typing function. They also added that designing a simpler email format could benefit not only people with 
disabilities but also people in general who are not tech-savvy and/or require only limited functionality.

\subsubsection{Human Resources Are a Critical Factor in Supporting AAC Sustainability}

Due to limited human resources, SensAct developers must find a solution to mitigate this problem themselves. Fortunately, they receive support from the community through the volunteer program at BSVH which currently consists of people with a computer programming and electronic engineering background. Participants reported that people from other organizations such as universities, non-profit and non-governmental organizations are starting to take an interest in developing SensAct as well. Such organizations may be able to assist with developing standards and/or guidelines for future development, a need identified by participants. The healthcare specialists (SLPs and OTs) in the interviews explained, for example, that they currently try to find the best AAC solution for clients through trial and error because there is no standardization or definitive guidelines to support the AAC assessment process.

Although there are no fixed or definitive guidelines to conduct an AAC assessment, the participants noted that a hospital or long-term care facility should have a structural operational procedure based on their job roles. Based on the interviews, the participants suggested a hierarchical procedure for AAC assessment, as shown below: 
SLP: Assess and prescribes AAC

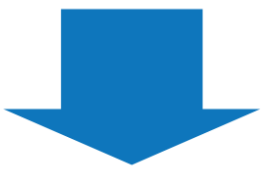

OT: Finding the best way to mount the AAC device on the client or client's accessories/environment

\section{AT: provide support if there are any technical problems \\ DSS: Implement AAC with the client on a daily basis}

Figure 22. AAC assessment procedure based on job roles

To conduct an AAC assessment requires a team of clinicians (Figure 22) as it is a specialized field. Participants commented on the limited number of medical professionals who have formal AAC training. Most of the participants also noted that there is no formal training or workshop provided by AAC manufacturers to learn how to use their devices. They added that learning from the manual book or video tutorials may not be sufficient to handle complicated cases.

The participants acknowledged that AAC clients often need continuous support in their daily communication activity and therefore, human resources are critical to maintaining such support when needed or finding ways to facilitate the client's independence in maintaining their ability to communicate. One of the participants emphasized that the growth of the internet and technology have promoted the growth of human communication needs and preferences as well. They also underlined that communication is no longer defined by face-to-face conversation or via telephone, but it 
has broadened into communication via social media (e.g., Facebook, Twitter, Instagram, etc.). Some of the participants reported receiving requests from clients wanting to access social media via AAC devices, so developing a device which can be integrated with online platforms will become a necessity in the future.

AAC clients are also susceptible to changes, especially with their physical ability. One participant described that when a client who is recovering from a stroke and following a rehabilitation program may see their physical ability progress throughout the rehabilitation program. They suggested that AAC devices should be able to adapt to such changes, and be customized easily to fit the client's needs without having to send it back to the manufacturer for reprogramming to minimize or eliminate the turnaround time for the device to be updated or upgraded.

"Yeah, sure. I give anything a shot. Well, if I find something that I think might be useful, then I'll learn how to use it. Not a problem."

--

"So I think it helps to have a personality who is comfortable and not afraid of technology, and can just comfortably kind of go searching until you figure things out."

Interview Excerpt 2: Quotes from participants describing their attitudes towards new technology

A team of experts is also required to continuously develop and calibrate AAC devices and systems like SensAct. Although the current team has a strong background in terms of hardware and software development, some participants commented that there has been minimal involvement of clinicians or the clients, which may explain some of the 
usability issues with the current system. During the interviews, two participants highlighted the importance of consulting with the caregivers, family members, and friends of the client to gain in-depth knowledge of the client's needs. This notion was supported by one other participant who underlined that knowing the client's needs can help build a better design for SensAct.

Due to limited support, the clinicians find resources to learn AAC by themselves. Most of the interview participants stated that they learn and find resources to solve problems through online media. They would also try the AAC method themselves first before testing it with a client and test all possible options that are available. One of the participants commented on being curious and resourceful describing that having a curious personality encourages them to solve their own problems, and that this kind of attitude works tremendously well when trying to implement a new AAC strategy with a client.

"So I think I would probably just borrow the device and try to familiarize myself with it, and maybe look up if there's any videos available online for training and for programming as well, either trial and error it, or watch a video online."

"I don't understand how someone can learn to use a device by just having it for like an hour or half an hour a day, that doesn't make sense to me. That's like me learning to use like a whole different computer or something and having someone give it to me for a couple minutes and then take it away."

Interview Excerpt 3: Quotes from participants describing their point of view on AAC implementation

All five participants agreed that they learn AAC through trial and error and transfer this knowledge to other client assessments and implementation strategies. One participant's strategy involved spending as much time as possible with a client who uses 
a new AAC method to familiarize themselves with the new device. This participant also encourages the client to use the devices more often. By consistently interacting and communicating with a client via the AAC device, this clinician learns the limitations of that particular device and tries to find resources and solutions to mitigate the problem. This consistency coupled with positive, proactive attitudes emphasized by participants speaks to the importance of the quality of human resources in developing effective AAC strategies for clients.

\subsubsection{People's Abilities, Limitations, Beliefs, Preferences, Motivation \& Attitudes Can Impact AAC Implementation}

Any process that involves people must consider their characteristics, motivations, behaviours, attitudes, and/or perspectives. There are many stakeholders within a hospital or long-term care environment, each providing independent opinions or interpretations of things based on their personal, educational or professional background.

For example, one participant voiced their concerns about AAC device implementation being performed by a non-professional which they felt may cause harm to the client. The participant stressed the importance of medical professionals setting up an AAC device on a client to prevent injury. However, another participant felt that one day, AAC devices will be versatile enough for a non-professional to setup such systems themselves. Regardless, all participants agreed that each client is unique and requires individualized care.

Another factor that emerged from the interviews was the need to consider someone's preferences. Both clients and healthcare workers may have their own 
individual preferences on how they would like to implement the AAC strategy. For example, some of the participants said that they prefer the Tobii Dynavox UI over other AAC devices' UI, but that they would prefer the hardware from another manufacturer, since the latter is more compatible with other electronic devices. One of the participants mentioned that some clients actually prefer to buy an Apple product, such as an iPad, because they felt it is more intuitive with built-in accessibility features at a fraction of the cost of other AAC devices. These different opinions and preferences can have an impact on devising and implementing an AAC strategy.

One factor that can impede AAC implementation may come from the client themselves. According to the participants, each client has a different level of disability and complexity, which can present complications in configuring or setting up an AAC device to meet their needs. It has also been reported that clients often feel overwhelmed with the high cognitive load when trying to use the AAC device. Three participants described that some clients prefer trying to communicate directly using whatever ability they still posses instead of using AAC devices because they find the AAC devices ineffective or too difficult to use. Such factors may decrease the motivation of healthcare workers to implement an AAC strategy.

One participant discussed when SensAct was first initially developed, it was designed to meet the needs of a specific client, and they succeeded. They started to build a solution for another client and had another success. This happened several more times until the developer team realized that they should develop a device that can be customized to meet more than one need. The team received attention from the public and 
support from different sectors (e.g., educational, non-profit or non-governmental organizations, etc.). People started to believe that SensAct had potential.

"One thing that I really liked though about the SensAct design in terms of ease of access, it's just the availability. Like normally, when you're testing the switch with someone, you have eight different switches or something, and we pull them all out, and you know, and with SensAct you just need one."

"One of the problems we had, sometimes a client would have a need, for example, to call the nurse. If a regular type of button in the room doesn't work or [is] not easy enough to press, with SensAct they will be able to have [a] light sensor or tap sensor, that would only need [a] very little press, just by being close by [the] proximity sensor or switch."

"But we had the first success, so people [are] starting to believe [in] the idea, because we have a proof of concept. It's working, and the client is using it. And then people who see what we're doing, we're starting to get a little bit of support, seed money here and there; and the volunteers are coming."

Interview Excerpt 4: Quotes from participants describing some of the success stories about SensAct

\subsubsection{Core Theme: Systemic Factors Influencing AAC/SensAct Implementation}

All interview participants agreed that external factors, such as limited funding, lack of AAC device standardization, and the high cost of AAC devices, may impact the process to assess and implement AAC strategies with their clients. Under such limiting conditions, the healthcare specialists are required to adapt quickly, or to accommodate clients' needs with whatever available resources they may have.

Human resources play a critical role in the implementation of AAC strategies. For example, it requires a team of specialized clinicians in order to conduct a proper AAC assessment for a client. Most of the participants revealed that they still require much 
needed support in terms of AAC training to keep their knowledge up-to-date with the latest technology. An interdisciplinary team of experts is also required to develop SensAct's system. At the moment, the development of the SensAct system relies heavily on support from the volunteer program at BSVH. During interviews, participants acknowledged that the involvement of the clinicians, clients, and their communication partners (e.g., caregivers, family, friends, etc.) would greatly reinforce the development of SensAct system.

There are many stakeholders involved in the implementation of AAC strategies. Clinicians come from various backgrounds and may have different personal preferences. It was revealed during interviews that some participants may have chosen an AAC device based on their familiarity, preference, and/or knowledge of the device. The majority of the participants also reported that clients' preferences and attitudes towards AAC strategies may be a deciding factor in selecting an AAC solution and may impact the effectiveness of an AAC implementation.

\subsection{Heuristic Evaluation}

Following Nielsen's usability heuristics guideline, the usability issues found during heuristic evaluation can be summarized into three main issues:

1) The use of complex and technical terms in the UI prevents novice or nontechnical users from comprehending the functionality of the software itself.

2) SensAct software UI lacks and requires an effective and efficient self-guiding system to direct the user to achieve their objectives. 
3) Error management is critical for the user to prevent, mitigate, or recover from an error.

\subsubsection{The use of complex and technical terms in the UI prevents the novice or non- technical users from comprehending the functionality of the software itself.}

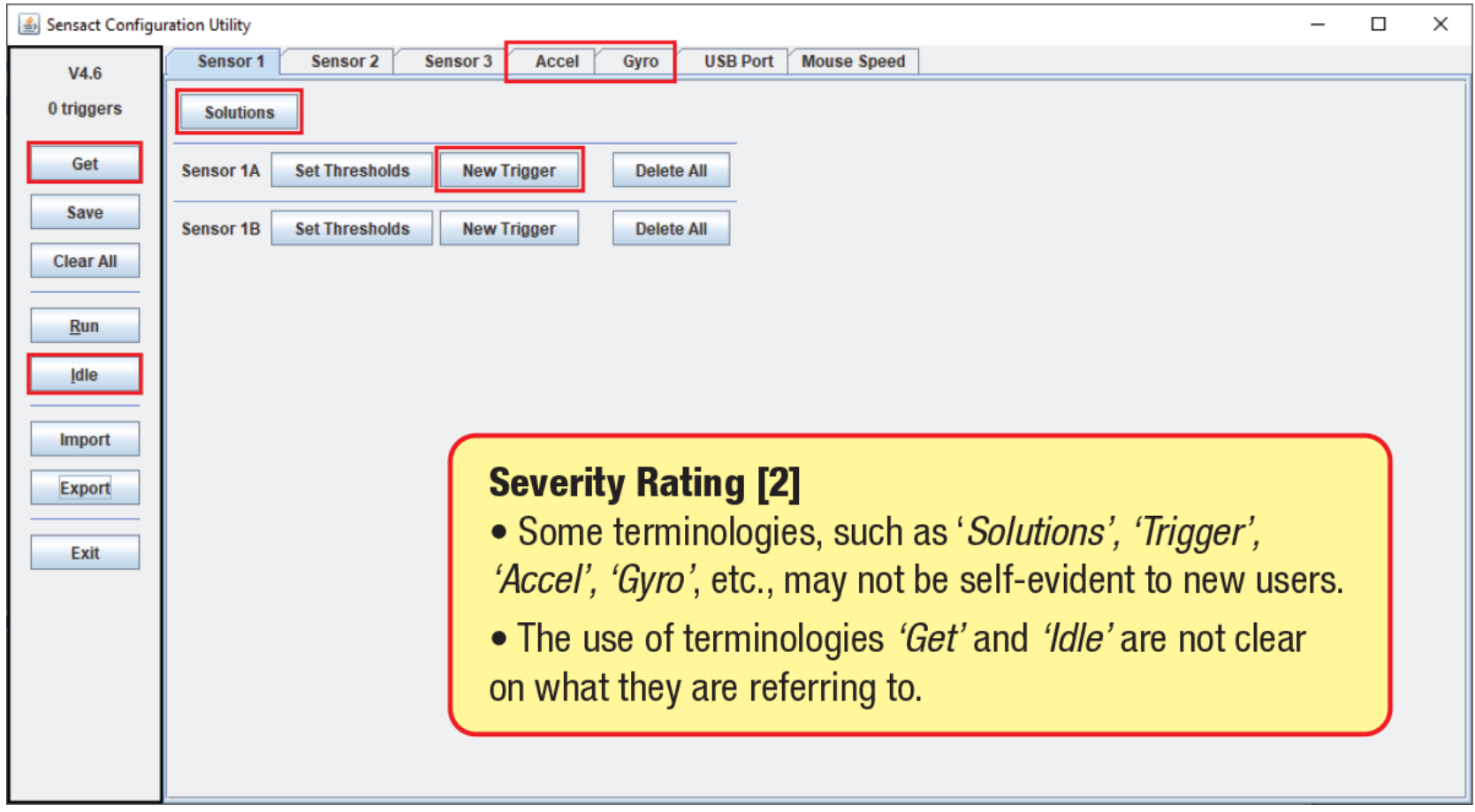

Figure 23. Examples of terminology in the SensAct UI that may not be understandable to novice, non-technical users

Nielsen (1994) suggested in one of his usability heuristic guidelines that the system should speak the users' language by using terms, phrases, and concepts that are familiar or easily understood by the users. Some of the key functions that need to be performed using SensAct's UI, as shown in Figure 23, employ technical terms (e.g., 'Solutions', 'Trigger'), whose function is not clear or evident. Some terms which are used as action buttons on the UI may use lay language (e.g., 'Get', 'Idle') but do not convey a clear meaning about what they refer to or what type of action they will perform. 
These findings are also supported by data collected in the interviews, where one of the interview participants mentioned that they could not understand the meaning of the terms used in SensAct or what they are intended to do. Nielsen (1994) suggested in his heuristic guidelines that the terms, phrases, and concepts used on UI should follow real-world conventions that novice users can easily comprehend without help documentation or extensive support from an expert user.

\subsubsection{The SensAct software UI requires effective and efficient self-guiding system to direct user to achieve their objectives.}

The current SensAct UI has minimal guidance or self-support features which may leave the user wondering what they should do next. Nielsen (1994) proposed that the system should always keep the user informed on the current status of the system which could be in the form of visual or audio feedback for screen-based displays.

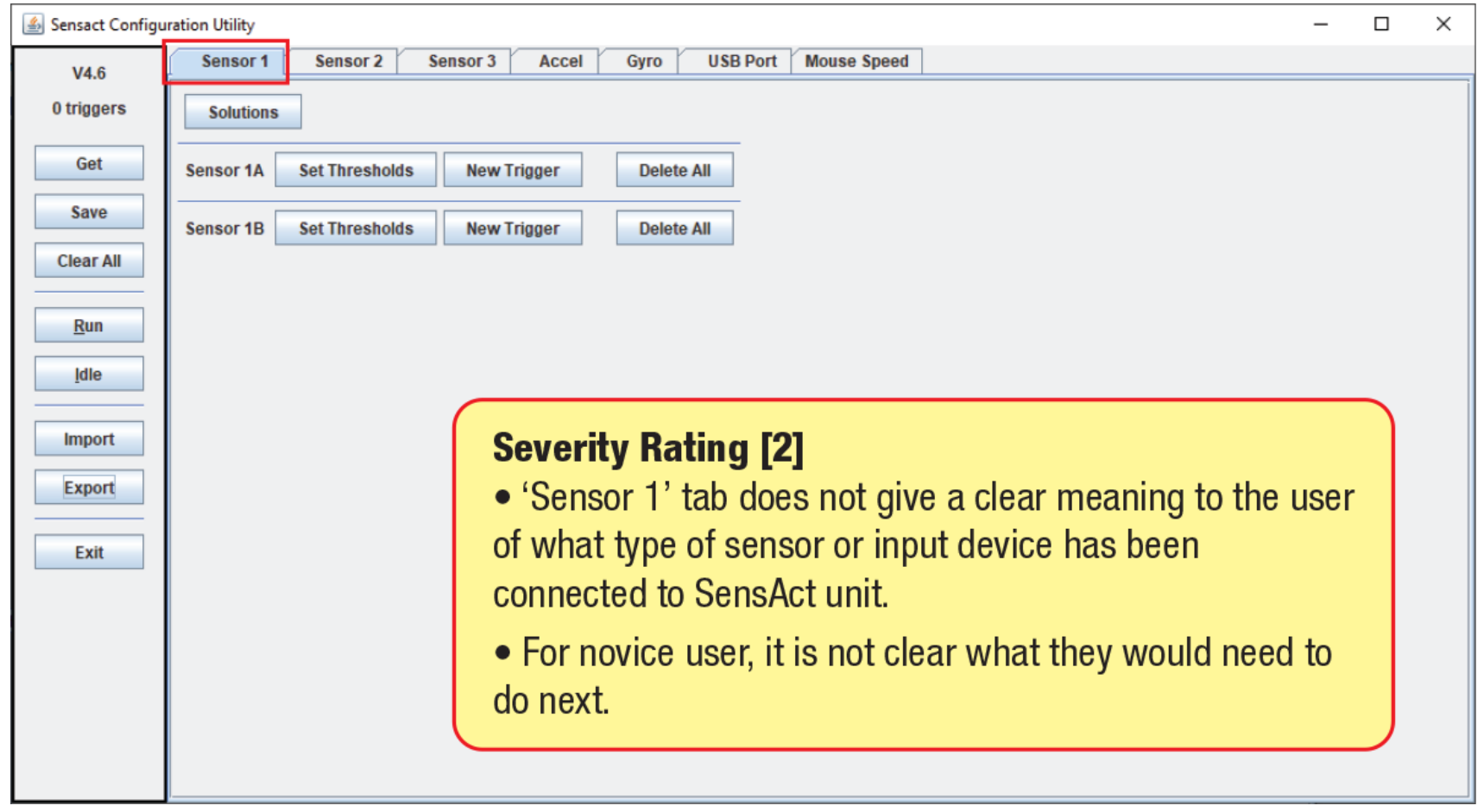

Figure 24. Lack of visibility of system status on SensAct UI 
Above screenshot (Figure 24) shows a lack of clear status feedback on whether a sensor or input device has been plugged in or what type of device has already been plugged into SensAct.

The 'Solutions' feature on SensAct's UI (Figure 25) provides the user with a selection of pre-configured settings of input devices. Although these pre-configured settings are a useful feature for novice users, they nevertheless present a challenge for novice users in trying to remember what each feature does. Nielsen suggests minimizing the memory load of the user by providing more visible, recognizable, and understandable elements, such as icons, symbols, or other visual cues.

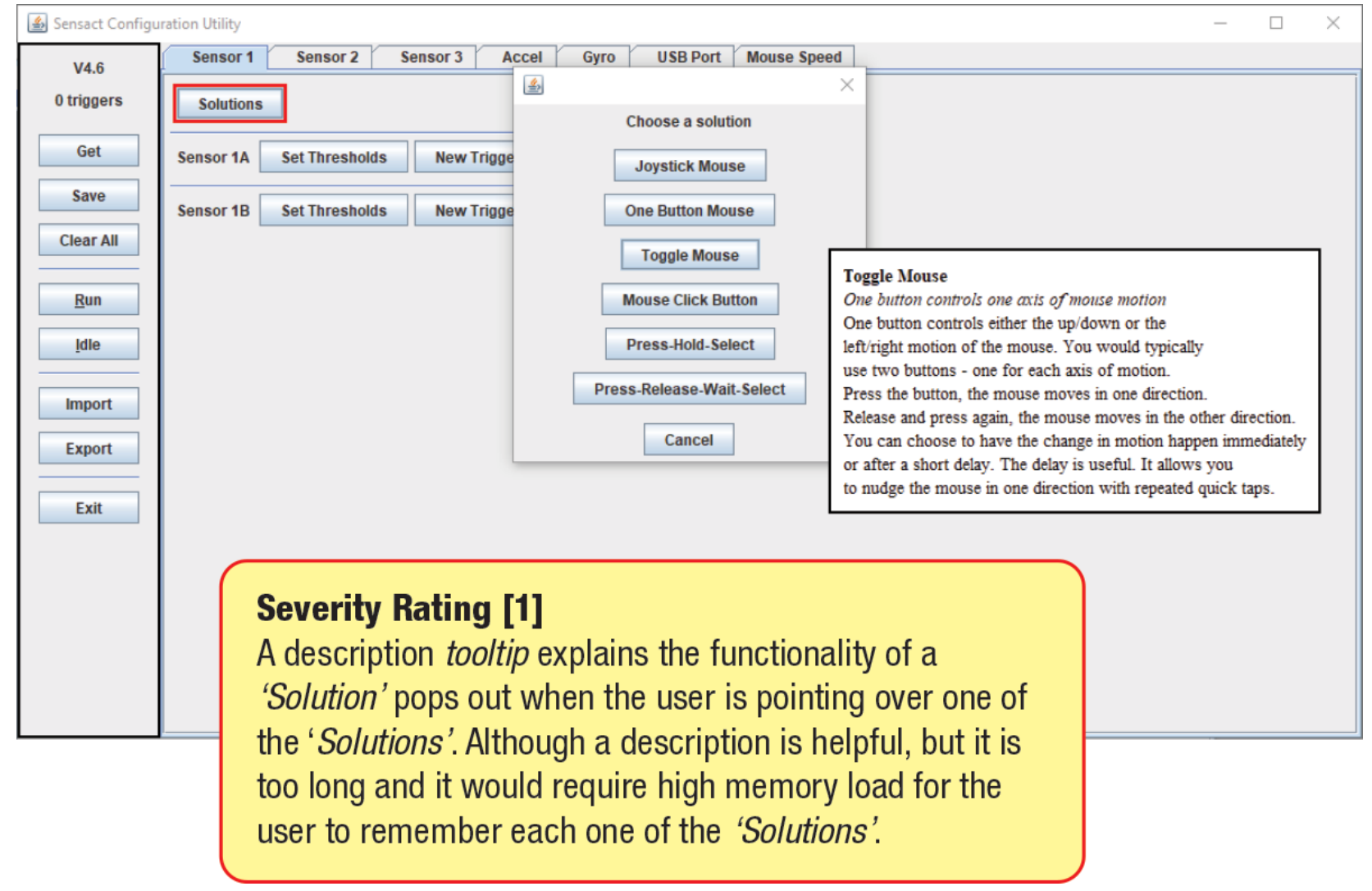

Figure 25. Example of a high memory load demand placed on the users 
In one of his heuristic guidelines, Nielsen (1994) proposed that a UI should cater to both novice and expert users. A detailed and comprehensive guidance system could assist novice users, and a quick shortcut system might suit expert users. In its current state, SensAct's UI is only catering to expert users, due to the complexity of its UI (Figure 26) and minimal guidance for someone who has less experience in using the software, a finding which was also supported by comments made during the interviews. Two participants who had tried to configure SensAct using the UI revealed during interviews that they felt overwhelmed with the amount of settings they had to configure.

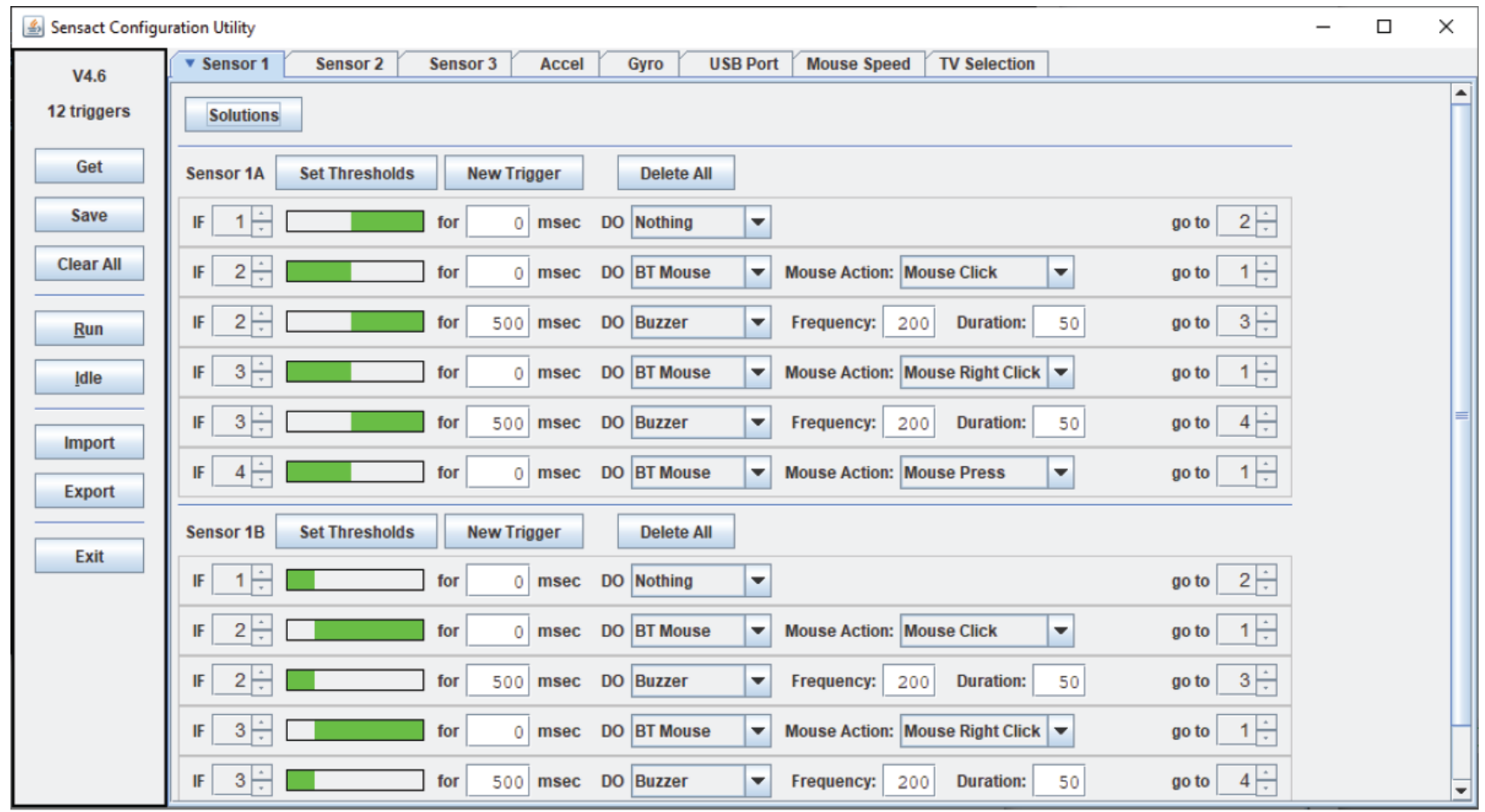

\section{Severity Rating [2]}

The level of detail in the configuration provides efficiency for expert users to edit it, but on the other hand, it may be too difficult for novice users to comprehend it.

Figure 26. Example of SensAct UI configured to simulate mouse control and complexity involved to configure 


\subsubsection{Error management is critical for the user to prevent, mitigate, or recover from}

an error.

Prevention from error is always better than to recover from it. In one of the heuristic guidelines, Nielsen recommended that a UI design should eliminate error-prone conditions or provide users with a warning dialog before committing to an action.

\section{Severity Rating [3]}

Upon starting or opening SensAct software, the Command Prompt window opens as the initial startup window and then the user can select which port to choose from to enter the configuration panel. But once the user has entered the configuration panel, the Command Prompt window remains open. Closing this Command Prompt window will actually be closing both the Command Prompt and the configuration panel window, and there is no warning dialog box.

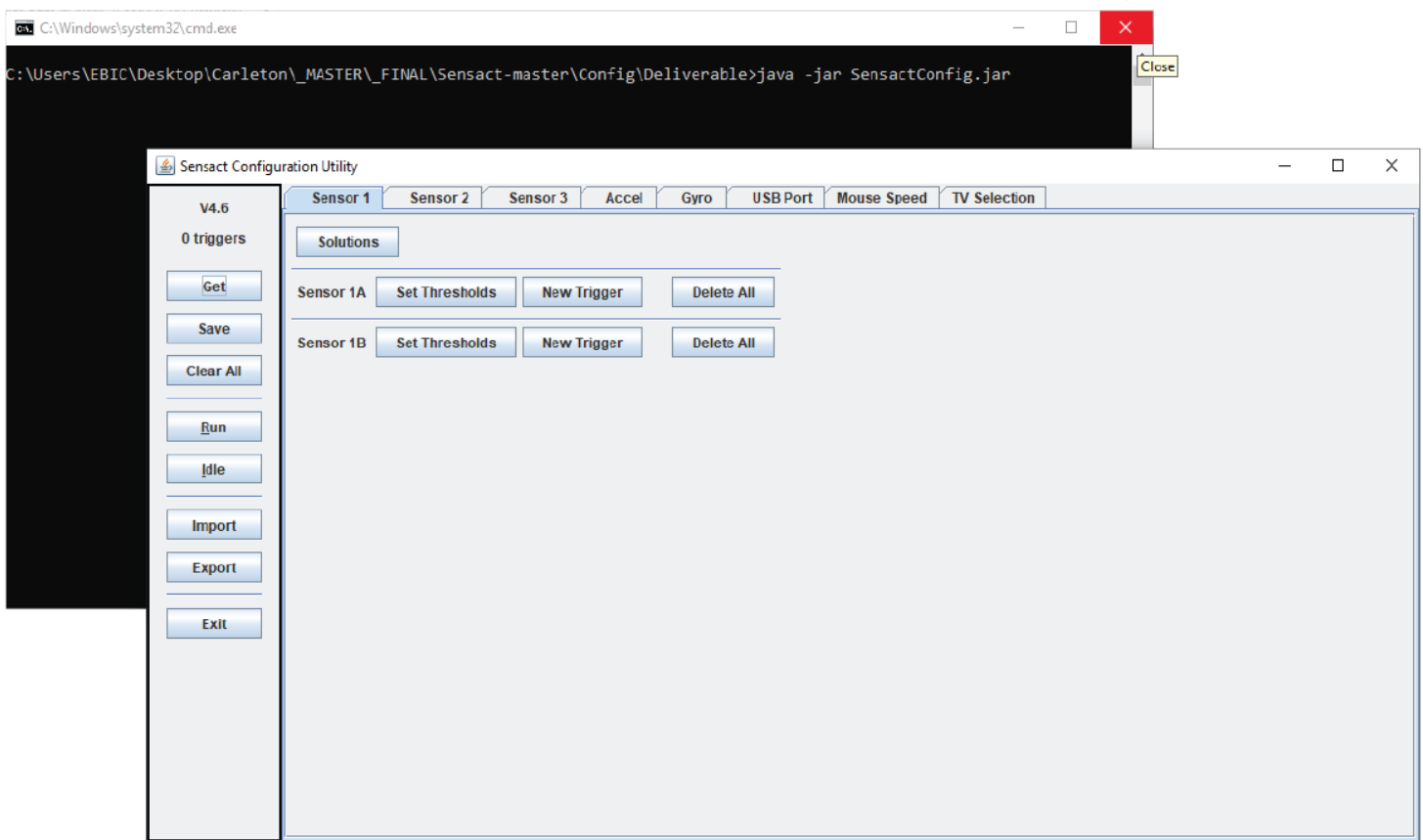

Figure 27. Example of an error that can be prevented by using a warning dialog box

This version of SensAct's software program does not have a 'help' or support feature that explains how the system works, or how to recover from an error. This type of 
information should be made available and easy to search to provide users with guidelines or instructions on how to perform a task or recover from an error. Nielsen (1994) suggests that an error message should be concise, in plain language, indicate the problem clearly, and provide a constructive solution.

\subsection{Observation}

The observation method was used to analyze potential usability issues with SensAct's hardware and/or software from a novice and expert user perspective. Two usecase scenarios were observed in succession, with the expert user assisting the novice user in setting up and configuring the SensAct unit.

\subsubsection{Issues with Setting up and Using the SensAct Hardware}

SensAct's physical housing interface (Figure 28) needs to be improved. Currently, there is no labelling on the case to identify the port entries (e.g., input 1, input 2, etc.), which would help identify which input port corresponds to the configuration settings displayed on the UI configuration panel. However, the developer participant noted that this is not an oversight, but due to limited resources as they currently do not have a volunteer with a product design background that could help address these issues.

Another issue that was observed was that switching an input sensor from one port to another required restarting the whole system. When this occurs, the configuration panel is not able to detect the input sensor properly. 


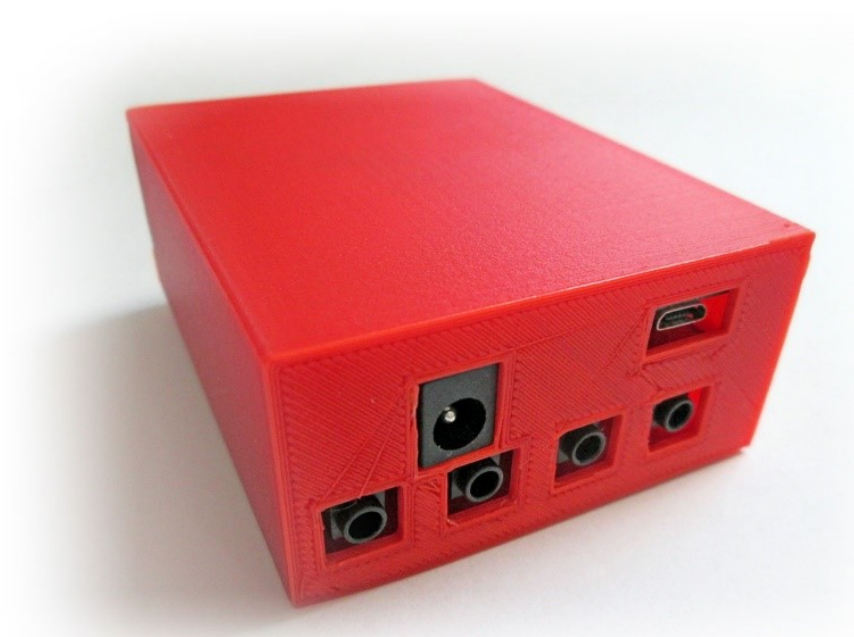

Figure 28. SensAct hardware casing

\subsubsection{Issues with Using the SensAct UI}

When the participants were asked to set up SensAct for the first time (initial setup), the software was not capable of showing through its UI that an input sensor was plugged into the SensAct hardware unit. In order to see this on the UI, the user had to add a 'Trigger' in the configuration setup on the UI so that the software was able to detect if there was a sensor device plugged into the hardware.

At the moment, SensAct has limited sound and light feedback for only two functions: 'Save' and 'Run'. During the observation, the novice user asked the expert user whether they had already saved the current configurations because there was no constant visual feedback that displayed the current system status. In line with one of Nielsen's (1994) usability principles: "visibility of system status", a system should always keep the user informed on what is going on throughout the configuration process. For example, if an input sensor device has been unplugged from the SensAct unit, the SensAct system 
should provide a visual or audio feedback to the user to notify them that a device has been unplugged from the system.
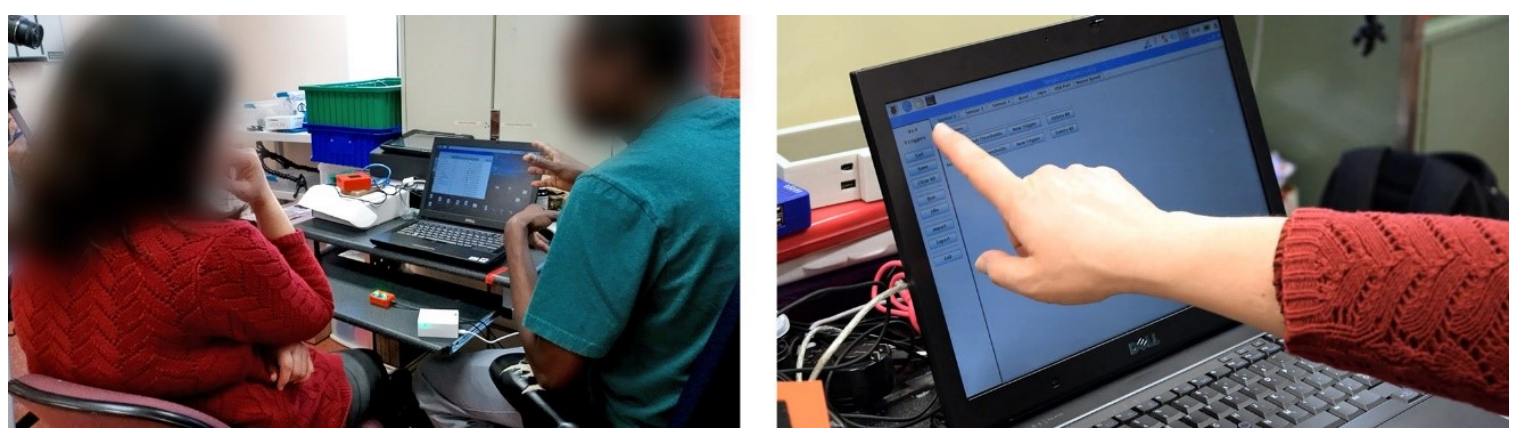

Figure 29. Participants interaction during observation session

In discussing commercial AAC devices during the observation session, the novice participant mentioned that if a client has only one reliable source of movement, they would have to choose between using that one source of movement for a call-bell or some other task, but that they would not be able to do both tasks with that one source of movement. The expert participant explained that SensAct solves this problem since it can be configured through the UI to operate two different devices with a single input method. This allows the client to use different electronic devices. Nielsen (1994) proposed in one of his heuristic guidelines: "help and documentation", information should be easy to search in a system, and help documentation should be easily understood by the user.

Other issues noted during observations included: the use of many technical terms in the UI's configuration panel, terms that may not be understood by non-technical people (e.g., Trigger, Run, HID, Relay, etc.); the novice participant's confusion about the whole configuration process; and the number of steps required to configure the system through the existing UI. These findings were also discovered during previous methods 
that an interface system should speak the users' language and follow real-world conventions to avoid confusion (Nielsen, 1994).

\subsection{Focus Group}

The focus group session was attended by four participants (an SLP, an OT, an AT, and a student) with the researcher as the facilitator. The purpose of the focus group was to involve the developer and healthcare users in a discussion and provide critique, input, and feedback on the development of SensAct. In reviewing the field notes and video recording of the focus group session, three key areas of focus emerged to assist with the future design of SensAct:

\section{1) AAC implementation requires an in-depth assessment of a client's ability.}

One participant (an SLP) underlined that an assessment of the client's physical ability has to be performed prior to setting up an AAC device, such as their level of language function (e.g., ability to read a word, recognize a symbol, compose a novel message, etc.), ability to navigate between pages, pointing to make a selection on screen.

Another participant (an OT) added that clinicians have to classify the client based on their age (pediatric, adult, or senior), gender (male or female), and other physical characteristics in order to fit the AAC device to the intended audience. In conclusion, they both agreed that the first questions in setting up an AAC device should be: What are the physical points on their body that the client can use to access the AAC device? Is there any repeatable and reliable movement that can be harnessed?

\section{2) Technical terms used on SensAct UI create barriers for novice users.}

Three novice participants noted that they do not understand some of the terms used 
for the buttons on the SensAct UI. For example, they pointed to the term 'Trigger' used for one of the buttons. The participants found it ambiguous because they thought that 'Trigger' meant the same thing as 'Thresholds', which actually are two different functions on the UI. One participant recommended replacing it with the word 'Action' instead. Although the expert participant agreed that the term 'Trigger' is ambiguous and may need to be replaced, but they also noted that the term 'Action' was already being used for a different function on the UI. Another example, brought up by a participant was that the term 'Mouse Click' on the UI implies only the clicking action of a mouse, but not the cursor movement on the computer screen. All participants agreed that perhaps the term 'Mouse Control' may be better instead. Issues with terminology has been noted consistently in the previous methods.

\section{3) Novice users require more guidance to configure complex UI.}

One participant noted that more and more AAC devices are utilizing a wizard tool on their software UI to assist the user identify what kind of client is going to use the device. In reviewing a screenshot of SensAct UI, all three novice participants agreed that they would prefer a simplified version of the UI. However, as this would involve removing some of the detailed settings, this may in turn limit an expert user in configuring the system. An expert participant argued that they would still need the advanced version to be able to configure the settings more effectively. A novice participant recommended that the 'Solutions' feature (Figure 25) could be simplified by categorizing it based on the client's objectives: recreational (e.g., television, radio, iPod, etc.), medical (e.g., call-bell), communication (e.g., speech generating devices), 
computer, environmental control unit (e.g., opening blinds, lighting control, temperature control, etc.).

\subsection{Prototype Testing}

A pilot prototype was developed based on the information collected, reviewed, and analyzed from the previous methods to improve usability of SensAct's UI. The prototype was tested by a panel consisting of one SensAct developer (an AT) and two healthcare specialists (an SLP and an OT) at BSVH.

There were three key usability issues with SensAct's UI that recurred throughout the previous four research methods (Figure 30).

\section{1) Difficulty with configuring the device to meet complex client needs under time constraints impacts first adoption of the device.}

Healthcare specialists must conduct an in-depth assessment process of the client's physical and cognitive ability, prior to applying or implementing an AAC strategy. Understanding the client's needs and abilities is fundamental to determine which AAC strategy will best fit the client. But the assessment process can be influenced by the healthcare specialists' ability to configure and fully comprehend an AAC device. Healthcare specialist participants noted their confusion with configuring SensAct in each data collection method. Further, during the interview process, healthcare specialists noted that will likely choose a device that they are familiar with. If an $\mathrm{AAC}$ device is too difficult to configure, it would deter the healthcare specialists to select that particular device as part of their AAC strategy. 


\section{2) The use of complex technical terms deters novice users from configuring}

SensAct.

The four previous methods documented that the use of complex technical terms in SensAct's UI has prevented novice users from understanding their meaning or what these terms do. Further, some terminologies used in the UI use lay language, but these terms do not follow conventional standards in UI design (e.g., 'Get', 'Idle', etc.) and may confuse the user. It was discovered during the heuristic evaluation that the descriptions and instructions on SensAct UI were lengthy and unclear because the developers were trying to explain or describe the technology in system-oriented language, instead of the users' language.

\section{3) A complex UI design combined with minimal support prevents users from} configuring SensAct effectively.

It was noted during the interviews that some participants felt overwhelmed by the complexity of SensAct's UI. It was not clear what they should do first when presented with a task to configure SensAct for a client. The design complexity of SensAct's UI also means that it only caters for users who are already familiar with the UI or have an expert knowledge in electronic engineering. The heuristic evaluation revealed that SensAct's UI lacks a 'system status' to update the user on the current state of the device (e.g., whether an input device is plugged in, what type of input device is plugged in, etc.) which may create confusion. The heuristic evaluation also revealed that SensAct's UI has insufficient help documentation to support the user to recover from an error. Error-prone conditions can be minimized by providing a list of concrete steps to be carried out. 


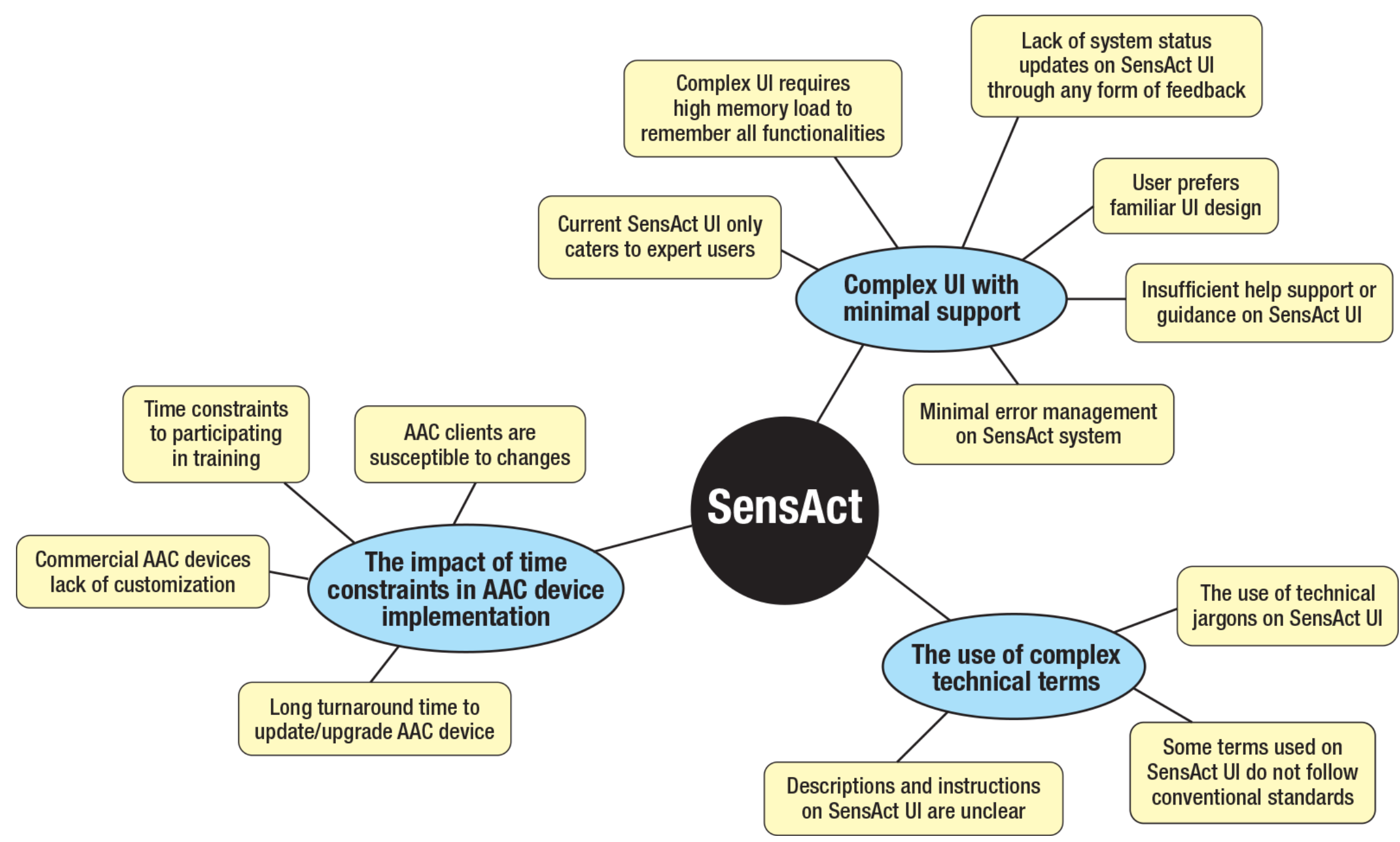

Figure 30. Key usability issues with SensAct's UI that recurred throughout the previous four research methods 
From the interviews and focus group, participants noted that novice users prefer to have a simplified UI that they can easily understand and configure; while on the other hand, the expert users prefer to keep the more detailed ability to configure SensAct.

Therefore, the prototype accommodated both requirements by providing two configuration options: a 'Wizard Setup' and 'Advanced Setup' (Figure 31).

\section{कำ SensAct}

Wizard Setup

Setting up SensAct using user-friendly wizard tools with pre-determined settings for a client's general needs, such as: call-bell, communication device, media player, etc.

Wizard Setup
Advanced Setup

This advanced setup is for an expert user with detailed advanced settings to configure SensAct to fit a client's more specific needs, or specific input methods that require detailed configuration.

\section{Advanced Setup}

Figure 31. Home screen of SensAct UI

The 'Wizard Setup' is a simplified configuration setting utilizing a UI wizard or setup assistant which presents the healthcare specialist, assistive technologist or other user with a sequence of dialog boxes that guide them through a series of well-defined steps. The 'Advanced Setup' is a more complex configuration setting which allows the user to customize the configuration in detail. 
During the evaluation of the prototype, the researcher presented the panel with two scenarios to run through. These scenarios are presented below along with the steps the researcher expected the participants would do to complete each scenario. The description of these steps is then followed by the participants' actual experience of or feedback on the prototype. These scenarios were designed to have the participants try the two setups ( 'Wizard Setup' and 'Advanced Setup') individually to assess their relative value for novice and advanced users.

\subsubsection{Scenario \#1 - Less Complex Client Requirement Using 'Wizard Setup'}

"A client would like to watch television. He has only one reliable movement through his index finger. Based on his ability, the occupational therapist recommended the client use a one button touch sensor. He only wants to watch certain television channels. He does not want to be bothered flipping through all the channels to find the ones that he likes. The television channels that he prefers are channels 3, 5, 12, and 20. Please configure SensAct based on these requirements."

Based on the short description on the home screen (Figure 31), a novice user would be inclined to choose the 'Wizard Setup' option to configure SensAct. The intent of the 'Wizard Setup' is to guide novice users through a step-by-step configuration using a simplified format and non-technical language. Once the user has selected the 'Wizard Setup' on the home screen, the user is taken to the initial screen of the 'Wizard Setup' which contains an illustrative description of how to connect all the necessary hardware components of the SensAct unit (Figure 32). It is essential for each component to be plugged into the correct port, otherwise the device will not work properly. 


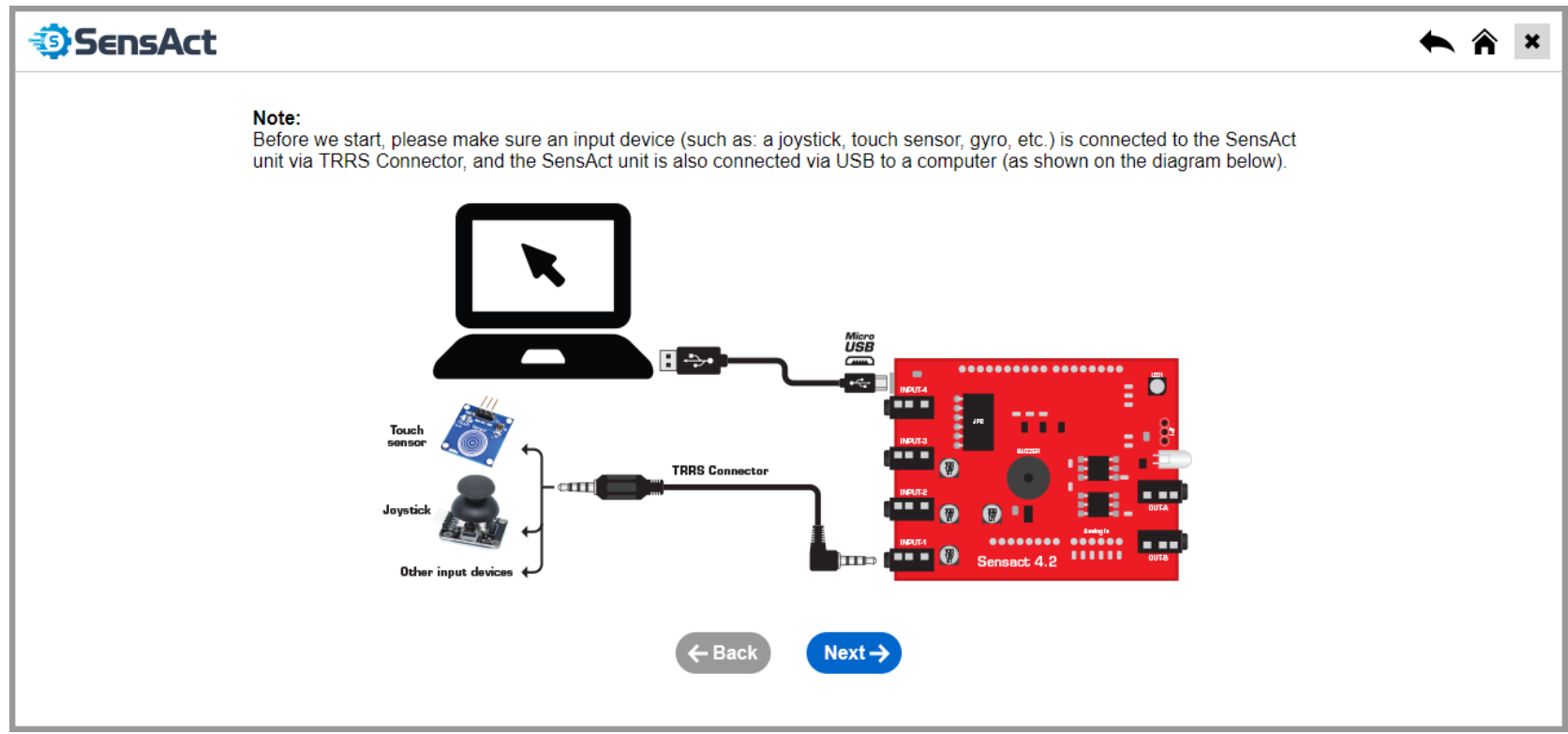

Figure 32. Initial screen of the 'Wizard Setup' illustrating how to set up hardware connections

Once the user connects all the device components correctly, they proceed to the next step by clicking the 'Next' button at the bottom of the screen. On the next screen (Figure 33), the user is prompted to select what they would like SensAct to do (activate or control) for their client from the dropdown list.

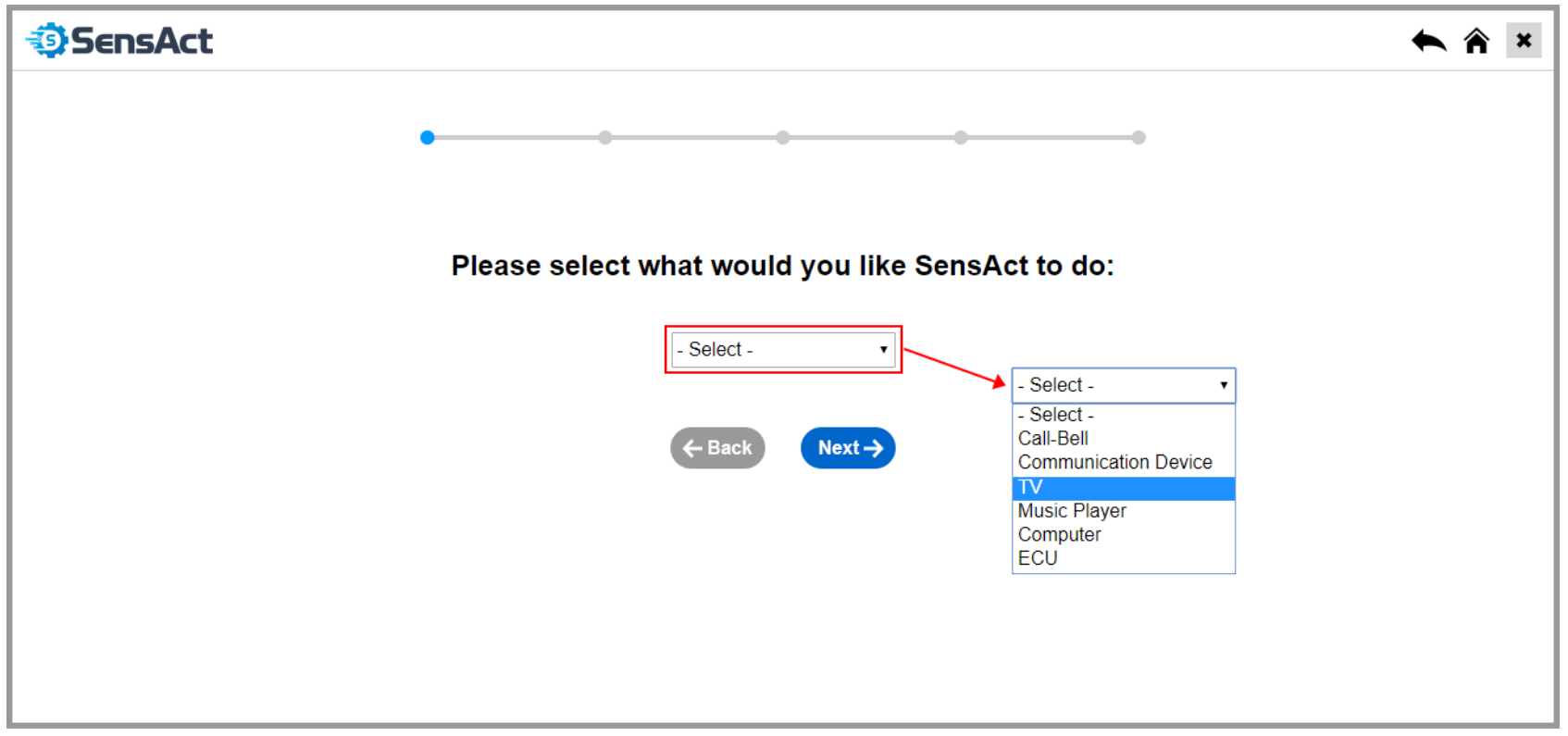

Figure 33. First software configuration step using the 'Wizard Setup' 
Examples of things a client might want to use and control include: a nurse callbell, communication device, television, music player, computer, and environmental control unit. In this particular scenario, the user would select 'Television' and click on the 'Next' button to proceed to the next step.

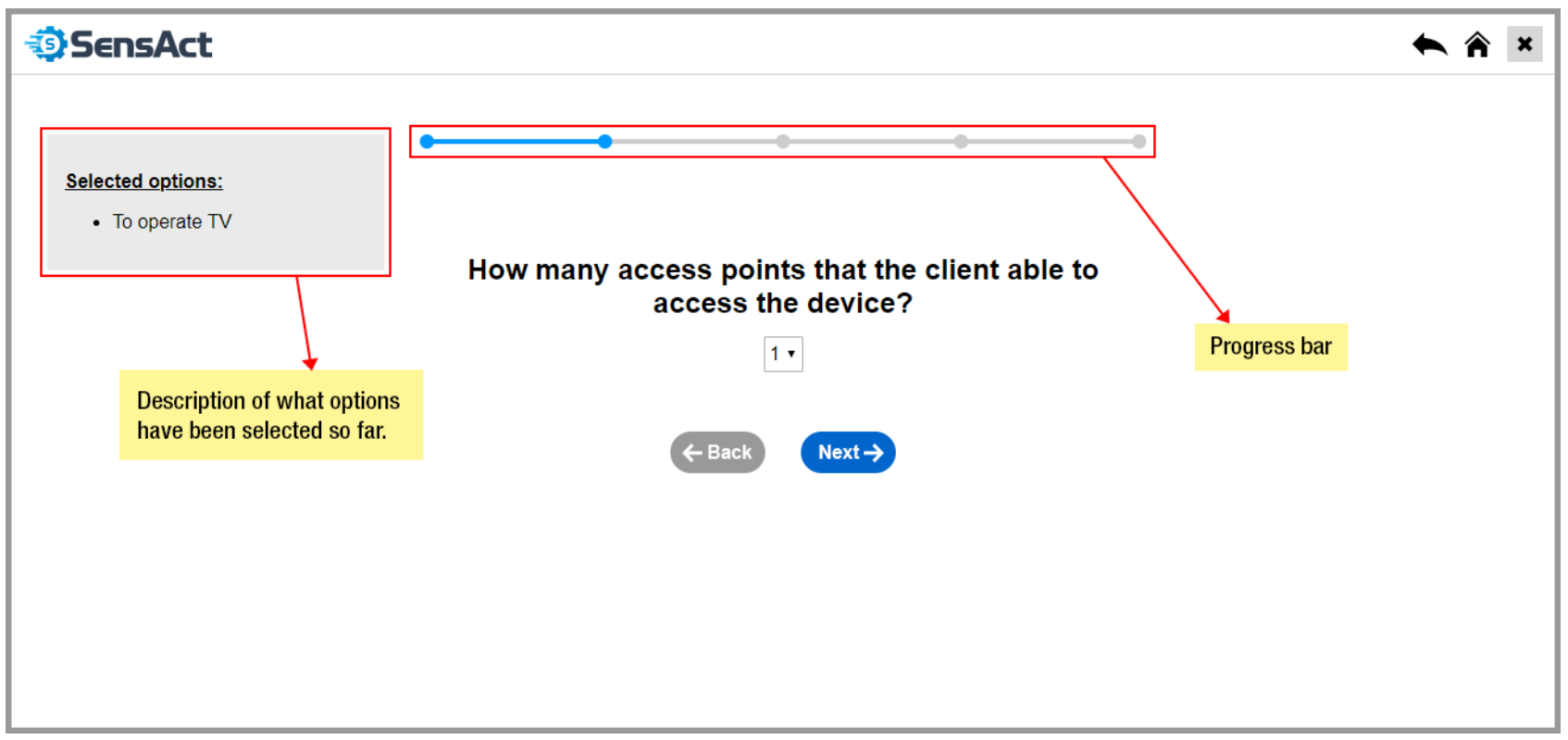

Figure 34. Second step on 'Wizard Setup'

During the second step, the user is able to select the number of ways the client can access the device (Figure 34). In Scenario \#1, the client only has one reliable movement through his index finger, and the total number of ' 1 ' (one) is already pre-selected for any user by default. On this screen, the blue 'Progress Bar' on top shows the user their step and progress through the 'Wizard Setup' by highlighting, in this case, the second dot (second step) in blue. On the left side of the screen, there is also a description box which would show the options that have been selected thus far, and it would continue to show more description as the 'Wizard Setup' progresses. To proceed to step three, the user again clicks on the 'Next' button. 


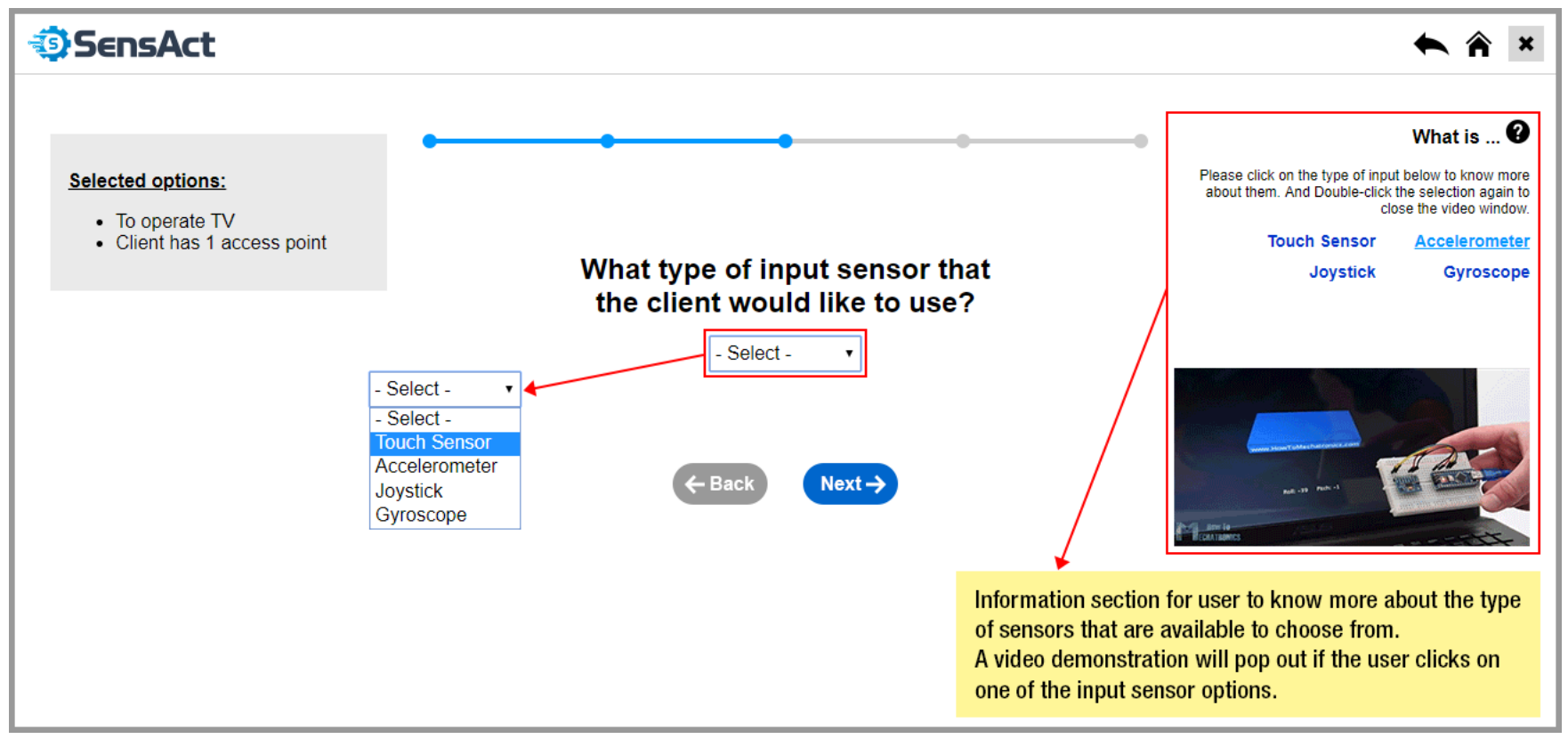

Figure 35. Third step on 'Wizard Setup'

During the third step (Figure 35), the user is given the option to select the appropriate or recommended input sensor(s) to match the client's ability(ies). In this prototype, there are four input sensors to choose from which include a touch sensor, accelerometer, joystick, and gyroscope. In Scenario \#1, the OT recommends the client try a one button touch sensor. For those who may need more information about the functionality or advantages of different input sensors, more information is available by clicking on one of available options on 'What is ... ?' section on the top right of the screen. A video demonstration of what the sensor can do then appears below that section. Once they have selected an input sensor for their client, they can proceed to the next step.

During the fourth step (Figure 36), the user can set up the control of the television either using a 'Preset Setting' that has been provided or they can customize it to suit specific client requests. The 'Preset Setting' already has a set of pre-configured mapping for controlling the television with a one button touch sensor and cannot be altered. For 
example, one press would activate the change channel up function, two presses would activate the change channel down function, etc. If the client prefers to use the 'Preset Setting', the 'Wizard Setup' is complete after clicking the 'Next' button, and SensAct will be ready to be used as a television remote controller for the client. However, in Scenario \#1, the client preferred certain channels which means the user would need to use the 'Customized Setting'. The user selects this option using a radio button which then brings them to next screen by clicking the 'Next' button where they can customize the settings for the touch sensor (Figure 37).

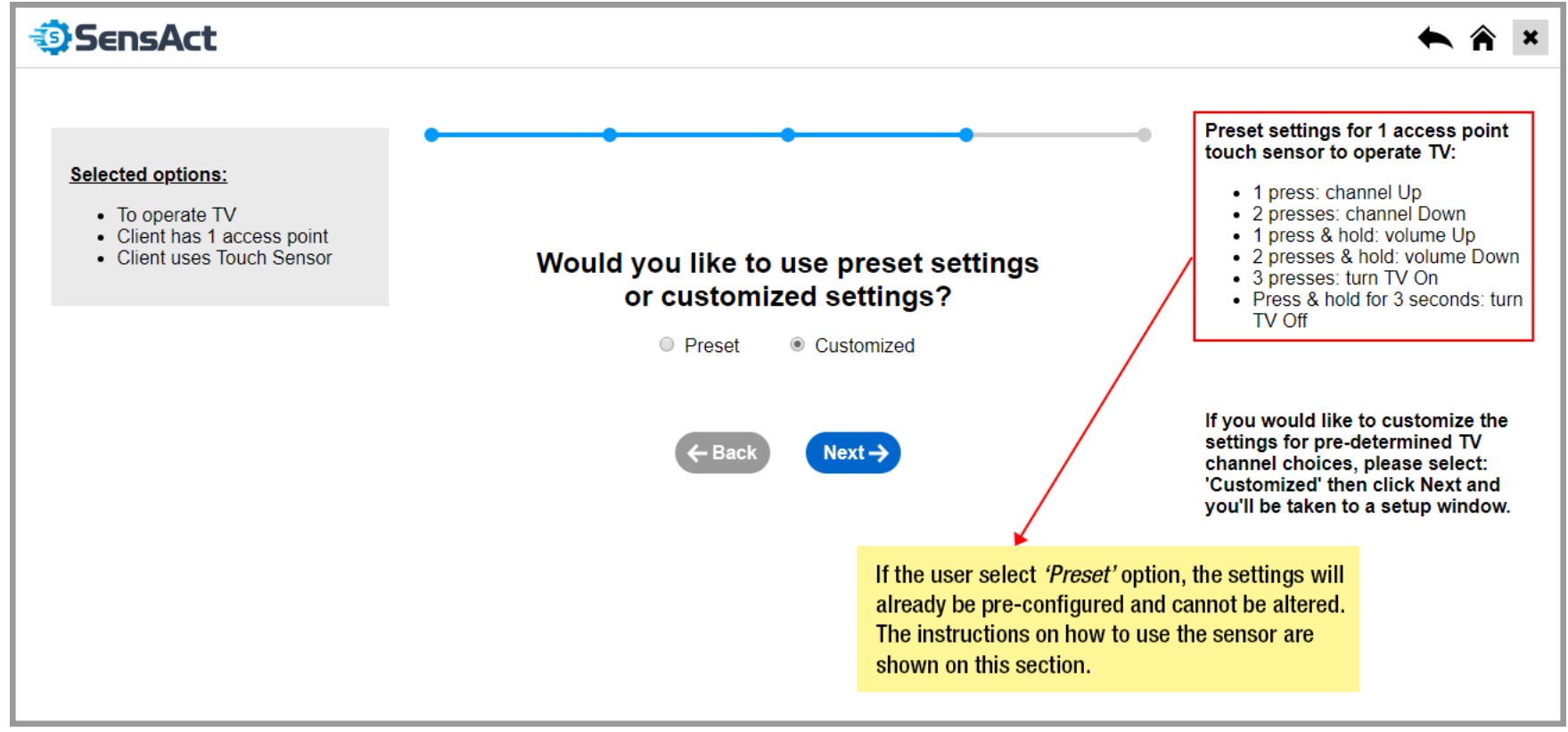

Figure 36. Fourth step on 'Wizard Setup'

On this final step, the user has the option to choose specific channels by filling the field boxes assigned to each touch sensor action. The user then completes the 'Wizard Setup' by clicking the 'Finish' button (Figure 37), which then brings the user to a confirmation screen showing that the 'SensAct Setup is Complete' (Figure 38). 


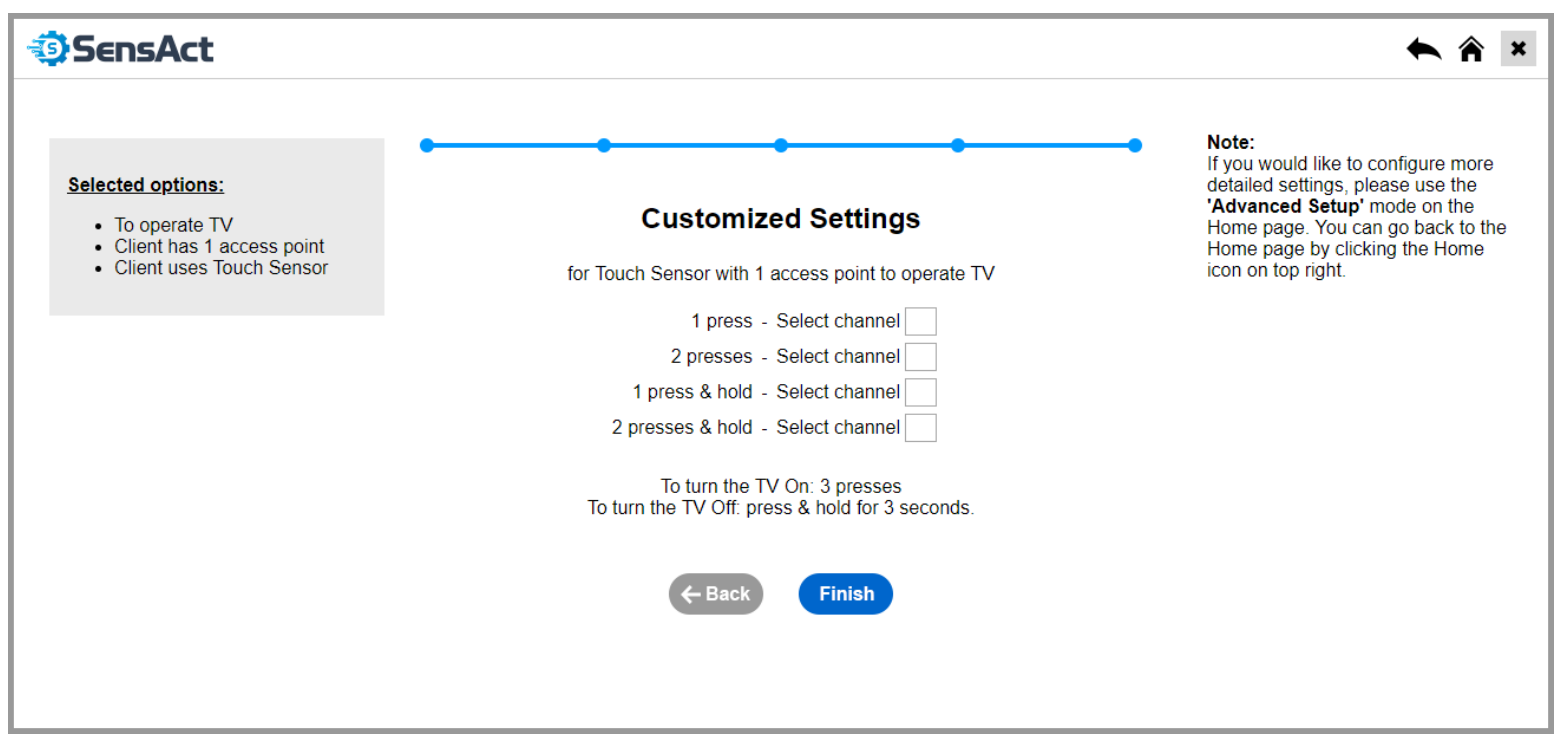

Figure 37. Final step on 'Wizard Setup' showing the UI for 'Customized Settings'

This confirmation screen (Figure 38) allows the user to verify all the options that have been selected previously which are shown on the left panel. Changes can be made using the 'Back' button to the step where the changes are required. Once the setup is confirmed, the user executes the program by clicking the 'Run' button, which concludes the 'Wizard Setup'.

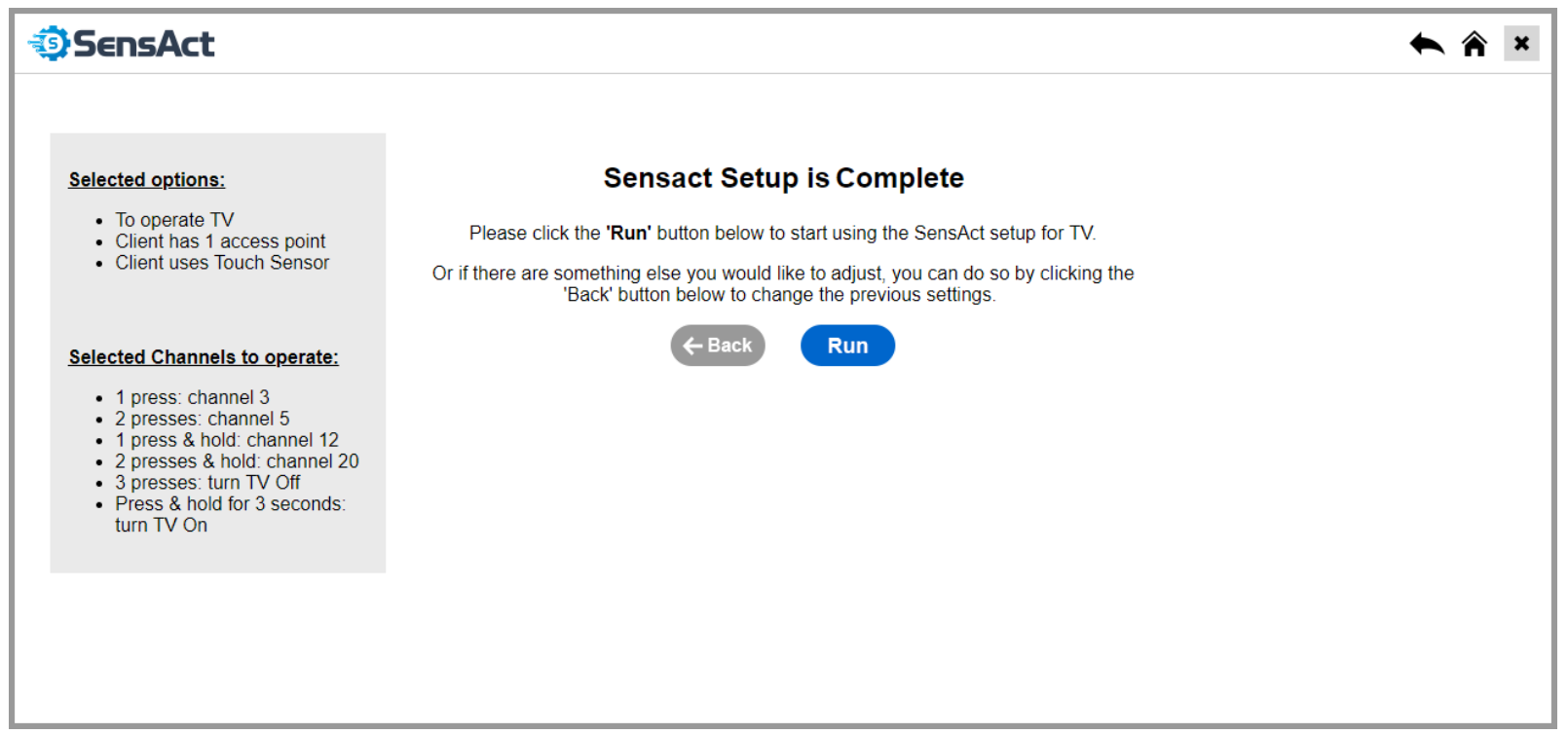

Figure 38. Confirmation screen on 'Wizard Setup' showing selected options 


\subsubsection{Scenario \#2 - 'Advanced Setup’ for More Complex and Detailed Configuration}

"A client would like to use a computer. He has only one reliable movement through his index finger. Based on his ability, the occupational therapist recommended the client use a one button touch sensor. In order to use a computer, SensAct must be able to simulate the controls on a mouse such as: going up, down, left, right, left-click, double left-click, and right-click. Please configure SensAct to meet these requirements."

The 'Advanced Setup' has a similar layout to SensAct's current UI. However, the use of icons, graphic illustration, and simpler non-technical terms have been applied throughout this interface in an attempt to improve usability and reduce difficulty with more complex configuration needs. After clicking on the 'Advanced Setup' option on the home screen, the user is taken to the initial screen of the 'Advanced Setup'.

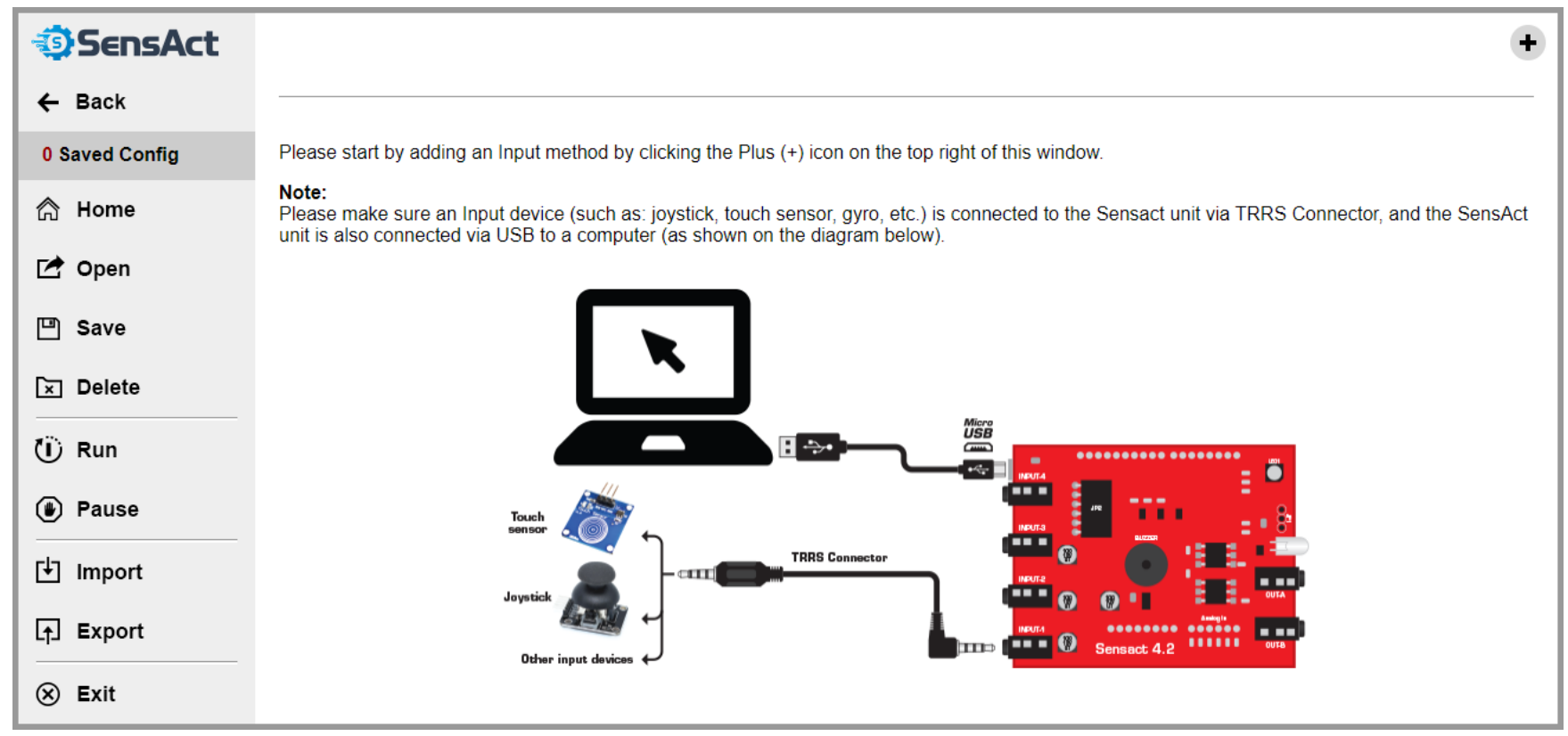

Figure 39. Initial screen of Advanced Setup 
The 'Advanced Setup' starts with an illustrative description similar to the 'Wizard Setup' to help the user connect the hardware components. The 'Advanced Setup' has a control panel on the left side, similar to the current SensAct UI. Following the instructions on the top of the screen (Figure 39) and once all the basic components have been correctly connected, the user can start the configuration process by clicking the ' + ' (plus) icon on the top right (Figure 39). This takes them to the next screen below.

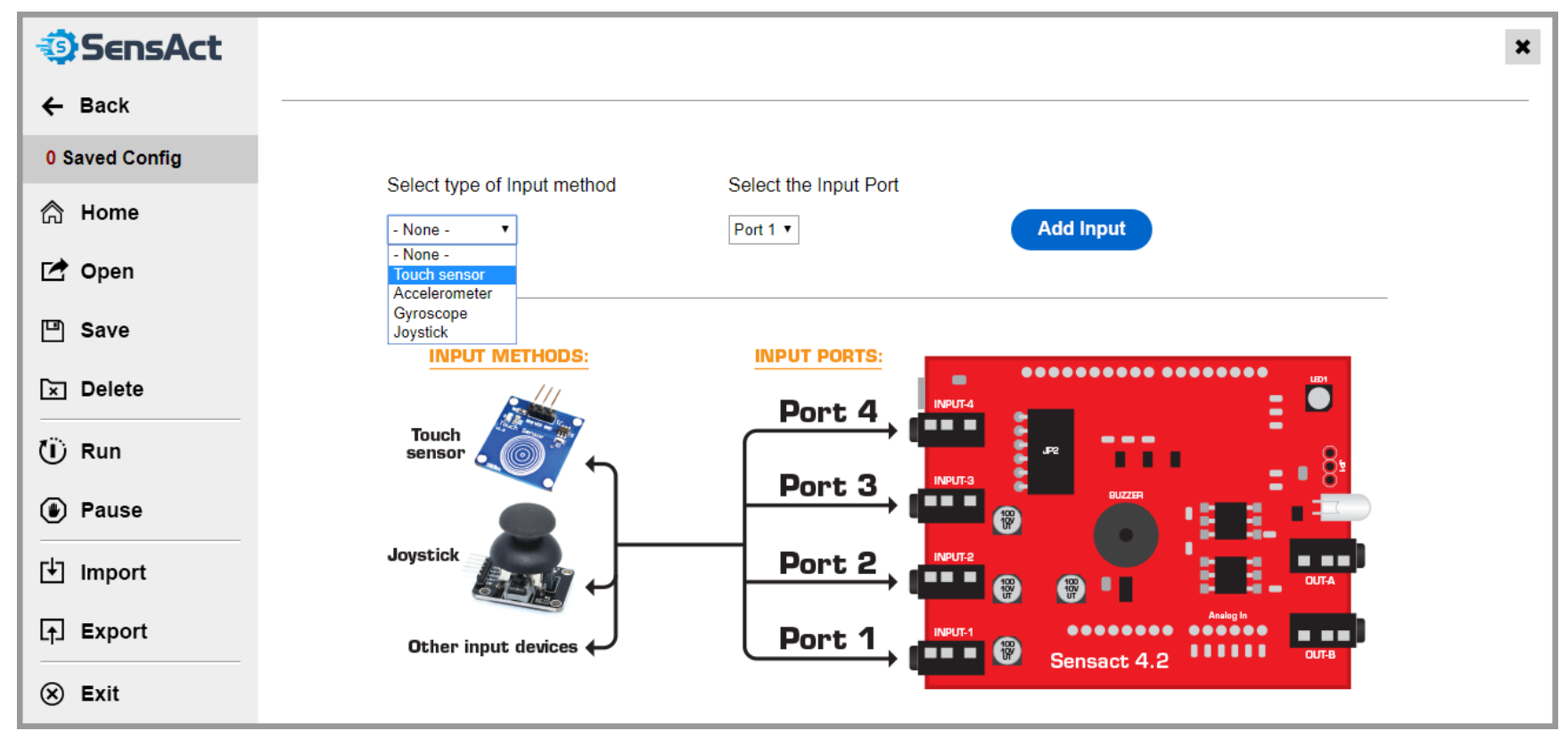

Figure 40. Input method configuration on 'Advanced Setup'

On this next screen (Figure 40), the user selects what type of input method that they prefer through a dropdown list. They also select which port they would like to plug the input device into. A diagram below the dropdown menus describes where to connect the input sensor to the main board (Figure 40). Once an appropriate input device and the port to plug in the device are selected, the user then can proceed with the configuration by clicking the 'Add Input' button. 


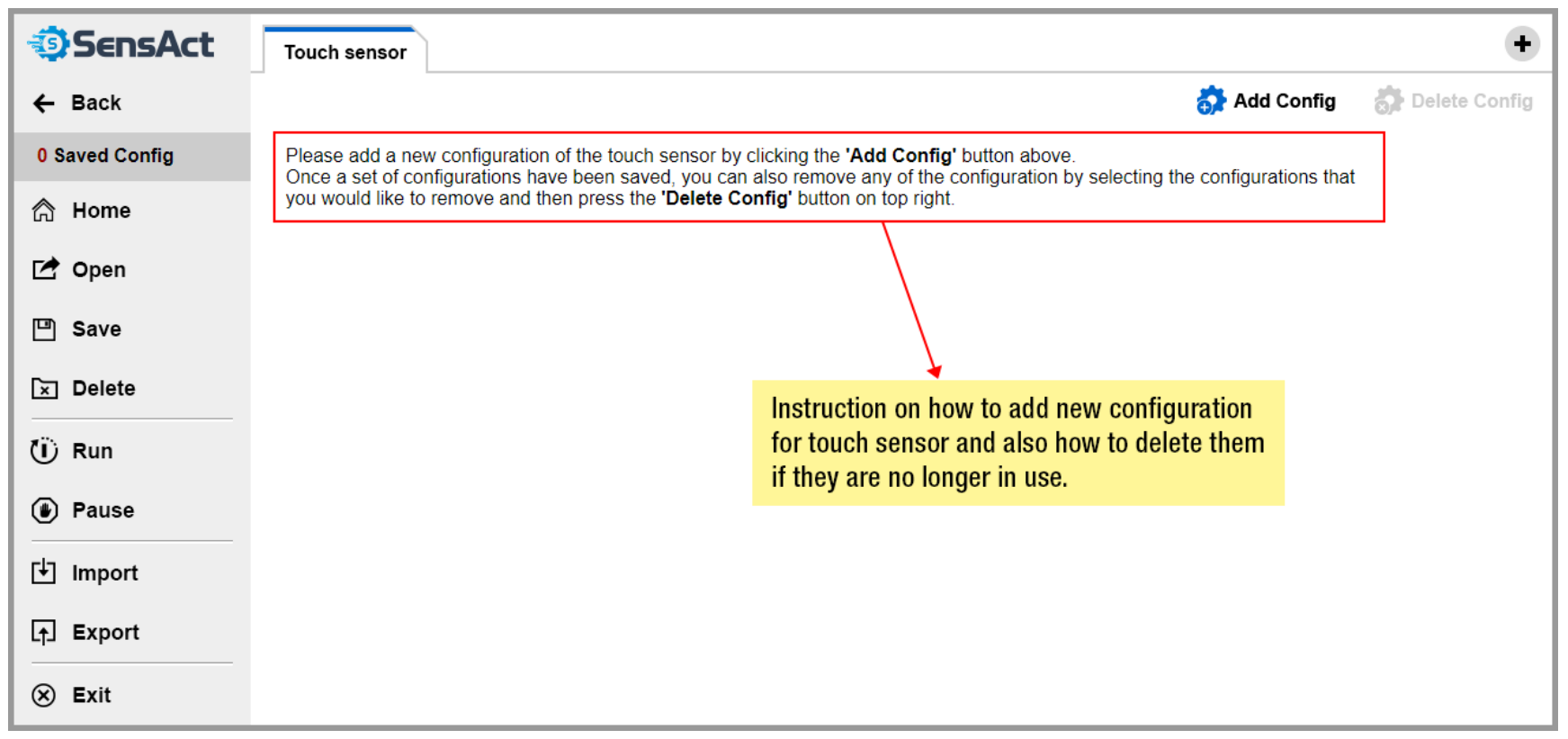

Figure 41. An example of instruction that guides the user to proceed to the next step in 'Advanced Setup'

A tab menu named 'Touch Sensor' has now been added to the screen (Figure 41) confirming the user has successfully added this as the input method. Below the tab, an instruction is displayed to assist a novice user with the next step (in this case, assisting them with creating a new configuration for the 'Touch Sensor'). Clicking the 'Add Config' button takes the user to the next screen to add a configuration (Figure 42).

The 'Add Config' feature has similar functionality to the 'New Trigger' feature on the current SensAct UI. Figure 42 displays the UI comparison of adding a new configuration between the prototype and current SensAct UI. On this screen, the user can set the value of the signal from the touch sensor based on client's ability and choose what type of functionality that this sensor will perform (e.g., simulate keyboard typing, mouse control, ring a buzzer, etc.). What is valuable about this is that various subtle configurations can be created to support a client with very limited functioning. Recall that for scenario \#2, the client only has reliable movement in his index finger and wants to use 
SensAct to mimic mouse control which involves more than one function to complete a variety of tasks. So once all the attributes of a specific configuration have been set, the user can proceed by clicking the 'Save Config' button (Figure 42, Prototype).

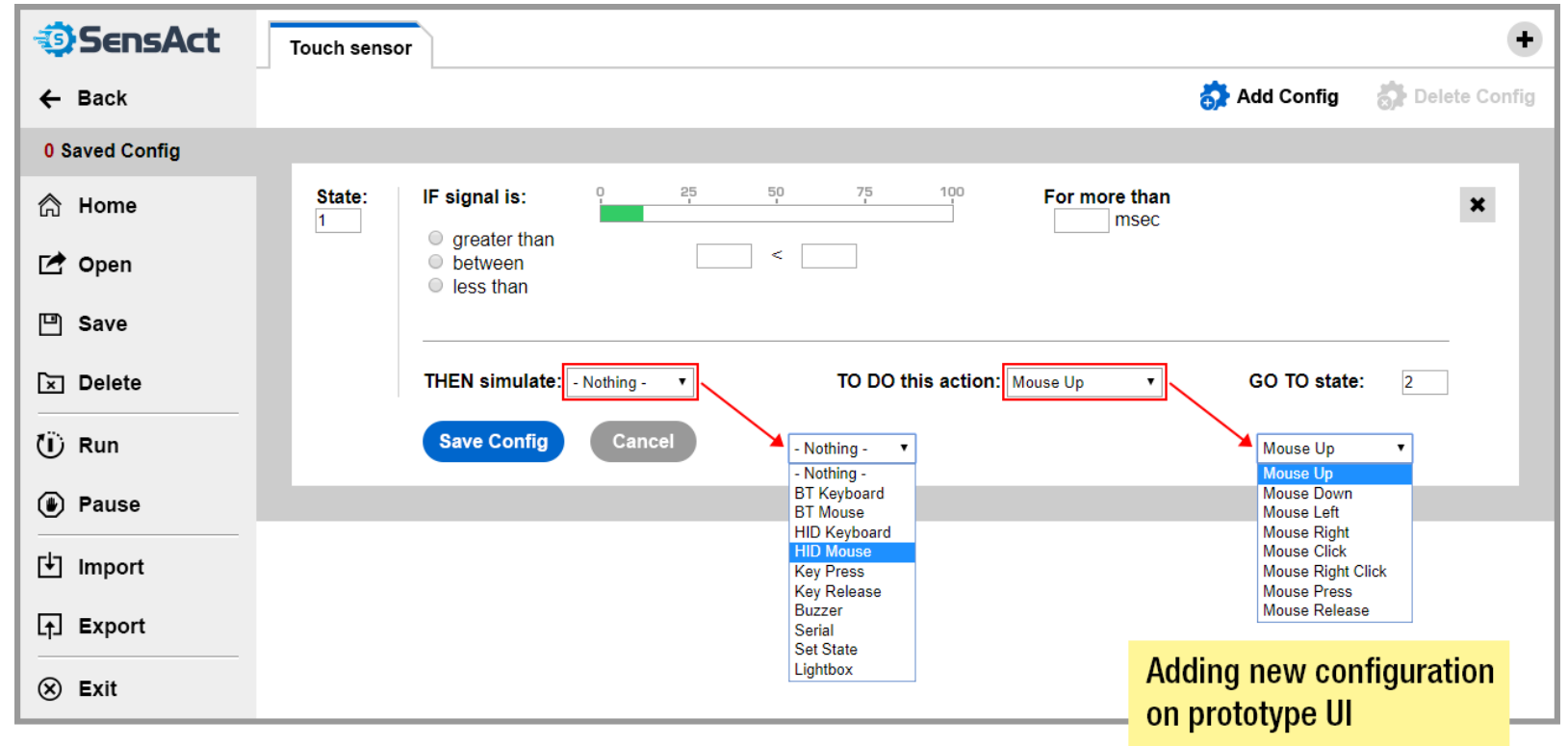

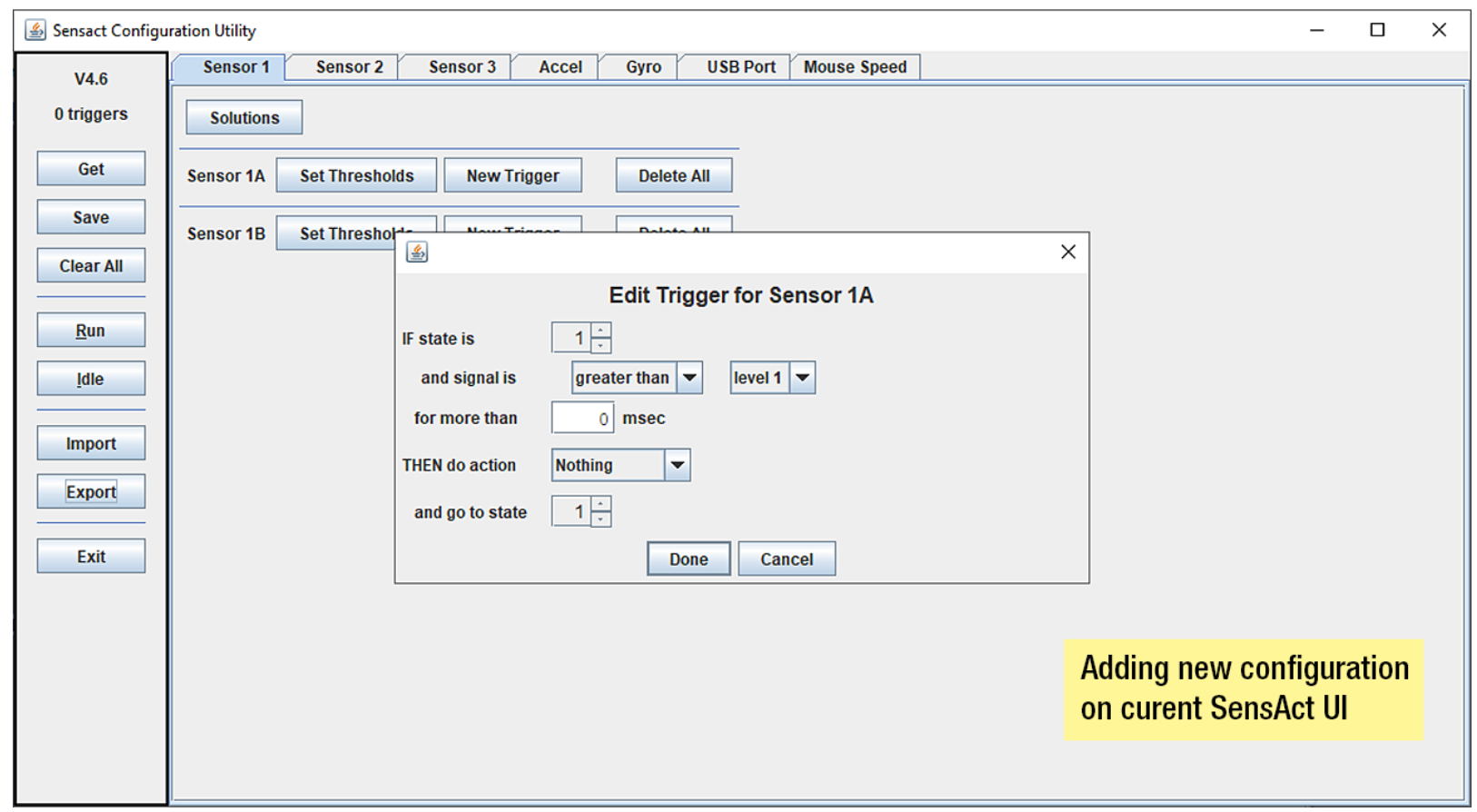

Figure 42. Comparison between prototype UI and current SensAct UI on adding new configuration 
All the saved configurations will then be listed on the screen (Figure 43). Users can select and individually edit any configuration from this list by clicking the pencil icon on the right side of each configuration list.

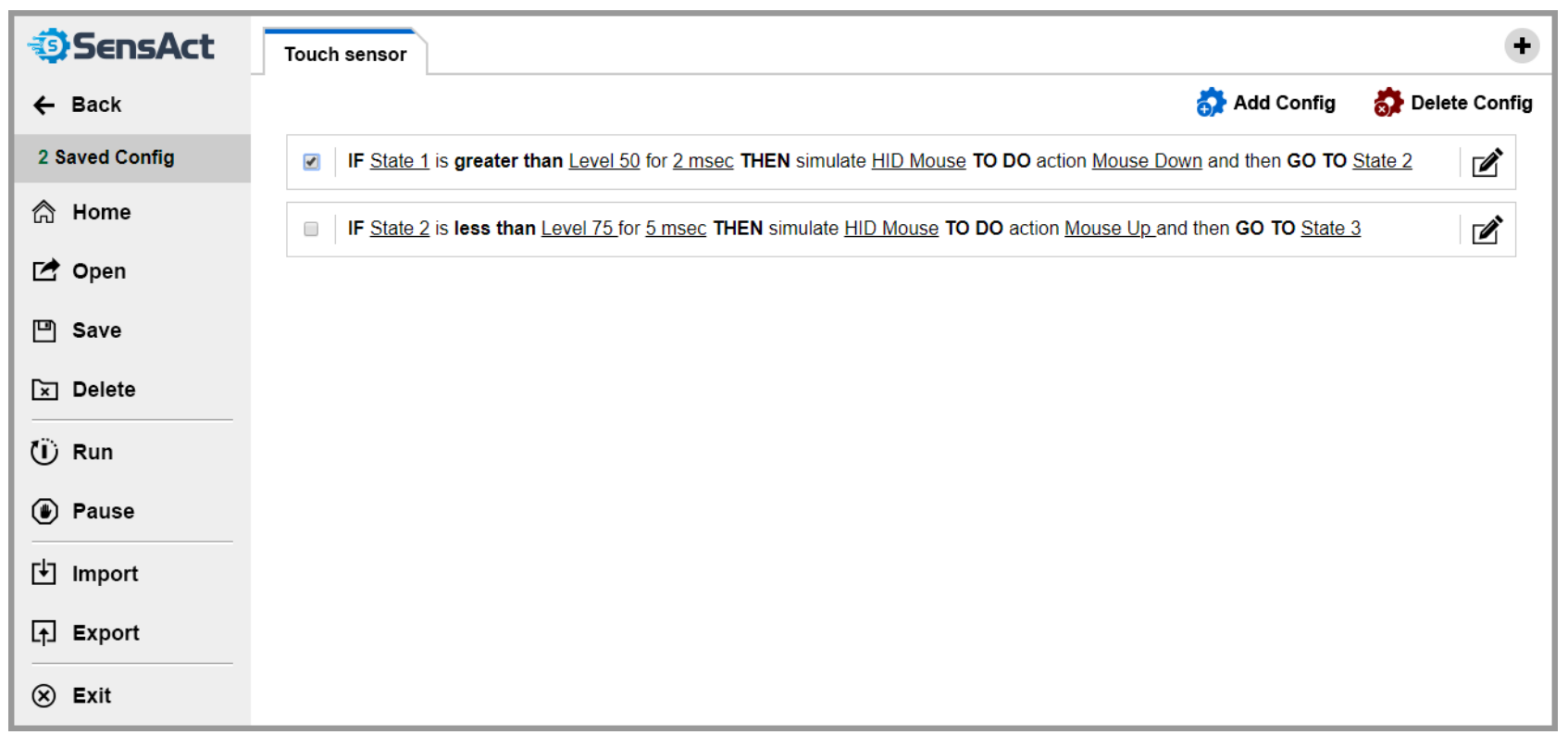

Figure 43. List of saved configurations on 'Advanced Setup'

Users can also remove a configuration by selecting the checkbox on the left side of each saved configuration, then clicking the red 'Delete Config' button on the top right of the screen (Figure 43). A warning dialog box then appears asking the user to confirm whether they want to delete the selected configuration(s) (Figure 44), in line with Neilsen's (1994) heuristic guidelines on error prevention that suggests error-prone conditions can be eliminated by presenting users with an option to confirm their action before committing to it. The users can add as many configurations as needed until the input device can meet the requirement to emulate the movement and control of a computer mouse. 


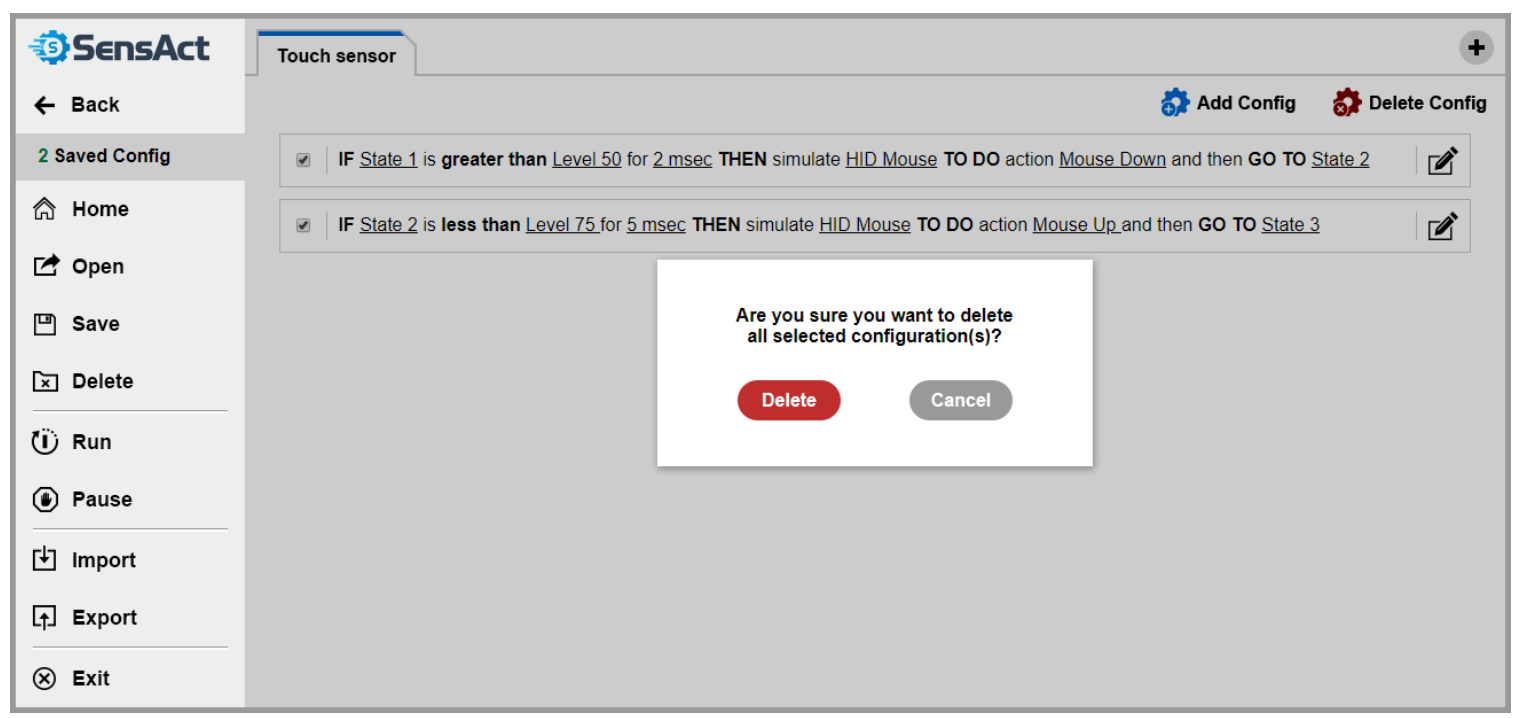

Figure 44. Dialog box to confirm deletion of selected configuration

\subsubsection{Participants Interaction and Feedback on the Prototype}

The design testing session was attended by one SLP, one OT, and one AT from BSVH. After a short introduction of the new UI design prototype, the participants were shown the home screen prototype of the SensAct UI (Figure 31). The initial comments from the SLP and OT, who had some exposure to the existing version of SensAct's UI, is that the prototype's home screen was not as intimidating as the current SensAct UI.

Given the first scenario to start with, the participants had two options on the home screen ('Wizard Setup' and 'Advanced Setup'); the SLP commented that because they have limited knowledge of SensAct, they would start by using the 'Wizard Setup'. Once the participants selected the 'Wizard Setup', they were taken to the initial screen of 'Wizard Setup' that displays an illustrative description on how to connect any necessary hardware to the SensAct unit. The participants expressed that the detailed illustrated 
description helped them to better understand the components of SensAct and how to assemble them correctly.

The participants were able to follow the step-by-step guidance on the 'Wizard Setup' easily. The first, second, and third step of 'Wizard Setup' were quickly understood and passed without any problem. On the third step (Figure 35), the researcher had anticipated that the participants would want to know more about what type of input sensor would suit their client best for assessment purposes and configurability. But the participants did not notice the information section on the right side of the screen because scenario \#1 had already stated that the touch sensor was recommended.

On the fourth step (Figure 36) of the 'Wizard Setup', the prototype gave options on whether the users would like to use 'Preset Settings' or 'Customized Settings' to configure the input sensor as a television remote controller. Unanticipated by the researcher, the SLP and the OT had a quick discussion between them and decided that they would rather use the 'Preset Settings' because they felt intimidated by customizing the settings. Having read the scenario only once at the beginning, the participants did not follow the requirements mentioned in the scenario that the client would like to customize the television channels to fit their preferences. The researcher then had to remind the participants that the client would prefer to customize the television channels. The participants admitted that they did not read the scenario carefully, and also missed reading the instruction section displayed on the right side of the screen. During this exchange, the AT suggested using a pop-out tooltip to provide more information on the UI features instead of a static information section on the right side of the screen. 
Now that the participants were back on track and following the scenario, the participants were able to complete step four and five easily and complete the 'Wizard Setup'. All three participants stated that they were surprised about how easy it was to follow the step-by-step guidance. The OT asked a question if a client would like to use two input sensors, would they need to use the 'Advanced Setup' instead of the 'Wizard Setup'. To answer this question, the researcher suggested that he would have to consult with SensAct's programmers to determine if this is possible. The AT, who has background in computer programming, also replied to this question that it would be possible.

At the end of this first scenario session, the AT commented that as an expert user and also the developer of SensAct, that they found the 'Wizard Setup' useful as a shortcut to quickly and simply configure an input method.

The participants went through the second scenario very quickly due to time constraints. Even though there was no step-by-step guidance, the SLP commented that the description and instruction was clear and understandable, and that it guided them on what they needed to do next. All participants agreed that the terms used for the buttons and features on the prototype UI were more understandable. The OT commented that as a novice user, they felt confident to be able to configure the 'Advanced Setup' because the terms and layout of the new UI were more comprehensible. The OT and SLP added that the use of conventional icons (e.g., pencil icon for edit function) were intuitive and that they were able to use the interface with minimal guidance. 


\section{DISCUSSION}

The objective of this study is to improve SensAct's usability and potential to support AAC implementation for individuals with complex communication needs. This objective was achieved by examining the existing SensAct system and the context in which it is used through an HCD approach. This approach involves looking at design problems and opportunities from multiple stakeholder perspectives using a variety of methods (Vechakul et al., 2015).

Qualitative methods, such as heuristic evaluation, observation, and focus group; were used to determine the usability issues that the developers and healthcare specialists are experiencing when they use the current SensAct UI to configure the system for a client, and semi-structured interview method was used to derive undermining factors that prevent SensAct to progress and reach a broader audience. Based on the analysis and synthesis from the findings of those qualitative methods, a set of design recommendations were proposed and tested by the developer of SensAct and healthcare specialists at BSVH to evaluate any improvement on SensAct's usability issues.

\subsection{Preliminary Design Recommendations}

Based on information gathered through interviews, heuristic evaluation, observation of participants using SensAct, a focus group, and participant use of the prototype; some preliminary design recommendations have been developed to improve 
the usability of SensAct's UI. These have been framed in reference to relevant usability heuristics developed by Neilsen (1994).

\subsubsection{Improving AAC System Efficiency to Compensate for Time Constraints}

It has been well-documented that time constraint is a major issue in the healthcare sector (Rombouts et al., 2016; Torrison et al., 2007; Hemsley et al., 2012). In an environment prone to changes (e.g., changes in a client's physical/cognitive ability, changes in hospital staff, changes in living conditions, etc.), an AAC system should be versatile, effective, and efficient to optimize the amount of the time used to implement the AAC system. Healthcare specialists should have an in-depth knowledge of AAC strategies to be able to perform an assessment for a client, and configure the AAC device properly to meet the client's needs. SensAct as part of an AAC strategy, should be made simple and easy to use for the healthcare specialists to save time and increase efficiency.

\subsubsection{Replacing System-Oriented Terms with Users' Language and Conventional Terms}

It was revealed during observation and focus group that the healthcare specialists were not able to configure SensAct because they could not understand the terms in the UI which were used as buttons and in descriptions. The prototype attempted to address this issue by following Nielsen's (1994) heuristic guidelines to replace the terms that were not clear with conventional terms for simpler understanding (e.g., 'Get' replaced by 'Open', 'Trigger' replaced by 'Config', 'Idle' replaced by 'Pause', etc.). 


\subsubsection{Designing a Simplified UI with a Self-Guidance System to Direct Users Configuring the SensAct System}

The "real consumer" of an AAC device may not be the client who uses the device itself, but rather the healthcare specialists who prescribe and implement the AAC device (Subrahmaniyan et al., 2017). SensAct developers should design a system that caters to the skills and knowledge of the healthcare specialists. Due to the lack of involvement of the intended audience, SensAct was designed and developed based on the skills and knowledge of the developers. The differences in skills and knowledge between SensAct developers and healthcare specialists may create a barrier in the application of the system. Designing a simplified and structured system (e.g., “Wizard Setup”) may bridge the gap between healthcare specialists and SensAct developers. 




Figure 45. Preliminary design recommendations for SensAct UI framed in reference to relevant usability heuristics developed by Neilsen (1994) 


\subsection{Stakeholders Involvement in SensAct's Development May Improve Usability}

Prior to this study, SensAct was primarily being developed by people with technical expertise (developers) and less involvement from healthcare specialists and designers; due to factors such as resource and time constraints, and a lack of a formalized HCD process in SensAct's development, among other issues. However, healthcare specialists play an important role in AAC strategies in assessing clients' needs and prescribing the best AAC solution for their clients. DSS have a role in supporting clients in their daily living activities but are also responsible for implementing an AAC strategy. The importance of having these well-defined roles has been noted by Binger et al. (2012) whereby failure to define these roles can create barriers in the assessment process and implementation of an AAC strategy, leading to abandonment of AAC devices.

The findings from the interview process suggest that healthcare specialists tend to choose an AAC strategy based on familiarity. Light \& McNaughton (2013) underlined that these individual preferences may influence the selection of new technology or other options that could potentially fit the clients' needs better. In order to properly prescribe an AAC strategy to a client, the healthcare specialists should have an in-depth knowledge of various AAC strategies and identify the best solution for their client. By involving healthcare specialists in SensAct's development process, it may broaden the healthcare specialists' knowledge and perspectives on various solutions that SensAct could offer, thereby opening more opportunities for SensAct to support a broader audience.

An HCD approach encourages the involvement of any relevant stakeholders and end-users throughout the development process of a product design lifecycle (Vechakul et 
al., 2015). The "end-user" (the client) is not merely a product tester at the end of the development process, but rather, an expert based on their experience of using other similar products adding value to product development. The focus of developing a new AAC technology should be driven by the needs and abilities of the clients, and not determined by the resources available to the developers (Light \& McNaughton, 2013). This focus on limited resources over clients' needs may result in an ineffective and inefficient AAC solution for the clients.

Understanding client's needs is the key to find the best AAC solution for the client. During interviews, two participants emphasized the importance of consulting the client's communication partners (e.g., caregivers, family members, and friends) to gain an in-depth knowledge of the client's needs. Because communication partners are the people who interact with the client on a day-to-day basis; ideally when needed, they should be able to adjust, fix an error, and troubleshoot the AAC device themselves. By sharing some of the workload of readjusting and troubleshooting the client's AAC device, this would alleviate some of the high-workload demand of the healthcare specialists (Rombouts et al., 2016), and ironically, perhaps free their time to assist in the development of AAc technologies.

Although persons with disabilities (the clients) and their communication partners (e.g., caregivers, family members, friends, etc.) were not part of this study, due to the limited scope for this phase of work (Figure 4); the study brought together the developers and healthcare specialists into a dialogue on the development of the SensAct system. The involvement of healthcare specialists in this study is in line with an HCD approach which focused on bringing different perspectives from various stakeholders to discover new 
insights on how SensAct could be developed as one of AAC solutions for individuals with complex communication needs.

\subsection{Improving Usability May Increase Consistency of AAC Usage}

According to Johnson et al. (2006), successful AAC strategies can be measured by the continuous use of the AAC strategy in a way that satisfies the client, their communication partners, and other medical professionals. At the moment, SensAct is not used consistently by healthcare specialists due to usability issues in setting up the device itself. One of the main usability issues is the complexity of SensAct's software UI. Based on the feedback from participants during prototype testing, the prototype demonstrated that SensAct's usability issues can be mitigated by applying an HCD approach throughout the development process.

Currently, AAC devices on the market would require days, if not weeks, to be upgraded or updated because they need to be sent back to the manufacturer. This demonstrates that these devices are too complicated in their current state since technical expertise is required to perform this task. Furthermore, control is another issue to consider in such scenarios, as manufacturers may not allow the devices to be tinkered with or repaired by non-trained users if they still want to keep them under warranty. For an individual who uses AAC as their method of communication, an AAC system feels like their voice. It is unimaginable to go for days or weeks without a voice to communicate with people. With an improved UI that can be configured by non-technical users, SensAct has the advantage over commercial AAC devices to reduce these inefficiencies and issues around control. Through further improvements and 
simplification of SensAct's UI, the system has the potential and versatility to be adjusted immediately to support dynamic changes in a client's condition. Although SensAct may still have some usability issues, with further development, it may be the solution to address current barriers to AAC implementation related to time effectiveness and adaptability.

\subsection{Dedicated Resources Required to Support the Implementation of AAC}

Time constraints and high workloads are major issues in the healthcare sector (Rombouts et al., 2016). Participants revealed during the interviews that there has been minimal involvement of healthcare specialists throughout SensAct's development due to time constraints. In fact, almost all of the research methods in this study conducted with the participants at BSVH were done during the participants' lunch break because they did not have available or dedicated time to participate in the study.

Due to this lack of involvement, SensAct has been developed without the vital input of the healthcare specialists. The findings in this study indicate that the healthcare specialists are running the risk of having to adapt to the technology (SensAct system), instead of developing a technology that that meets their skills and abilities (Light \& McNaughton, 2013).

Participants reported having difficulties keeping up with the latest AAC technology because they do not get enough training on new AAC technologies. Torrison et al. (2007) stated that inadequate knowledge on how to implement an AAC device may cause ineffective AAC strategy implementation and lead to its abandonment. Therefore, it is imperative for healthcare specialists to have an in-depth knowledge of various AAC 
strategies in order to prescribe it properly for a client. To increase the number of medical professionals to be qualified to practice $\mathrm{AAC}$ strategies, the medical facility requires dedicated resources (e.g., dedicated funding, hiring more staff to mitigate staff shortages, etc.) that are allocated to send their staff to formal training or training in-house.

The support from the community through the BSVH volunteer program has contributed to the development of SensAct tremendously. However, the resources provided from the volunteer program still have limitations. Currently, most of the volunteers who contributed to the development of SensAct have come from a computer programming or electronics background, and none have been involved from a UI design or product design background. This imbalance has impacted SensAct's usability with regards to configuration but likely also client usability. This reinforces the notion proposed by Baxter et al. (2011) that in order to solve a wide range of communication challenges for individuals with complex communication needs, expertise from various backgrounds are required, and teams cannot rely only on limited fields for knowledge.

Although healthcare specialists are presented with limited resources on a daily basis, they are able to maximize whatever resources afforded to them to an extent. The analysis from the interview process confirms Rombouts et al. (2016) report that the success of AAC implementation depends on three aspects:

1) the resourcefulness of the clinicians to adapt to circumstances;

2) a positive attitude to learn new things; and

3) consistency in implementing an AAC strategy with a client. 
Participants revealed during interviews that they do not get the support they need to implement AAC strategy with clients (e.g., not enough human resources, minimal staff training, etc.). However, the participants also noted that most clinicians have a positive attitude in solving problems by finding resources on their own (e.g., watching online tutorial videos, reading device manuals, etc.) and learning by themselves through trial and error. One participant mentioned that one of their strategies to familiarize themselves with a new AAC device is by spending as much time as possible with a client using a new AAC method. By consistently communicating and interacting with a client via the AAC device, the clinicians are encouraging the client to use the device more often. This also helps the clinicians to learn the limitations of that particular device and find resources to mitigate the problem.

\subsection{Applying an HCD Approach in SensAct's Development May Bridge the Communication Gap Between Developers and Healthcare Specialists}

It was evident from the observation and focus group methods that SensAct developers and healthcare specialists use different language in discussing AAC and had trouble understanding each other with regards to SensAct's application. The use of complex technical terms in SensAct's software UI has created a barrier for the healthcare specialists and their ability to understand how the device works. Nielsen (1994) has pointed out that a system should speak the users' language instead of using systemoriented terms. The researcher developed a prototype based on the analysis from research methods that utilized an HCD approach. The positive feedback on the UI prototype from BSVH participants indicates that applying an HCD approach throughout the development 
process and implementing UI guidelines, such as Nielsen's (1994) heuristic guidelines, could mitigate SensAct's usability issues (Figure 45).

During the interviews, the developer participant revealed that SensAct was initially built to meet the needs of one specific client. After having this success, the developers then started to build more features to solve other clients' problems. The developers were then inclined to design a solution that provided a variety of features to solve many problems all at once without considering the complexity that may follow. It was also revealed during these interviews that healthcare specialists were not involved throughout the development of SensAct which may have helped mitigate the complexity. Applying an HCD approach in SensAct's development focused on addressing the needs of the healthcare specialists to assist their clients (Vechakul et al., 2015), SensAct's developers may benefit by learning the language of these users and design features that fit their skills and needs.

SensAct was developed in a hospital/long-term care setting with real clients and real users (clinicians, healthcare workers, etc.), rather than in an experimental lab setting. In this case, the social dynamic of teams in a medical facility involved in the development process may influence the end result of the product (Binger et al., 2012; Blackstone et al., 2007; Dietz et al., 2012; Mumford et al., 2013). Hospitals and longterm care facilities have fluid and dynamic environments, where workers and clients may shift and be compelled to adapt to different and, at times, challenging conditions. Under such conditions, the application of an HCD framework brought this group together at the same table and their respective expertise to improve this system (e.g., by exploring possible non-technical terms in SensAct's software UI that everyone could understand). 


\subsection{Limitations in Study Methods}

Due to the lack of participants available, the researcher was only able to gather data from five participants, thereby making this a preliminary case study approach, and limiting the study's generalizability. A larger sample pool may yield more data to support generalization and new findings (Regnauld, 2015).

The researcher was only able to secure the participation of one developer of SensAct, although many developers have been involved. Each developer brings expertise to the table and may have different thoughts and opinions with regards to SensAct's usability, but these perspectives are not captured in this study.

This research study was isolated to the BSVH environment (e.g., participants, client case study examples, and the location where the research methods were performed). However, SensAct has also been used at the Clinic for Augmentative Communication at the Children's Hospital of Eastern Ontario (CHEO). The clients at CHEO range from young children up to teenagers, while the clients at BSVH are adults. These target audiences may have different needs that can affect the design and development of SensAct. Further, the team dynamic and organizational structure within these two different facilities may also yield different results in the data collection process.

Thomas Green and Marian Petre (1996) developed an evaluation method called the 'Cognitive Dimensions' framework that may be more suitable to perform a usability evaluation on SensAct's UI. This method examines how easy it is for users to understand and use a UI system to achieve their goals. The 'Cognitive Dimensions' framework was initially developed from cognitive and psychology approaches to user interface design 
which may define the needs of the end-users more clearly (Green \& Petre, 1996). Typically, the 'Cognitive Dimensions' framework is conducted in the early stage of development to perform a quick review of a system and analyze how it can be improved (Green \& Petre, 1996), while heuristic evaluation can be performed in any stage of development (Forsell, 2012).

The focus group was initially planned to be held in two sessions and each session to be attended by two participants (a combination of an expert and novice user of SensAct). The second session was cancelled due to time constraints and participants' availability. Unanticipated by the researcher, the participants invited two other participants to attend the session. The pen and paper tools provided during the focus group session were intended for the participants to interactively share their thoughts in a tangible form (e.g., sharing ideas about SensAct UI through co-design activities such as sketches or mock-ups). But because the number of participants doubled, this focused activity changed and the dynamic became more fluid and developed into an extended 'focus group' discussion rather than the intended co-design session. Therefore, the pen and paper tools were not fully used to gain more insight on SensAct's software UI.

The researcher acknowledges the possibility of bias in focusing more on finding SensAct's UI usability issues, which may result in narrowing the focus on negative aspects of the UI design to the exclusion of positive aspects. Positive aspects on the current SensAct's UI design could be explored further and reused as appropriate.

Generally, prototype development can range from low to high fidelity. This research study utilized a high-fidelity prototype. However, it must be acknowledged that the use of low-fidelity prototypes may also bring some benefits to the study. An example 
of low-fidelity prototype is card sorting or paper-prototyping. Low-fidelity prototypes are usually developed quickly with limited functionality to depict concepts or to demonstrate the general look and feel of an interface. Because low-fidelity prototyping is easy to develop, the researcher may be able to develop multiple prototype design alternatives to be tested with the end-users; which may result in more possible design solutions or more input from the end-users. Low-fidelity prototypes are normally used in the early design cycle to generate ideas or formulate concepts. In contrast, high-fidelity prototypes are typically used in the later stages of the design cycle and closely represents the actual interface to test or evaluate the usability of the proposed UI design.

The prototype developed by the researcher also had some UI limitations (e.g., unable to show tooltip description) due to the researcher's limited knowledge of programming language. This affected the performance of the prototype UI when presented to the panel at BSVH for evaluation and was explained to participants. This prototype was also developed only for a computer platform, which may have limited the possibility of exploring other potential platforms, such as mobile device platforms (e.g., smartphones, tablets).

During scenario \#1 'Wizard Setup' prototype testing, the participants were not aware of the input method information section on the third step. The participants were perhaps just following the instruction from the scenario and did not investigate the other types of input sensors available. This was an oversight in developing the scenario. To evaluate this feature, the scenario should not state a specific input sensor to use and let the choices be open to the participants' interpretation. 
Although 'Wizard Setup' or setup assistants generally help novice users to easily configure settings on an interface, this type of setup assistant may also pose some challenges. Because the interaction process of 'Wizard Setup' is a linear progression, the UI may not allow the user to compare information between steps, and it would require longer steps if the user would like to redo a function in the previous steps. The 'Wizard Setup' also limits users' control to edit more detail in the functionality due to the simplification of a complex UI design split into only a few steps.

\subsection{Future Recommendations}

An AAC research should focus on prioritizing the needs of the intended audience (Vechakul et al., 2015). Continued application of the HCD approach on future studies of SensAct would ensure the involvement of all relevant stakeholders. As mentioned previously, this research study was isolated to the BSVH environment, and future studies should include participants from different facilities that have used SensAct for their clients. Studies from different facilities and various stakeholders could bring a wealth of knowledge on SensAct's usability and better inform design development.

Future studies should take into account the time constraints in conducting research at a medical facility. The research methods should be properly planned and flexible at the same time to accommodate any situation changes due to the unpredictable nature of healthcare workplace conditions (e.g., availability of the participants, schedule changes, impromptu attendance when conducting a research method, etc.).

One factor that requires further study in SensAct's UI is cognitive load. Although AAC devices can provide solutions for individuals with complex communication needs, 
they also impose a new demand on working memory or the cognitive ability of the client, in order to preserve and manipulate information while performing a task (Thistle \& Wilkinson, 2013). The limits of people's working memory load should be examined in AAC device usage. The importance of this factor can be seen in the complexity of setting up a variety of configurations within an 'Advanced Setup' for a client who is required to learn and remember a number of key functions to mimic a hardware device (e.g., a mouse) that they can no longer use. 


\section{CONCLUSION}

In conclusion, this research study aimed to answer the following question: How to improve SensAct's usability and potential to support AAC implementation for individuals with complex communication needs? SensAct's usability and potential can be improved by applying a human-centred design (HCD) approach throughout the development process. This approach involves looking at design problems and opportunities from multiple stakeholder perspectives using a variety of methods. Three different perspectives (from the developers, healthcare specialists, and the researcher) were captured in this study on issues with the existing design of SensAct and possibilities for improvement. Five research methods were used to do this, each providing additional information as the project progressed: 1) semi-structured interviews, 2) heuristic evaluation, 3) observation, 4) focus group, 5) prototype design \& evaluation.

This research also answers the following sub-questions:

Subquestion 1: What issues are developers and healthcare specialists experiencing when they use SensAct's current user interface (UI) to configure the system for a client?

Through heuristic evaluation, observation, and focus group methods; three key usability issues in setting up SensAct system were identified, and design recommendations were proposed (in a form of UI prototype) to mitigate those issues:

1. Difficulties in configuring SensAct under time constraints may be mitigated by improving the efficiency of the UI. 
2. The use of complex technical terms should be minimized or replaced by users' language and conventional terms.

3. SensAct's UI should cater to both novice and expert users. Novice users require a simplified and structured UI with a self-guidance system to help them configure the device, while expert users require detailed configuration settings with shortcuts for efficiency.

Subquestion 2: What factors may be undermining SensAct's ability to progress and reach a wider audience?

The analysis and findings from the five research methods mentioned above indicate several factors contribute to SensAct's usability issues which undermine its ability to reach a broader audience. Interviews with the SensAct developer and healthcare specialists who have had experience in AAC suggest that systemic factors, such as external factors; human resources; and people's preferences, motivation, and attitudes may influence the implementation of an AAC strategy, including SensAct.

Stakeholder involvement in SensAct's development is key to improving and/or maintaining its usability in the longer term. However, in order to properly design, develop, maintain, and improve the SensAct system; dedicated resources must be allocated (e.g., more healthcare personnel participation in the development process, more experts to develop the device, more funding, etc.). The application of an HCD approach throughout SensAct development would give developers valuable input and feedback from relevant stakeholders, which may bridge the gap of skills and knowledge among expert and novice users. Most importantly, improving SensAct's usability, may increase consistency in use and opportunities to reach broader audiences. 


\subsection{Future Research}

Future research studies could include scope B and C of the study with healthcare clients and their caregivers, as shown in Figure 4. As Baxter et al. (2012) notes, most $\mathrm{AAC}$ device users and their communication partners find AAC devices difficult to set up or program. It is essential to gain insights from these stakeholders in order to further improve SensAct's usability so that more people can benefit from it.

The rapid development of smart devices, which now include environmental control (e.g., lighting, room temperature control, smart television, security \& alarm systems, etc.), allow people to have more control over their environment. A study on how to integrate SensAct with these technologies will enable individuals with complex needs to gain more independence and attain a better quality of life.

Many UI designs of websites and email systems on the internet provide a variety

of features to facilitate many different tasks without considering the complexity that may follow. Although SensAct may be able to solve a client's need to gain access to the internet, it is important to recognize that their ability to browse the internet is not at the same level as a person without a disability. Currently, the use of such systems often requires more steps to be able to perform one simple task (e.g., write an email). Future studies should take such external factors into account and foster more awareness of accessible design in industry and the need for integration.

The future goal of SensAct is to provide individuals with complex communication needs a means to facilitate effective communication, develop social interaction, and to be part of the community; future studies that involve the developers of SensAct, healthcare 
specialists, clients, and their communication partners can provide the fundamental framework to reach that goal. 


\section{REFERENCES}

Allen, J. (2005). Designing desirability in an augmentative and alternative communication device. Universal Access in the Information Society, 4(2), 135 145. doi:10.1007/s10209-005-0117-2

Batorowicz, B., \& Shepherd, T. A. (2011). Teamwork in AAC: Examining Clinical Perceptions. Augmentative and Alternative Communication, 27(1), 16-25. doi: 10.3109/07434618.2010.546809

Baxter, S., Enderby, P., Evans, P., \& Judge, S. (2011). Barriers and facilitators to the use of high-technology augmentative and alternative communication devices: A systematic review and qualitative synthesis. International Journal of Language \& Communication Disorders, 47(2), 115-129. doi:10.1111/j.14606984.2011.00090.x

Binger, C., Ball, L., Dietz, A., Kent-Walsh, J., Lasker, J., Lund, S., . . Quach, W. (2012). Personnel Roles in the AAC Assessment Process. Augmentative and Alternative Communication, 28(4), 278-288. doi:10.3109/07434618.2012.716079

Blackstone, S. W., Williams, M. B., \& Wilkins, D. P. (2007). Key principles underlying research and practice in AAC. Augmentative and Alternative Communication, 23(3), 191-203. doi:10.1080/07434610701553684

Bradshaw, J. (2001). Complexity of staff communication and reported level of understanding skills in adults with intellectual disability. Journal of Intellectual Disability Research,45(3), 233-243. doi:10.1046/j.1365-2788.2001.00318.x

Calculator, S. (1999). AAC outcomes for children and youths with severe disabilities: When seeing is believing. Augmentative and Alternative Communication, 15(1), 4-12. doi:10.1080/07434619912331278525

Charmaz, K. (2001). Grounded theory. In R. M. Emerson (Ed.), Contemporary field research: Perspectives and formulations (2nd ed.) (pp. 335-52). Prospect Heights, IL: Waveland Press.

Clarke, V., \& Braun, V. (2016). Thematic analysis. The Journal of Positive Psychology, 12(3), 297-298. doi:10.1080/17439760.2016.1262613

Clarkson, P. J., \& Coleman, R. (2015). History of Inclusive Design in the UK. Applied Ergonomics, 46, 235-247. doi:10.1016/j.apergo.2013.03.002

Cockerill, H., Elbourne, D., Allen, E., Scrutton, D., Will, E., Mcnee, A., . . Baird, G. (2013). Speech, communication and use of augmentative communication in young people with cerebral palsy: The SH\&PE population study. Child: Care, Health and Development,40(2), 149-157. doi:10.1111/cch.12066

Communication aids. (n.d.). Retrieved from https://www.ontario.ca/page/communicationaids 
Dietz, A., Quach, W., Lund, S. K., \& Mckelvey, M. (2012). AAC Assessment and Clinical-Decision Making: The Impact of Experience. Augmentative and Alternative Communication, 28(3), 148-159. doi:10.3109/07434618.2012.704521

Fishbein, M., \& Ajzen, I. (2010). Predicting and changing behavior: The reasoned action approach. New York, NY: Psychology Press.

Forsell, C. (2012). Evaluation in Information Visualization: Heuristic Evaluation. 2012 $16^{\text {th }}$ International Conference on Information Visualisation. doi:10.1109/iv.2012.33

Green, T., \& Petre, M. (1996). Usability Analysis of Visual Programming Environments: A ‘Cognitive Dimensions' Framework. Journal of Visual Languages \& Computing, 7(2), 131-174. doi: 10.1006/jvlc.1996.0009

Hemsley, B., Balandin, S. \& Worrall, L. (2012), Nursing the patient with complex communication needs: time as a barrier and a facilitator to successful communication in hospital. Journal of Advanced Nursing, 68: 116-126. doi:10.1111/j.1365-2648.2011.05722.x

Hodge, S. (2007). Why is the potential of augmentative and alternative communication not being realized? Exploring the experiences of people who use communication aids. Disability \& Society,22(5), 457-471. doi:10.1080/09687590701427552

Interface. (n.d.). In Cambridge Dictionary. Retrieved from https://dictionary.cambridge.org/dictionary/english/interface

ISO 9241-11:2018(en). Ergonomics of human-system interaction - Part 11: Usability: Definitions and concepts. Retrieved from https://www.iso.org/obp/ui/\#iso:std:iso:9241:-11:ed-2:v1:en

Johnson, J. M., Inglebret, E., Jones, C., \& Ray, J. (2006). Perspectives of speech language pathologists regarding success versus abandonment of AAC. Augmentative and Alternative Communication, 22(2), 85-99. doi:10.1080/07434610500483588

Kirk, D., McClelland, I., \& Suri, J. F. (2015). Involving People in Design Research. Evaluation of Human Work, 4th Edition, 249-298.

Light, J. (1989). Toward a definition of communicative competence for individuals using augmentative and alternative communication systems. Augmentative and Alternative Communication, 5(2), 137-144. doi:10.1080/07434618912331275126

Light, J., \& McNaughton, D. (2012). The Changing Face of Augmentative and Alternative Communication: Past, Present, and Future Challenges. Augmentative and Alternative Communication, 28(4), 197-204. doi:10.3109/07434618.2012.737024

Light, J., \& McNaughton, D. (2013). Putting People First: Re-Thinking the Role of Technology in Augmentative and Alternative Communication Intervention. Augmentative and Alternative Communication, 29(4), 299-309. doi: $10.3109 / 07434618.2013 .848935$ 
Light, J., \& McNaughton, D. (2014). Communicative Competence for Individuals who require Augmentative and Alternative Communication: A New Definition for a New Era of Communication? Augmentative and Alternative Communication, 30(1), 1-18. doi:10.3109/07434618.2014.885080

McCall, F., Markova, I., Murphy, J., Moodie, E., \& Collins, S. (1997). Perspectives on AAC systems by the users and by their communication partners. International Journal of Language \& Communication Disorders, 32, 235-256. doi:10.3109/13682829709177099

McNaughton, D., \& Light, J. (2013). The iPad and Mobile Technology Revolution: Benefits and Challenges for Individuals who require Augmentative and Alternative Communication. Augmentative and Alternative Communication, 29(2), 107-116. doi:10.3109/07434618.2013.784930

Mumford, L., Lam, R., Wright, V., \& Chau, T. (2013). An access technology delivery protocol for children with severe and multiple disabilities: A case demonstration. Developmental Neurorehabilitation, 17(4), 232-242. doi:10.3109/17518423.2013.776125

Murphy, J., Markova, I., Collins, S., \& Moodie, E. (1996). AAC systems: Obstacles to effective use. International Journal of Language \& Communication Disorders, 31(1), 31-44. doi:10.3109/13682829609033150

National Core Indicators (2012). National Core Indicators Chart Generator. Retrieved from https://www.nationalcoreindicators.org/charts/archive/

National Core Indicators (2014). National Core Indicators Chart Generator. Retrieved from https://www.nationalcoreindicators.org/charts/archive/

Nielsen, J. (1994). Enhancing the explanatory power of usability heuristics. Conference Companion on Human Factors in Computing Systems - CHI 94. doi: $10.1145 / 259963.260333$

Nielsen, J., \& Molich, R. (1990). Heuristic evaluation of user interfaces. Proceedings of the SIGCHI Conference on Human Factors in Computing Systems Empowering People - CHI 90. doi:10.1145/97243.97281

North, B. (2015). The Growing Role of Human Factors and Usability Engineering for Medical Devices. What's Required in the New Regulatory Landscape. Sydney: BSI Standards Ltd.

Regnauld, N. (2015). Generalisation And Data Quality. ISPRS - International Archives of the Photogrammetry, Remote Sensing and Spatial Information Sciences, XL-3/W3, 91-94. doi:10.5194/isprsarchives-xl-3-w3-91-2015Rombouts, E., Maes, B., \& Zink, I. (2016). The behavioural process underlying augmentative and alternative communication usage in direct support staff. Journal of Intellectual \& Developmental Disability, 42(2), 101-113. doi:10.3109/13668250.2016.1219023

Rudd, J., Stern, K., \& Isensee, S. (1996). Low vs. high-fidelity prototyping debate. Interactions, 3(1), 76-85. doi: 10.1145/223500.223514

Saldaña, J. (2015). The coding manual for qualitative researchers. Los Angeles: SAGE. 
Segalman, R. (2011). AAC, Aging, and Telephone Relay Access Technology. Disability Studies Quarterly, 31(4). doi:10.18061/dsq.v31i4.1722

Severity Ratings for Usability Problems: Article by Jakob Nielsen. (n.d.). Retrieved from https://www.nngroup.com/articles/how-to-rate-the-severity-of-usability-problems/

Stancliffe, R. J., Larson, S., Auerbach, K., Engler, J., Taub, S., \& Lakin, K. C. (2010). Individuals with Intellectual Disabilities and Augmentative and Alternative Communication: Analysis of Survey Data on Uptake of Aided AAC, and Loneliness Experiences. AAC: Augmentative \& Alternative Communication, 26(2), 87-96. doi: 10.3109/07434618.2010.481564

Statistics Canada (2018). A demographic, employment and income profile of Canadians with disabilities aged 15 years and over, 2017. Statistics Canada Catalogue no. 89-654-X2018002. /pub/89-654-X/89-654-x2018002-eng.htm (June 22 $\left.{ }^{\text {nd }}, 2019\right)$.

Subrahmaniyan, N., Higginbotham, D. J., \& Bisantz, A. M. (2017). Using Personas to Support Augmentative Alternative Communication Device Design: A Validation and Evaluation Study. International Journal of Human-Computer Interaction, 34(1), 84-97. doi:10.1080/10447318.2017.1330802

Thistle, J. J., \& Wilkinson, K. M. (2013). Working Memory Demands of Aided Augmentative and Alternative Communication for Individuals with Developmental Disabilities. Augmentative and Alternative Communication, 29(3), 235-245. doi:10.3109/07434618.2013.815800

Torrison, C., Jung, E., Baker, K., Beliveau, C., \& Cook, A. (2007). The impact of staff training in Augmentative/Alternative communication (AAC) on the communication abilities of adults with developmental disabilities. Developmental Disabilities Bulletin, 35(1), 103-130.

Vechakul, J., Shrimali, B. P., \& Sandhu, J. S. (2015). Human-centred Design as an Approach for Place-Based Innovation in Public Health: A Case Study from Oakland, California. Maternal and Child Health Journal, 19(12), 2552-2559. doi:10.1007/s10995-015-1787-x

Volkmar, F. R. (2013). Encyclopedia of Autism Spectrum Disorders. New York, NY: Springer.

Williams, B. (2000). More than an exception to the rule. In M. Fried-Oken \& H. Bersani (Eds.), Speaking up and spelling it out (pp. 245 - 254). Baltimore, MD: Paul H. Brookes.

Williams, M. B., Krezman, C., \& McNaughton, D. (2008). "Reach for the Stars": Five Principles for the Next 25 Years of AAC. Augmentative and Alternative Communication, 24(3), 194-206. doi:10.1080/08990220802387851

Windley, D., \& Chapman, M. (2010). Support workers within learning/intellectual disability services perception of their role, training and support needs. British Journal of Learning Disabilities, 38(4), 310-318. doi:10.1111/j.14683156.2010.00610.x 


\section{APPENDICES}

\section{Appendix A: Ethics}

\section{A.1 Ethics Clearance from Bruyère - Saint-Vincent Hospital}

\section{Page 1}

\section{Bruyère}

Bruyère pour des soins continus. Bruyère Is Continuing Care.

Hôpital Élisabeth-Bruyère Hospital 43, rue Bruyere $S t$. Ottawa ON KIN 5 C8 Tél./Tel.: 613-562-6262

Hôpital Saint-Vincent Hospital 60, rue Cambridge St. $N$. Tél./Tel: $613-562-6262$ Téléc./Fax: 613-782-2785

Institut de recherche Élisabeth-Bruyère Elisabeth Bruyere Research Institure 43, rue Bruyere St.

Ottava ON KIN SC8

Téléc./Fax: 613-562-4266

Résidence Saint-Louis Residence 879, chemin Hiawatha Park Road Ottawa ON KIC $2 Z 6$ Tél./Tel.: 613-562-6262 Téléc./Fax: 613-683-5001

Résidence Élisabeth-Bruyère Residence 75 , rue Bruyère St.

Tél./Tel: : 613-562-626

Téléc./Fax: 613-562-4223

Centre de médecine familiale Bruyère Bruyère Family Medicine Centre

75, rue Bruyère St.

Ottawa ON KIN 5 C8

Tél./Tel:: 613-241-3344
Téléc./Fax: 613-241-1971

Centre de médecine familiale Primrose

Primuse Family Medicine Centre

35, rue Primrose St.

Ottawa ON KIR OAI

Tél./Tel.: 613-230-778

Téléc./Fax: 613-230-7778

Fondation Bruyère Foundation

43, rue Bruyere St.
Ottawa oN KIN 5 .

Tél./Tel.: 613-562-6319

Téléc./Fax: 613-562-6023

Affilié à / Affitiated with

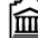

uOttawa
November 26, 2018

Ebic Tristary

Carleton University

RE: Quality Improvement of Sensact as an Augmentative and Alternative Communication (AAC) Device (Bruyère REB \# M1618-054)

Letter of Exemption from REB Review

Dear Mr. Tristary,

The Bruyère Research Ethics Board has reviewed your project description regarding the above-mentioned project.

Upon review of submission materials, the REB has determined that this project constitutes a program evaluation, quality improvement, or quality assessment activity. It is therefore exempt from REB review according to Article 2.5 of the Tri-Council Policy Statement 2, and so does not require REB approval.

Please note that in order to undertake your project at Bruyère you may need to seek permissions from other parties such as clinical managers or directors, your supervisor, the Privacy office, etc., and must otherwise meet Bruyère requirements to carry out the project.

The Bruyère REB recommends that you manage and mitigate ethical issues, privacy risks, or other concerns that relate to your project. Participants should be informed of reasonably foreseeable risks and consent forms may be helpful in communicating risks and benefits and other information that may affect a person's willingness to take part. There should be no reference to the Bruyere REB in your communications with participants (including, but not limited to, the consent form) as the REB has not reviewed and does not provide oversight for this project.

If, during the course of this study, there are changes to the project or new information comes to light, which would affect the determination stipulated above, these should be brought to the immediate attention of the REB for re-assessment.

We wish you the best of luck with your research. 
Page 2

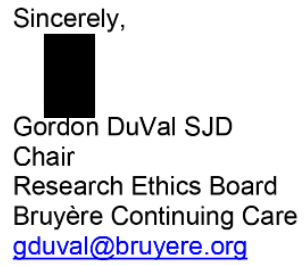




\section{A.2 Ethics Clearance from Carleton University}

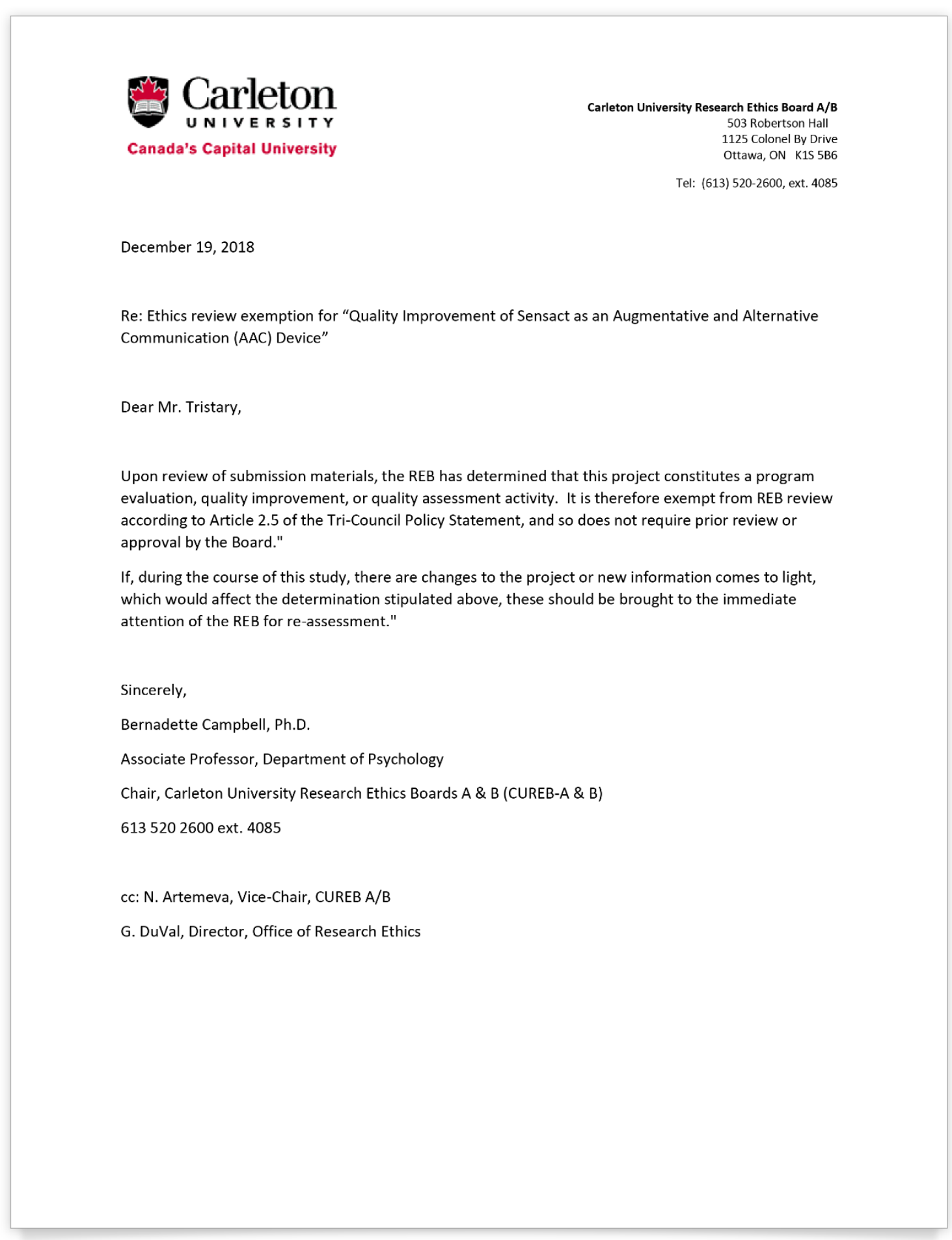




\section{A.3 Consent Form for Interview}

\section{Page 1}

Carleton

Canada's Capital University
Consent Form: Interview

Name and Contact Information of Researcher:

Ebic Tristary

Carleton University, School of Industrial Design, Faculty of Engineering and Design

Tel.:

Email: ebic.tristary@carleton.ca

Supervisor and Contact Information:

Professor Chantal Trudel

Carleton University, School of Industrial Design, Faculty of Engineering and Design

Phone: 613-520-2600 ext. 5626

Email: chantaltrudel@cunet.carleton.ca

Dr. Adrian Chan

Carleton University, Department of Systems and Computer Engineering

Phone: 613-520-2600 ext. 8016

Email: adcchan@sce.carleton.ca

Project Title:

Quality Improvement of Sensact as an Augmentative and Alternative Communication (AAC) Device.

Project Sponsor and Funder (if any):

N/A

Carleton University Project Clearance:

Exemption letters attached.

I, choose to participate in a study on Quality

Improvement Study of Sensact as an Augmentative and Alternative Communication (AAC) Device. This study aims to investigate the barriers and difficulties that the healthcare workers (such as: occupational therapist or speech/language pathologist) at Bruyère Saint-Vincent Hospital (BSVH) are having in setting up and configuring/calibrating Sensact device. The researcher for this study is Ebic Tristary from the School of Industrial Design, Faculty of Engineering and Design at Carleton University. He is working under the supervision of Professor Chantal Trudel from the School of Industrial Design, Faculty of Engineering and Design at Carleton University, and Dr. Adrian Chan from the Department of Systems and Computer Engineering at Carleton University.

This study involves a 30 minutes interview. With your consent, this interview will be audiorecorded. Once the recording has been transcribed, the audio-recording will be destroyed.

This document has been printed on both sides of a single sheet of paper.

Please retain a copy of this document for your records. 


\section{Page 2}

You have the right to end your participation in the study at any time, for any reason, up until Macrh 31 ${ }^{\text {st }}, 2019$. You can withdraw by phoning or emailing the researcher or the research supervisor. If you withdraw from the study, all information you have provided will be immediately destroyed.

I will not be collecting personal information that could identify you (e.g. name, address) but I may collect general demographic information (age, gender, ethnicity). Any personal information that is collected (e.g. signatures on the consent forms, contact information, identifying information from data) will only be viewed by the student researchers and their supervisors.

Any electronic versions of personal information (e.g. email contact information obtained in recruitment, identifying photos or video) and research data will be encrypted and passwordprotected during the duration of the project. Any hard copies of data (including any handwritten notes or USB keys) will be kept in the supervisor's locked office at Carleton University for a period of 5 years. Research data will only be accessible by the researcher and the research supervisor.

Once the project is completed, the research may be published. I may use excerpts from photos, videos in publications which may show your identity. Manuscripts will be developed in collaboration with the hospital stakeholders involved in the project and will be reviewed and approved by the hospital stakeholders for publication. All research data will be kept for 5 years and potentially used for other educational purposes, secondary analysis, presentations, publications or other research projects. At the end of 5 years, all research data will be securely destroyed. (Electronic data will be erased and hard copies will be shredded.)

If you would like a copy of the finished research project, you are invited to contact the researcher to request an electronic copy which will be provided to you.

This project was reviewed and cleared by the Carleton University Research Ethics Board [B]. If you have any ethical concerns with the study, please contact Dr. Bernadette Campbell, Chair, Carleton University Research Ethics Board (by phone at 613-520-2600 [ext. 4085] or by email at ethics@carleton.ca). 


\section{Page 3}

Statement of consent - print and sign name

I voluntarily agree to participate in this study:

-Yes $\quad$ Yes ${ }^{\text {No }}$

I agree to be audio recorded:

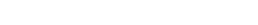

Signature of Participant

\section{Research team member who interacted with the subject}

I have explained the study to the participant and answered any and all of their questions. The participant appeared to understand and agree. I provided a copy of the consent form to the participant for their reference.

Signature of researcher

Date 


\section{A.4 Consent Form for Observation}

\section{Page 1}

Carleton

Canada's Capital University

\section{Consent Form: Observation}

Name and Contact Information of Researcher:

Ebic Tristary

Carleton University, School of Industrial Design, Faculty of Engineering and Design

Tel

Email: ebic.tristary@carleton.ca

Supervisor and Contact Information:

Professor Chantal Trudel

Carleton University, School of Industrial Design, Faculty of Engineering and Design

Phone: 613-520-2600 ext.5626_Email: chantaltrudel@cunet.carleton.ca

Dr. Adrian Chan

Carleton University, Department of Systems and Computer Engineering

Phone: $613-520-2600$ ext. 8016

Email: adcchan@sce.carleton.ca

Project Title:

Quality Improvement of Sensact as an Augmentative and Alternative Communication (AAC) Device.

Project Sponsor and Funder (if any):

N/A

Carleton University Project Clearance:

Exemption letters attached.

I, choose to participate in a study on Quality

Improvement Study of Sensact as an Augmentative and Alternative Communication (AAC) Device. This study aims to investigate the barriers and difficulties that the healthcare workers (such as: occupational therapist or speech/language pathologist) at Bruyère Saint-Vincent Hospital (BSVH) are having in setting up and configuring/calibrating Sensact device. The researcher for this study is Ebic Tristary from the School of Industrial Design, Faculty of Engineering and Design at Carleton University. He is working under the supervision of Professor Chantal Trudel from the School of Industrial Design, Faculty of Engineering and Design at Carleton University, and Dr. Adrian Chan from the Department of Systems and Computer Engineering at Carleton University.

This study involves observing the whole setup process and configuring or calibrating Sensact device. With your consent, I would like to document the observations with notes, photos and/or

Page 1 of 3

This document has been printed on both sides of a single sheet of paper.

Please retain a copy of this document for your records. 


\section{Page 2}

video. I may also ask you questions related to these activities to develop a deeper understanding of what is being observed.

You have the right to end your participation in the study at any time, for any reason, up until February $28^{\text {th }}, 2019$. You can withdraw by phoning or emailing the researcher or the research supervisor. If you withdraw from the study, all information you have provided will be immediately destroyed.

I will not be collecting personal information that could identify you (e.g. name, address) but I may collect general demographic information (age, gender, ethnicity). Any personal information that is collected (e.g. signatures on the consent forms, contact information, identifying information from data) will only be viewed by the student researchers and their supervisors.

Any electronic versions of personal information (e.g. email contact information obtained in recruitment, identifying photos or video) and research data will be encrypted and passwordprotected during the duration of the project. Any hard copies of data (including any handwritten notes or USB keys) will be kept in the supervisor's locked office at Carleton University for a period of 5 years. Research data will only be accessible by the researcher and the research supervisor.

Once the project is completed, the research may be published. I may use excerpts from photos, videos in publications which may show your identity. Manuscripts will be developed in collaboration with the hospital stakeholders involved in the project and will be reviewed and approved by the hospital stakeholders for publication. All research data will be kept for 5 years and potentially used for other educational purposes, secondary analysis, presentations, publications or other research projects. At the end of 5 years, all research data will be securely destroyed. (Electronic data will be erased and hard copies will be shredded.)

If you would like a copy of the finished research project, you are invited to contact the researcher to request an electronic copy which will be provided to you.

This project was reviewed and cleared by the Carleton University Research Ethics Board [B]. If you have any ethical concerns with the study, please contact Dr. Bernadette Campbell, Chair, Carleton University Research Ethics Board (by phone at 613-520-2600 [ext. 4085] or by email at ethics@carleton.ca). 


\section{Page 3}

Statement of consent - print and sign name

I voluntarily agree to participate in this study:

I agree to answer questions during the observations:

I agree to be audio/video recorded/photographed:

$$
\begin{aligned}
\text { Yes } & { }^{\mathrm{No}} \\
\text { Yes } & { }^{\mathrm{No}} \\
\text { Yes } & \text { No }
\end{aligned}
$$

Signature of Participant

Date

\section{Research team member who interacted with the subject}

I have explained the study to the participant and answered any and all of their questions. The participant appeared to understand and agree. I provided a copy of the consent form to the participant for their reference.

Signature of researcher

Date

This document has been printed on both sides of a single sheet of paper.

Please retain a copy of this document for your records. 


\section{A.5 Consent Form for Co-Design Workshop}

\section{Page 1}

Name and Contact Information of Researcher:

Ebic Tristary

Carleton_Hniversity_School of Industrial Design, Faculty of Engineering and Design

Tel.:

Email: ebic.tristary@carleton.ca

Supervisor and Contact Information:

Professor Chantal Trudel

Carleton University, School of Industrial Design, Faculty of Engineering and Design

Phone: $613-520-2600$ ext. 5626

Email: chantaltrudel@cunet.carleton.ca

Dr. Adrian Chan

Carleton University, Department of Systems and Computer Engineering

Phone: 613-520-2600 ext. 8016

Email: adcchan@sce.carleton.ca

Project Title:

Quality Improvement of Sensact as an Augmentative and Alternative Communication (AAC) Device.

Project Sponsor and Funder (if any):

N/A

Carleton University Project Clearance:

Exemption letters attached.

I, choose to participate in a study on Quality

Improvement Study of Sensact as an Augmentative and Alternative Communication (AAC) Device. This study aims to investigate the barriers and difficulties that the healthcare workers (such as: occupational therapist or speech/language pathologist) at Bruyère Saint-Vincent Hospital (BSVH) are having in setting up and configuring/calibrating Sensact device. The researcher for this study is Ebic Tristary from the School of Industrial Design, Faculty of Engineering and Design at Carleton University. He is working under the supervision of Professor Chantal Trudel from the School of Industrial Design, Faculty of Engineering and Design at Carleton University, and Dr. Adrian Chan from the Department of Systems and Computer Engineering at Carleton University.

This study involves a co-design workshop where you will be working with the researcher to create design ideas related to your own experience. I will bring a variety of fun and engaging

This document has been printed on both sides of a single sheet of paper. Please retain a copy of this document for your records. 


\section{Page 2}

non-toxic, craft materials to brainstorm and create ideas (e.g. paper, markers, sticky notes, collage materials, paints, modeling clay, Lego, foam models, etc.). I will create a variety of fun activities to explore varies ideas using these materials. With your consent, the workshop will be video recorded. Once the recording has been reviewed and the relevant data transcribed or saved for later use, the recording will be destroyed.

You have the right to end your participation in the study at any time, for any reason, up until February $\mathbf{2 8}^{\text {th }}, 2019$. You can withdraw by phoning or emailing the researcher or the research supervisor. If you withdraw from the study, all information you have provided will be immediately destroyed.

I will not be collecting personal information that could identify you (e.g. name, address) but I may collect general demographic information (age, gender, ethnicity). Any personal information that is collected (e.g. signatures on the consent forms, contact information, identifying information from data) will only be viewed by the student researchers and their supervisors.

Any electronic versions of personal information (e.g. email contact information obtained in recruitment, identifying photos or video) and research data will be encrypted and passwordprotected during the duration of the project. Any hard copies of data (including any handwritten notes or USB keys) will be kept in the supervisor's locked office at Carleton University for a period of 5 years. Research data will only be accessible by the researcher and the research supervisor.

Once the project is completed, the research may be published. I may use excerpts from photos, videos in publications which may show your identity. Manuscripts will be developed in collaboration with the hospital stakeholders involved in the project and will be reviewed and approved by the hospital stakeholders for publication. All research data will be kept for 5 years and potentially used for other educational purposes, secondary analysis, presentations, publications or other research projects. At the end of 5 years, all research data will be securely destroyed. (Electronic data will be erased and hard copies will be shredded.)

If you would like a copy of the finished research project, you are invited to contact the researcher to request an electronic copy which will be provided to you.

This project was reviewed and cleared by the Carleton University Research Ethics Board [B]. If you have any ethical concerns with the study, please contact Dr. Bernadette Campbell, Chair, Carleton University Research Ethics Board (by phone at 613-520-2600 [ext. 4085] or by email at ethics@carleton.ca). 


\section{Page 3}

Statement of consent - print and sign name

I voluntarily agree to participate in this study:

I agree to answer questions during workshop:

I agree to be audio/video recorded/photographed:

$\begin{array}{rr}\text { Yes } & \text { No } \\ \text { Yes } & \text { No } \\ \text { Yes } & \text { No }\end{array}$

Signature of Participant

Date

\section{Research team member who interacted with the subject}

I have explained the study to the participant and answered any and all of their questions. The participant appeared to understand and agree. I provided a copy of the consent form to the participant for their reference.

Signature of researcher

Date

This document has been printed on both sides of a single sheet of paper

Please retain a copy of this document for your records. 
A.6 Tri-Council Policy Statement (TCPS 2) Certification on Ethical Conduct for Research Involving Humans.

\section{PANEL ON}

RESEARCH ETHICS

TCPS 2: CORE

Navigating the ethics of human research

\section{Certificate of Completion}

This document certifies that

\section{Ebic Tristary}

has completed the Tri-Council Policy Statement:

Ethical Conduct for Research Involving Humans

Course on Research Ethics (TCPS 2: CORE)

Date of Issue: 1 October, 2017 


\section{Appendix B: Semi-Structured Interviews}

\section{B.1 Interview Questions for SensAct Developer}

- When was SensAct initially started?

- What made you (or your team) decided to develop SensAct?

- What was the initial goal of developing SensAct?

- Now that SensAct has reached maturity level in the development process, has that goal changed from when it first initially set? If yes, please describe what the new goal is.

- How did you first assemble a team to develop SensAct?

- Were the SLPs or the OTs or any other healthcare workers being involved in the development process? If they were not involved, why?

- In the majority of SensAct development process, how many persons are involved in developing SensAct? What are their backgrounds?

- SensAct has now been developed for quite some time, and there few iterations/versions have since been developed. How many milestones does it have so far? Can you explain more on what were the progress key points on each milestone/iteration?

- In each milestone/iteration, were there any some problems in which you had to overcome in order to progress in the development process? Can you explain more about those problems and what were the steps you have taken to solve those problems?

- When SensAct UI was first being developed, had it gone through any design processes (such as user research, design draft or wireframing, mockups, usability testing)?

- Were any of the healthcare workers involved in the UI design process? If not, why?

- If the design processes mentioned earlier were not applied, what were the processes used in developing SensAct UI?

- At its current state, what are the problems that SensAct currently having? Please describe the problems from the technical/technological perspective, and also from the UI perspective.

- What are the things that you think can improve SensAct but you and your team have not able to do?

- What is the future goal of SensAct?

- What are the things that still preventing you and your team to reach that goal? 


\section{B.2 Interview Questions for SensAct User}

- What do you think is an ideal way to communicate between healthcare workers and a client who has complex communication needs?

- In a complex situation where you are having difficulties in communicating with a client, how do you manage to communicate with your client?

- What is the assessment process to determine whether a client might benefit from SensAct/AAC?

- When and how do you normally implement an AAC strategy with a client?

- Up to this moment, is there a client who uses SensAct on a regular basis as their AAC device? Is it working well?

- How did you learn the AAC methods that you are currently applying?

- Do you feel confident to implement an AAC strategy that you are not familiar with?

- How would you implement an AAC method that you are not familiar with?

- Do you think setting up an AAC device should be something you should be able to do it by yourself, or is it something that should be left to the expert?

- What are the difficulties that you have experienced while implementing an AAC/SensAct method so far?

- Based on your past experience, could you give an example where an AAC strategy has succeeded to meet the client's needs?

- Based on your past experience, could you give an example where an AAC strategy has not succeeded to meet the client's needs?

- Could you give an example of a computer application that you feel confident using without any help from other people?

- If you can make any suggestions on how to improve SensAct, what would that be? 


\section{B.3 The First and Second Cycle Coding of the Interviews Sorted by Occurrences}

\begin{tabular}{|c|c|c|}
\hline Second Cycle Coding & First Cycle Coding & Occurrences \\
\hline \multirow{9}{*}{$\begin{array}{l}\text { Lack of funding is a } \\
\text { major issue in } \\
\text { healthcare sector. }\end{array}$} & Funding are limited. & 5 \\
\hline & Hospital infrastructure has been degrading. & 2 \\
\hline & $\begin{array}{l}\text { Clients from other province not having access to Ontario } \\
\text { health care program. }\end{array}$ & 1 \\
\hline & $\begin{array}{l}\text { Clinicians in different facilities may be having more } \\
\text { specialization. }\end{array}$ & 1 \\
\hline & Funding for healthcare being cut through the years. & 1 \\
\hline & Identifying limitations of current hospital devices. & 1 \\
\hline & Larger facilities may be having more human resources. & 1 \\
\hline & $\begin{array}{l}\text { Setting up home properly can be a better environment than the } \\
\text { hospital. }\end{array}$ & 1 \\
\hline & Disadvantageous of working in a small clinic. & 1 \\
\hline \multirow{26}{*}{$\begin{array}{l}\text { Currently available } \\
\text { AAC devices lack } \\
\text { usability despite } \\
\text { high-cost to obtain } \\
\text { them. }\end{array}$} & Frustrated in getting reliable movement to activate AAC. & 10 \\
\hline & Physical setup of AAC becoming the most common problem. & 8 \\
\hline & $\begin{array}{l}\text { Having limited customization for current available AAC } \\
\text { devices. }\end{array}$ & 6 \\
\hline & Setting up AAC is a complicated process. & 6 \\
\hline & Paying high price for AAC devices. & 5 \\
\hline & Current AAC devices not meeting clients' needs. & 4 \\
\hline & Developing AAC devices that are not universal. & 3 \\
\hline & Feeling frustrated not able to meet clients' AAC needs. & 3 \\
\hline & Setting up AAC is time-consuming. & 3 \\
\hline & $\begin{array}{l}\text { Assistive technologies developed for small market, resulting in } \\
\text { high cost. }\end{array}$ & 2 \\
\hline & Difficulties setting up AAC with a new client. & 2 \\
\hline & Aligning SensAct with the mainstream technology. & 2 \\
\hline & Technology is changing to become more adaptable. & 2 \\
\hline & Difficulties programming an AAC device. & 1 \\
\hline & $\begin{array}{l}\text { Difficulties getting replacement when AAC device breaks } \\
\text { down. }\end{array}$ & 1 \\
\hline & Long turnaround time for updating/upgrading AAC device. & 1 \\
\hline & High demand in providing AAC solution. & 1 \\
\hline & Gaming industry is a huge market. & 1 \\
\hline & Growing number of AAC devices are now Windows-based. & 1 \\
\hline & Family members becoming barriers in AAC usage. & 1 \\
\hline & Recognizing good reception to new technology. & 1 \\
\hline & Noting that $\mathrm{AAC}$ is a small market. & 1 \\
\hline & Unreliable AAC software delaying implementation. & 1 \\
\hline & $\begin{array}{l}\text { Technologies being developed for big/mainstream market } \\
\text { resulting in low cost. }\end{array}$ & 1 \\
\hline & Utilizing materials from the gaming industry can reduce cost. & 1 \\
\hline & Certain AAC devices targeting specific audience. & 1 \\
\hline \multirow{5}{*}{$\begin{array}{l}\text { Commercial AAC } \\
\text { devices do not have } \\
\text { standardization or } \\
\text { universal design } \\
\text { compatibility. }\end{array}$} & Finding the best possible AAC solution. & 3 \\
\hline & Assessing communication strategy. & 2 \\
\hline & Choosing the right AAC based on client's needs. & 2 \\
\hline & Lacking standardization between different AAC devices. & 1 \\
\hline & $\begin{array}{l}\text { Suggesting standardization in programming/setting up an AAC } \\
\text { device. }\end{array}$ & 1 \\
\hline
\end{tabular}




\begin{tabular}{|c|c|c|}
\hline & $\begin{array}{l}\text { Categorizing communication boards based on words/images or } \\
\text { tasks needs. }\end{array}$ & 1 \\
\hline & Identifying barriers to technology. & 1 \\
\hline \multirow{12}{*}{$\begin{array}{l}\text { Clinicians are getting } \\
\text { limited support to } \\
\text { improve AAC } \\
\text { implementation. }\end{array}$} & Getting limited human resources. & 11 \\
\hline & Not getting enough exposure to SensAct. & 8 \\
\hline & Difficulties applying AAC with a client. & 6 \\
\hline & Not having a specialty in AAC assessment. & 6 \\
\hline & Acquiring an AAC device on lease/loan. & 5 \\
\hline & Difficulties keeping up with new technologies. & 3 \\
\hline & Identifying clients language barriers. & 2 \\
\hline & Clinicians acknowledging they should learn more about AAC. & 1 \\
\hline & Clinicians mostly working on an evident-based solution. & 1 \\
\hline & Difficulties setting up and managing older AAC device. & 1 \\
\hline & $\begin{array}{l}\text { Clinicians' limited knowledge in AAC can hinder its } \\
\text { application. }\end{array}$ & 1 \\
\hline & Not getting enough information about AAC training. & 1 \\
\hline \multirow{5}{*}{$\begin{array}{l}\text { Awareness of } \\
\text { accessibility and } \\
\text { usability in product } \\
\text { design need to be } \\
\text { improved. }\end{array}$} & $\begin{array}{l}\text { Criticizing software/device developed without accessibility } \\
\text { consideration. }\end{array}$ & 2 \\
\hline & Difficulties in setting up email in general. & 2 \\
\hline & Identifying that email UI is a complex system. & 2 \\
\hline & Difficulties understanding error messages. & 1 \\
\hline & Underlining the complexity of software UI accessibility. & 1 \\
\hline \multirow{5}{*}{$\begin{array}{l}\text { Due to limited } \\
\text { resources, getting } \\
\text { support from } \\
\text { community is vital. }\end{array}$} & $\begin{array}{l}\text { Recruiting volunteers with background in electronic } \\
\text { engineering. }\end{array}$ & 6 \\
\hline & Students volunteering to help develop SensAct. & 4 \\
\hline & Getting support from NGO. & 2 \\
\hline & Programmers volunteer developing SensAct software UI. & 1 \\
\hline & Not getting support financially and more volunteers. & 1 \\
\hline \multirow{18}{*}{$\begin{array}{l}\text { Hospital or long-term } \\
\text { care require } \\
\text { standardization or } \\
\text { definitive guidelines } \\
\text { to assess and } \\
\text { implement AAC. }\end{array}$} & Assessing client's physical ability. & 14 \\
\hline & Assessing client's speech impairment. & 14 \\
\hline & Assessing client's background in technology. & 5 \\
\hline & Assessing client's cognitive ability. & 5 \\
\hline & $\begin{array}{l}\text { Assigning OTs to work on clients based on their location on } \\
\text { the facility. }\end{array}$ & 3 \\
\hline & $\begin{array}{l}\text { Speech pathologist solving client's communication/speech } \\
\text { deficit. }\end{array}$ & 3 \\
\hline & $\begin{array}{l}\text { Speech pathologist is responsible for programming AAC } \\
\text { interface for a client. }\end{array}$ & 3 \\
\hline & Assessing client's skills. & 3 \\
\hline & $\begin{array}{l}\text { Assistive technologist supporting clients to troubleshoot their } \\
\text { AAC device. }\end{array}$ & 2 \\
\hline & Working for clients on the entire floor of the facility. & 2 \\
\hline & Underlining AAC assessment as non-standardized process. & 2 \\
\hline & Evaluating the AAC assessment process. & 2 \\
\hline & Prioritizing communication based on client's abilities. & 2 \\
\hline & $\begin{array}{l}\text { Assistive technologist acting as a facilitator between developer } \\
\text { and meeting client's needs. }\end{array}$ & 1 \\
\hline & $\begin{array}{l}\text { OT at the Children Treatment Center having more exposure to } \\
\text { SensAct. }\end{array}$ & 1 \\
\hline & $\begin{array}{l}\text { Prescribing AAC in an institution has clinical structure } \\
\text { process. }\end{array}$ & 1 \\
\hline & $\begin{array}{l}\text { Speech pathologist is leading the team in AAC assessment } \\
\text { process. }\end{array}$ & 1 \\
\hline & Learning AAC from school. & 4 \\
\hline
\end{tabular}




\begin{tabular}{|c|c|c|}
\hline \multirow{8}{*}{$\begin{array}{l}\text { Proper training is still } \\
\text { the most effective } \\
\text { way to learn AAC. }\end{array}$} & $\begin{array}{l}\text { There is no formal training/workshop provided by AAC } \\
\text { manufacturers. }\end{array}$ & 4 \\
\hline & $\begin{array}{l}\text { Additional training required for OTs to qualify to implement } \\
\text { AAC strategy. }\end{array}$ & 3 \\
\hline & \begin{tabular}{|l} 
Learning AAC from formal training/workshop/seminar. \\
\end{tabular} & 3 \\
\hline & Having background in computer programming. & 2 \\
\hline & \begin{tabular}{|l} 
Having background in adult learning. \\
\end{tabular} & 1 \\
\hline & Having background in public communication. & 1 \\
\hline & \begin{tabular}{|l} 
Having technological background. \\
\end{tabular} & 1 \\
\hline & OTs not having qualification to implement AAC. & 1 \\
\hline \multirow[t]{8}{*}{$\begin{array}{l}\text { AAC clients require } \\
\text { continuous support. }\end{array}$} & $\begin{array}{l}\text { Clients need constant support in adjusting and updating their } \\
\text { AAC device. }\end{array}$ & 4 \\
\hline & Pointing out the limitation of call-bell system. & 3 \\
\hline & Accommodating changes in client's AAC needs. & 3 \\
\hline & Growing needs in using AAC. & 3 \\
\hline & Accessing social media through AAC device. & 2 \\
\hline & Changing AAC device settings. & 1 \\
\hline & Utilizing communication boards. & 1 \\
\hline & Utilizing communication board as call-bell. & 1 \\
\hline \multirow{19}{*}{$\begin{array}{l}\text { Ease of customization } \\
\text { of an AAC device is } \\
\text { key to meet clients' } \\
\text { varied needs. }\end{array}$} & Setting up or using SensAct is difficult. & 15 \\
\hline & Hardware limitation in developing SensAct. & 12 \\
\hline & $\begin{array}{l}\text { Developing low cost and open-source AAC that allow } \\
\text { customization. }\end{array}$ & 11 \\
\hline & Simplifying SensAct UI. & 7 \\
\hline & Looking for customized solution for a client using SensAct. & 6 \\
\hline & SensAct utilizing light sensor to control other devices. & 4 \\
\hline & Looking for low cost hardware to build SensAct. & 4 \\
\hline & Developing SensAct for call-bell. & 4 \\
\hline & Connecting input methods to AAC/SensAct device. & 3 \\
\hline & Reviewing SensAct hardware reliability. & 3 \\
\hline & Developing various input methods for AAC. & 2 \\
\hline & Exploring SensAct different input methods. & 2 \\
\hline & $\begin{array}{l}\text { SensAct solving one communication problem but limiting } \\
\text { clients to do other things. }\end{array}$ & 2 \\
\hline & Thinking that SensAct still can be improved further. & 2 \\
\hline & Building Arduino to control Human Interface Device. & 1 \\
\hline & Possibility of integrating AI technology with SensAct. & 1 \\
\hline & Developing SensAct software from web UI. & 1 \\
\hline & Exploring SensAct by trials \& errors. & 1 \\
\hline & $\begin{array}{l}\text { Going through several changes on SensAct programming } \\
\text { languages. }\end{array}$ & 1 \\
\hline \multirow{10}{*}{$\begin{array}{l}\text { Developing SensAct } \\
\text { requires } \\
\text { interdisciplinary team } \\
\text { and human-centred } \\
\text { design approach. }\end{array}$} & Solving client's AAC needs as a team. & 14 \\
\hline & Consulting with experts to solve AAC problems. & 10 \\
\hline & $\begin{array}{l}\text { Developing SensAct based on feedback from clients and } \\
\text { clinicians. }\end{array}$ & 7 \\
\hline & Solving SensAct hardware limitation problems. & 5 \\
\hline & Developing SensAct based on real use case. & 5 \\
\hline & Building SensAct as one-off solution for a client. & 5 \\
\hline & Developing SensAct requires a team of experts. & 4 \\
\hline & $\begin{array}{l}\text { Assistive technologist is the only one having the ability to do } \\
\text { the initial setup of SensAct. }\end{array}$ & 4 \\
\hline & Saving time on high demand clinical time. & 3 \\
\hline & No UX designers involved in developing SensAct. & 3 \\
\hline
\end{tabular}




\begin{tabular}{|c|c|c|}
\hline & $\begin{array}{l}\text { Consulting with the caregivers/family members/friends about } \\
\text { the client's needs. }\end{array}$ & 2 \\
\hline & $\begin{array}{l}\text { Incorporating feedback from UX designers in developing } \\
\text { SensAct. }\end{array}$ & 1 \\
\hline & Knowing client's needs can help build a better design. & 1 \\
\hline & $\begin{array}{l}\text { Minimizing AAC cost by utilizing assistive technologist to } \\
\text { setup commercial AAC device. }\end{array}$ & 1 \\
\hline & $\begin{array}{l}\text { Solving many small problems can result in solving problems in } \\
\text { general. }\end{array}$ & 1 \\
\hline & Solving SensAct software problems. & 1 \\
\hline & Not getting approval from the management. & 1 \\
\hline & Taking so much time to build one solution for one client. & 1 \\
\hline Clinicians & Learning AAC through trials \& errors. & 18 \\
\hline resourcefulness of to & Trying AAC strategy with themselves first. & 7 \\
\hline adapt to & Learning how to use AAC device from online media. & 6 \\
\hline circumstances is & Learning AAC from experience at work. & 5 \\
\hline critical to the success & Trying SensAct as possible solution. & 5 \\
\hline of $\mathrm{AAC}$ & Letting client use AAC device more often. & 5 \\
\hline implement & Having curious personality to solve own problems. & 4 \\
\hline & Trying to find new technology to meet clients' needs. & 3 \\
\hline & Feeling confident to try new things. & 4 \\
\hline & Trying any possible AAC methods with a client. & 3 \\
\hline & Clinicians must have ability adapting to new technology. & 3 \\
\hline & Trying to implement AAC early on. & 3 \\
\hline & Feeling confident to use unfamiliar AAC device. & 3 \\
\hline & Finding resources and solving problems through online media. & 2 \\
\hline & Knowing client's problems and limitations through interaction. & 2 \\
\hline & $\begin{array}{l}\text { Practicing to use AAC during appointment and therapy session } \\
\text { with client. }\end{array}$ & 2 \\
\hline & $\begin{array}{l}\text { Trying out a client's AAC device implementation in local } \\
\text { environment. }\end{array}$ & 2 \\
\hline & Keep on practicing AAC to get familiar with it. & 1 \\
\hline & Learning AAC from more experienced user. & 1 \\
\hline & $\begin{array}{l}\text { Not believing that client can learn to use AAC device in } \\
\text { limited time. }\end{array}$ & 1 \\
\hline & Having both knowledge in AAC software and hardware. & 1 \\
\hline & Solving communication barriers through Yes-No questions. & 1 \\
\hline & Spending more time with client who uses AAC. & 1 \\
\hline & Teaching the nurses to setup AAC. & 1 \\
\hline & Applying common sense in solving a problem. & 1 \\
\hline Clinicians' point of & OTs' roles are solving client's physical deficit. & 7 \\
\hline $\begin{array}{l}\text { view can affect the } \\
\text { daily operation in }\end{array}$ & $\begin{array}{l}\text { Acknowledging that other clinicians prefer standardized } \\
\text { procedures. }\end{array}$ & 4 \\
\hline hospital or long-term & Preferring if they are able to set AAC/SensAct themselves. & 4 \\
\hline settings. & Feeling more comfortable with familiar Software UI. & 4 \\
\hline & OTs responsible for finding AAC mounting solution. & 3 \\
\hline & $\begin{array}{l}\text { OTs may be taking the responsibility to customize AAC } \\
\text { device. }\end{array}$ & 3 \\
\hline & Suggesting that software UI should be more intuitive. & 2 \\
\hline & Thinking that each client deserves a chance to try AAC. & 2 \\
\hline & Comparing personal experience as similar to others. & 2 \\
\hline & $\begin{array}{l}\text { Worrying that unsupervised use of AAC can cause physical } \\
\text { harm to the user. }\end{array}$ & 2 \\
\hline & Feeling scared to try new things. & 2 \\
\hline
\end{tabular}




\begin{tabular}{|c|c|c|}
\hline & $\begin{array}{l}\text { Feeling that traditional communication methods are not } \\
\text { effective. }\end{array}$ & 1 \\
\hline & Finding the right $\mathrm{AAC}$ is not the actual barrier. & 1 \\
\hline & Underlining cost is not the main barrier in clinical setting. & 1 \\
\hline & Talking is less strenuous than using AAC. & 1 \\
\hline & Consolidating client's goals and priorities. & 1 \\
\hline & Highlighting each client as unique. & 1 \\
\hline & Small clinic prefers using more familiar AAC to save time. & 1 \\
\hline & Feeling comfortable with basic Software UI. & 1 \\
\hline & OT is the clinician who is making first contact with clients. & 1 \\
\hline & Identifying sources of ineffective communication. & 1 \\
\hline & $\begin{array}{l}\text { Thinking that for more complicated client, an expert should } \\
\text { setup AAC/SensAct. }\end{array}$ & 1 \\
\hline & Communicating with clients is two-way process. & 1 \\
\hline \multirow{7}{*}{$\begin{array}{l}\text { AAC users tend to } \\
\text { use familiar devices. }\end{array}$} & Preferring Tobii Dynavox brand over other AAC devices. & 7 \\
\hline & Feeling anxious that SensAct would be difficult to use. & 4 \\
\hline & Not feeling confident to use unfamiliar AAC. & 4 \\
\hline & Comparing Apple UI as easy to use to other devices. & 3 \\
\hline & Setting up SensAct would be easier with preset. & 2 \\
\hline & $\begin{array}{l}\text { Preferring to buy Apple device with accessibility features than } \\
\text { an expensive AAC device. }\end{array}$ & 1 \\
\hline & Tobii Dynavox has been investing a lot in their software. & 1 \\
\hline \multirow{10}{*}{$\begin{array}{l}\text { Clients' attitudes and } \\
\text { preferences } \\
\text { preventing them to } \\
\text { access AAC. }\end{array}$} & Client's complex disability preventing them access to AAC. & 12 \\
\hline & $\begin{array}{l}\text { Clients feeling overwhelmed with high cognitive load using } \\
\text { AAC. }\end{array}$ & 6 \\
\hline & Clients' difficulties accessing email. & 4 \\
\hline & Clients prefer trying to speak over using AAC. & 3 \\
\hline & Clients' lack of motivation impeding AAC progress. & 2 \\
\hline & Clients struggling to implement AAC. & 1 \\
\hline & Clients' difficulties in communicating. & 1 \\
\hline & Clients not liking paper communication boards. & 1 \\
\hline & $\begin{array}{l}\text { Clients feeling overwhelmed with the amount of AAC } \\
\text { features. }\end{array}$ & 1 \\
\hline & Clients difficulties accessing social media. & 1 \\
\hline \multirow{17}{*}{$\begin{array}{l}\text { Current SensAct has } \\
\text { met some of clients' } \\
\text { needs and encouraged } \\
\text { further development. }\end{array}$} & Integrating SensAct with smart devices. & 16 \\
\hline & SensAct customization meeting client's needs. & 11 \\
\hline & Improving SensAct for broader audience. & 10 \\
\hline & Improving SensAct to be more user-friendly. & 7 \\
\hline & Developing SensAct to be adaptable to new technologies. & 6 \\
\hline & Expecting ease of use when implementing AAC. & 3 \\
\hline & Receiving attention from public media. & 2 \\
\hline & Having OTs to do the initial setup of SensAct. & 2 \\
\hline & Building a simple email system for AAC clients. & 2 \\
\hline & AAC device helps translating client's ability. & 1 \\
\hline & People starting to believe SensAct can work well. & 1 \\
\hline & $\begin{array}{l}\text { Being able to troubleshoot or solve AAC problems on their } \\
\text { own when experts are not available. }\end{array}$ & 1 \\
\hline & Connecting SensAct via voice command to call-bell. & 1 \\
\hline & Integrating all communication solution. & 1 \\
\hline & Integrating SensAct with voice command. & 1 \\
\hline & Releasing SensAct product to the public. & 1 \\
\hline & Scaling SensAct production to reach more clients. & 1 \\
\hline
\end{tabular}




\section{Appendix C: Introduction Script for Focus Group Session}

The purpose of this focus group is to identify any issues that you may have encountered in your experience in implementing any type of AAC devices, including SensAct. This session is also meant to generate new ideas on how this user interface can be easily understood and to provide input on what kind of elements that should be included or removed for easy access to the device based on your own experiences using the AAC devices throughout the years.

Please feel free to share your thoughts. There is no right or wrong in this process, we are trying to figure out the best way to solve any usability and accessibility issues that SensAct may have.

Let us start by sharing your experience in implementing any type of AAC devices. What are the difficulties that you are facing? 